The Behavior of

Straight Open Channels

With Movable Beds

GEOLOGICAL SURVEY PROFESSIONAL PAPER 622-A 


\section{The Behavior of}

Straight Open Channels

With Movable Beds

By THOMAS MADDOCK, JR.

BEHAVIOR OF NATURAL ALLUVIAL CHANNELS

GEOLOGICAL SURVEY PROFESSIONAL PAPER 622-A

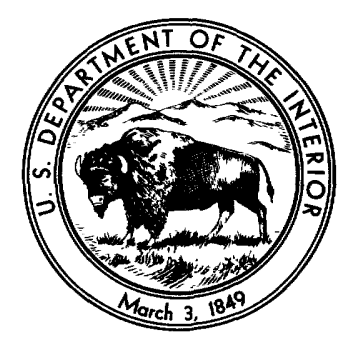

UNITED STATES GOVERNMENT PRINTING OFFICE, WASHINGTON : 1969 


\section{UNITED STATES DEPARTMENT OF THE INTERIOR \\ WALTER J. HIGKEL, Secretary \\ GEOLOGICAL SURVEY \\ William T. Pecora, Director}




\section{CONTENTS}

Abstract

Introduction

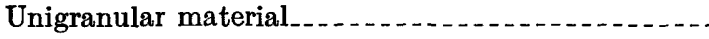

Mid-velocity range...............

Low-velocity range..........

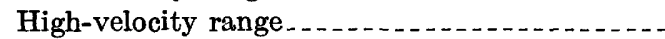

Mixtures of sediment sizes.

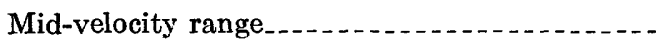

Low-velocity range...........

High-velocity range........................

Extrapolation from flume studies.

Two-dimensional flow

Slope.

Independent versus dependent variables

Constraints

Discharge and sediment load as independent variables.

Discharge and slope as independent variables.............................

Variance of shear stress and friction factor ..........................

Variance of velocity and friction

factor lation between sediment load and velocity ..........

\begin{tabular}{|c|c|c|}
\hline Page & & Page \\
\hline A1 & Two-dimensional flow-Continued & \\
\hline 1 & Slope-Continued & \\
\hline 3 & Constraints-Continued & \\
\hline $\mathbf{5}$ & Discharge and slope & \\
\hline 6 & variables-Continued & \\
\hline 7 & Variance of concentration and friction & \\
\hline 12 & factor & A $33^{?}$ \\
\hline 14 & Behavior of flumes operated at constant & \\
\hline 15 & depth & \\
\hline 18 & Summary of slope as an element in stream & \\
\hline 19 & behavior & 48 \\
\hline 22 & Three-dimensional flow & \\
\hline 25 & Width as an independent variable & 50 \\
\hline 25 & Width as a dependent variable & 52 \\
\hline 28 & Sediment size as dependent or independent & \\
\hline 30 & variable $\ldots$ & \\
\hline & Summary of width as a dependent variable.... & \\
\hline 30 & Stable channels & \\
\hline & Gravel channels $\ldots \ldots \ldots$ & \\
\hline 33 & Sand channels..... & \\
\hline & "Regime" channels & \\
\hline 33 & Nonregime channels_._........... & \\
\hline & Conclusion......- & \\
\hline 35 & References & \\
\hline
\end{tabular}

\section{ILLUSTRATIONS}

Figure 1-6. Graphs showing relations between velocity and load:

1. In the Gilbert experiments, sand $B$

2. In the Gilbert experiments, sand $\mathrm{E}_{-}$

3. In the Gilbert experiments, sand $G$

4. In the Williams experiments

5. In the Simons and Richardson experiment

6. In the Waterways Experiment Station studies and Gilbert experiments

7. Dimensionless plot of mean velocity, fall velocity, load, and discharge per foot of width in the mid-velocity range.

8-12. Graphs showing:

8. Relations between velocity and load, unit discharge, and size of sediment for unigranular material in the mid-velocity range

9. Values for the coefficient $k_{1}$ in equations 4 and 5 with variations in the diameter and fall velocity of

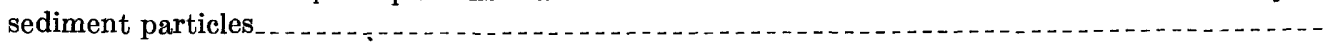

10. Relations between velocity and effective load and size of sediment in the low-velocity range ........

11. Relations between load and discharge, slope, and sediment size, in the high-velocity range.

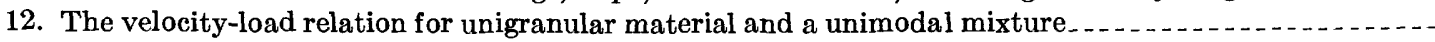

13. Dimensionless plot of velocity, fall velocity, and load for sands A through H, Gilbert experiments . . . . . 14-49. Graphs showing:

14. Relations between velocity and load, unit discharge, and mean grain size for sediment mixtures in the mid-velocity range . .

15. Relations between velocity and load for sediment mixtures. Flume data

16. Relations between velocity and effective load and mean grain size for sediment mixtures in the lowvelocity range.

17. Relations between velocity and effective load and mean grain size for sediment mixtures in the lowvelocity range.

18. The behavior of the sediment load of the Colorado River at Yuma, Ariz

Pr.ge 
Frgures 14-49. Graphs showing-Continued

19. Relations between load and unit discharge, slope, and sediment size for sand mixtures in the highvelocity range. . .

20. Relation between sediment discharge and water discharge for Mountain Creek, N.C., and V'est Goose Creek, Miss.

21. Relation between discharge of coarser grades of sediment and water discharge of the Colorado River at Yuma, Ariz

22. Relations between velocity and unit discharge, slope, and size of sediment for unigranular material in the mid-velocity range.

23. Relations between velocity and unit discharge, slope, and mean grain size of sediment mixture in the low-velocity range.

24. Relations between velocity and unit discharge, slope, and mean grain size of sediment mixture in the low-velocity range

25. Values of sediment size parameters from equations 19 and 20

26. Relations between velocity and unit discharge, slope, and mean grain size of sediment..........

27. Relations between velocity and unit discharge, slope, and mean grain size of sediments for certain canals and natural streams

28. Relation between unit discharge and depth for Mountain Creek near Greenville, N.C. . . . . . ....

29. Relation between unit discharge and depth for West Goose Creek near Oxford, Miss _.............

30. Relation of velocity to hydraulic radius for San Francisco riverside drain near Bernardo, N. Mex.....

31. Relations between velocity and the product of unit discharge and slope for locations on the Colorado River at Grand Canyon, Ariz., and below Davis Dam .

32. Relation between unit discharge and depth for Colorado River at Taylors Ferry, Ariz ..........

33. Relation of width, depth, velocity, water-surface elevation, and stream-bed elevation to discharge, Colorado River at Yuma, Ariz

34. Relations between velocity and unit discharge and slope

35. Relations between velocity and slope when depth is approximately constant

36. Relations between velocity and unit discharge, slope, and mean grain size of sediment, small recircu-

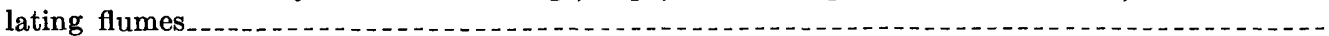

37. Relations between velocity and the product of unit discharge and slope for 0.4 and $0.45 \mathrm{~mm}$ sard.

38. Relations between velocity and slope for various depths of flow and different sizes of sand

39. Relation between velocity and slope for certain depths

40. Relation between depth and slope at constant discharge

41. Relation between mean velocity and $q S$ for uniform and mixed sediments of about $0.3 \mathrm{~mm}$ mean diameter in flume experiments

42. Relation between width and slope, the Rio Grande near Vinton, Tex

43. Variations of width and slope of the water surface with discharge and relation of slope of water surface to size of bed material, Brandywine Creek, Pa . . . . . . . . . . . .

44. Variations of mean depth and mean velocity with discharge in the downstream direction at the kank full stage, Brandywine Creek, $\mathrm{Pa}$

45. Relation between tractive force and sediment size with slope a dependent variable

46. Recommended limiting tractive forces (or shear stresses) for canals.

47. Relation between tractive force and sediment size with slope an independent variable

48. Relation between width and discharge, San Luis Valley, Colo., canals

49. Relations between sediment size and discharge and slope, San Luis Valley, Colo., canals...........

50. Aerial photograph of the Colorado River near the Nevada-California boundary showing systematic bed forms under water

51. Strip aerial photograph of the Rio Grande near Vinton, Tex., at low flow showing river reworking systematic bed forms that are relics from higher discharges

52. Graph showing relations in equation 70

Page

24

\section{TABLES}

TABLE 1. Behavior of flumes of unit width and same sediment sizes with different independent and dependent variables $\ldots$

2. Data for the Marala-Ravi Link Canal relating to behavior

3. Data for the Marala-Ravi Link Canal 


\title{
SYMBOLS
}

\author{
Definition \\ A constant. \\ An exponent of $Q$ or $q$ relating discharge to width. \\ A constant. \\ The diameter of a sediment particle, in feet. \\ The base of natural logarithms. \\ An exponent of depth. \\ An exponent of $Q$ or $q$ relating discharge to depth. \\ The acceleration of gravity, in feet per second per second. \\ An exponent of concentration. \\ An exponent of $Q$ or $q$ relating discharge to load. \\ A constant. \\ A variable which is a function of sediment size and fall velocity. \\ A variable in an equation by Velikanov (1949). \\ An exponent of $Q$ or $q$ relating discharge to velocity. \\ The unit discharge of water, in cubic feet per second per foot of width. \\ A constant. \\ An exponent of slope relating slope to velocity. \\ Time, in seconds. \\ An exponent of slope relating slope to depth. \\ Fall velocity of a sediment particle, in feet per second. \\ An exponent of load relating load to depth. \\ An exponent of $Q$ or $q$ relating discharge to slope. \\ A constant. \\ A constant. \\ Bed form. \\ The concentration of the sediment discharge, in parts per million. \\ Mean depth of channel, in feet. \\ A Froude number. \\ Total sediment load. \\ Head loss of a water sediment mixture moving in a pipe. \\ Head loss in a pipe with clear water of the same discharge as in $J$. \\ A coefficient. \\ Rate of sediment movement, in pounds per second per foot of width. \\ Load to the first power. \\ A constant. \\ An effective load, in pounds per second per foot of width. \\ The total water discharge of the stream, in cubic feet per second. \\ The total sediment discharge of a stream, in pounds per second. \\ Slope or energy gradient. \\ Slope to the first power. \\ A constant. \\ Mean velocity of the flowing stream, in feet per second. \\ Velocity of water at the bed, in feet per second. \\ A critical velocity at which sediment motion begins, in feet per second. \\ Width of channel, in feet. \\ An exponent of velocity relating velocity to load. \\ An exponent of load relating load to slope. \\ The weight of water, in pounds per cubic feet. \\ The dynamic viscosity. \\ The kinematic viscosity. \\ A function of. \\ 3.1416 . \\ Mass density of water, in mass per cubic foot. \\ The mass density of sediment, in mass per cubic foot. \\ The standard deviation of the logarithm of the depth. \\ The standard deviation of the logarithm of the discharge. \\ The standard deviation of the logarithm of the velocity. \\ The standard deviation of the logarithm of the width. \\ A shear force. \\ The submerged weight of the sediment, in pounds per cubic feet. \\ The friction factor.
}




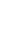


BEHAVIOR OF NATURAL ALLUVIAL CHANNELS

\title{
THE BEHAVIOR OF STRAIGHT OPEN GHANNELS WITH MOVABLE BEDS
}

\author{
By Thomas Maddock, JR.
}

\begin{abstract}
The chief variables related to the behavior of alluvial channels are mean velocity, depth,- width, slope, quantity of sediment transport, and sediment size composition. Except for a relation between mean velocity and quantity of uniform-sized sediment in motion, relations among these variables are to some degree indeterminate. Because changes in one variable result in mutual adjustment of all other variables, the actual results depend on the constraints that may be imposed, either natural of artificial.

Analysis of flume data indicates that no single simple equation describes the relation between mean velocity and load, the sediment discharge per foot of width of channel. Three separate equations for three ranges of velocity are developed. These ranges are called (1) the mid-velocity range, in which most natural streams and canals flow (hence, the most important); (2) the low-velocity range, associated with beginning of sediment motion; and (3) the high-velocity range, which is infrequently encountered in the field and is somewhat uncertain. Different equations for unigranular sediment and for sediment mixtures are proposed. These equations are based on flume data and are tested with data collected in the field.

Relations among mean velocity, depth, and slope are indeterminate because of the variability of the hydraulic roughness caused by changes in the characteristics of the bed forms. Consistent relations among the variables exist only when certain constraints are present and result from minimization processes. Velocity, depth, and slope may be expressed in terms of a unit discharge $q$ :

$$
V \propto q^{m}, D \propto q^{f}, S \propto q^{z} .
$$
\end{abstract}

Then the exponent of the independent variable is an index of the deviation of the dependent variable for any change in the independent variable. The variability of the dependent variable or of a function of the dependent variable is minimized when the variance of the variable or its function is minimized. If two different functions are jointly minimized, the sum of the variances of the two functions is minimized. For example, to minimize the variance of $D S$, which can be expressed as $(f+z)^{2}$, set the derivative with respect to $f$ equal to zero from whence $f=-z$. If the variance of the shear $\gamma D S$ and the friction factor $q D S / V^{2}$ are to be jointly minimized,

$$
\left(f=z^{2}\right)^{2}+\left(f+z-2^{m}\right)^{2} \rightarrow \text { minimum. }
$$

Although there are a number of constraints, the principal one is the constraint of joint minimization of the variances of the shear stress and of the friction factor. The nature of the result is determined by the selection of the dependent and independent variables. If velocity, depth, and slope are all dependent vari- ables, $V \propto(q S)^{0.4 \cdot}$ If unit discharge and slope are independent variables, and load, velocity, and depth are dependent variables; $V \propto(q S)^{0.4}$. If discharge is an independent variable and depth is not permitted to vary, then the variance of the friction facto" or the variance of the shear stress is minimized-that is, eithe the friction factor or the shear stress is constant. Results of flum? and field measurements are compared with the hypothesized values. I emphasize that these relations are not unique but only the most probable.

The effect of variation of width is considered. It is shown that width and slope are related and that a three-dimensional analysis is associated with a minimization process. But, in contrast to using variances of the shear stress and the friction factor, the joint variance of certain ways streampower may be expresset is minimized. These ways are, power per unit length per unit discharge, or $S$; power per unit of area of channel bed, or $q \mathbb{S}$ : and power per unit length of channel, or QS. The Lacey equations are developed by using this approach, as are other "regime" equations for specific conditions found in streams with beds of sand or of rarely moved coarse material.

Finally the problem of stable channels is considered. Recommendations are made for equations to be used in design of stable channels and values of coefficients are expressed based on studies of flume and field data.

\section{INTRODUCTION}

The objective of workers in the field of movable-bed hydraulics has been to find unique or determinate relations among velocity, depth, slope, and the rate of sediment movement. The thesis of this report is that this objective is, to some degree, impossible to achieve. Although there are usable relations among discharge, mean velocity, and load for the transport of sediment of uniform size in a channel of symmetrically distributed velocities, it will be shown that these determinate relations are only partially applicable for mixtures $c^{f}$ sediment sizes and for odd-shaped channels. Further, I will show that any function containing slope as a parameter will be indeterminate within wide limits. A unique relation will be found only when constraints, natural or artificial, limit the possible combinations of depth, slope, velocity, and load.

This report will attempt to identify and describe some of the constraints that control the behavior of 
alluvial channels. These will be the most obvious and, it is hoped, the most important.

Of all the elements that make up a plan of waterresources development, those concerning the movement of water in alluvial channels are the least understood. This is because the bed, where most of the stream energy is dissipated, constantly changes form. Thus, the flow in these channels is locally unsteady and nonuniform, and the departures from a steady or uniform state may vary widely.

It has been recognized since Gilbert's (1914) time that a river system is the result of the movenient of both water and debris. The mutual adjustment of certain variables has not been generally recognized despite the fact that Rubey (1952, p. 131) clearly stated: "Summarizing, if discharge, load, grain size, and sorting are considered the controlling factors, then velocity, slope, width, and depth of channel are dependent variables that are affected not only by the independent variables but also by one another." (Author's emphasis.)

Unfortunately, Rubey's paper, although completed in 1936, was not published until 1952. During that period, analysis of the flow of water in alluvial channels followed, in general, the same pattern as that for channels with rigid boundaries. It is but speculative to consider whether the early publication by Rubey might have prevented this type of analysis and its unfortunate results. For example, even today it is not fully recognized that when given a depth, a slope, and a size of bed material, the velocity is indeterminate. What is lacking is a measure of the hydraulic roughness associated with some characteristic of the deformation of the bed.

Defornation of the bed is accomplished by the movement, in certain specific ways, of many grains of sediment. Because the grains must move with the current in a general downstream direction, deformation of the bed results in the sediment load of streams. Under a particular set of conditions of discharge, slope, and size of material, a given bed form requires a specific amount of sediment in motion. Thus, the load of a stream beconies an important factor in the consideration of the hydraulics of alluvial streams.

Another characteristic of alluvial streams is an ability to adjust width, depth, velocity, and slope. The fact that all rivers have the same general features indicates that this adjustment is constrained by sonve phenomena to within rather specific limits. Given a discharge and a load, as Rubey (1952) noted, the width, depth, velocity, and slope of a stream must be the result of mutual adjustments within a set of limits not yet defined in an acceptable manner.

These conditions clearly differ from those found in rigid-boundary hydraulics and must be treated differently if they are to be analyzed successfully. One of the possible methods of analysis is to corsider the problem as indeterminate and use statistical $f$ rocedures as much as possible. Thus, the variation in bohavior of experimental alluvial channels can be attributed to errors of measurement, which are normally di tributed, and to systematic variation due to constraints placed on the flow system because of the size of the channels, the magnitude of the discharge, certain phys: cal limits of stability, or the way in which the experiment was conducted.

This report will consist of three major par's: (1) an evaluation of the role of sediment transport in fluvial hydraulics; (2) an analysis of two-dimensional flowwidth will not be considered as having a specific influence; and (3) a study of the effect of the introduction of width-three-dimensional flow-on the principal variables and a consideration of the elements of channel stability. In the second and third parts, variations in load, velocity, depth, and slope will be evaluated.

The initial step must be to determine the parameters controlling the movement of sediment, as this movement is the distinguishing feature of the flow of water in alluvial channels. I will show that the movement of sediment cannot be described by a simple function and that the behavior of a load of uniform-rized sediment is different from that of a load of a nixture of sand sizes. There is considerably more uncertainty about pertinent relations when mixtures of sand sizes are involved because of the difference between the sizes of the sediment making up the bed anc' the sizes of the sediment in motion.

The discussion on sediment movement will lead to the conclusion that the mean velocity of a stream is the best available index of the rate of sediment transport. This statement is reversible - that is, the sediment transport is the best index of velocity. This immediately leads to a corollary that the shear velocity is not at all well related to sediment movement.

The second part of the report will consider how the slope of the energy gradient responds to changes in other hydraulic variables and the rate of sediment movement. First, the nature of this response will be shown to vary with different types of experimental procedures in the laboratory and with different sets of independent and dependent variables in the field. Next, the relations between the independent and dependent variables will be deternined by the method of minimizing variance as proposed by Langbein $(1964,1965)$. The theoretical result will be compared with observations made under specific sets of conditions in the laboratory and in the field. In this part the movement of water and sediment will be considered 
as two-dimensional flow-that is, discharge of both water and sediment will be evaluated in terms of a unit width.

The final section of the report will consider the behavior of the whole stream-width will be treated as an independent or dependent variable. Using width as a dependent variable, a "regime" relation will be defined; "regime equations," such as the Lacey and Blench equations, will be developed as will "regime equations" for other particular sets of conditions. Finally, the problem of stable channels will be discussed in terms of movable and relatively immovable beds and the pertinent factors involved.

Throughout this report no attempt will be made to divide the hydraulic radius. Hydraulic radii of the bed and wall have not been computed, and data from all channels having width-depth ratios of less than 4.5 have not been used in determining any of the hydraulic relations. Furthermore, hydraulic radius and mean depth are considered equivalent. This may introduce a systematic error, but it also eliminates one value, hydraulic radius, that is hard to compute.

Acknowledgments. - This report has been in preparation for a considerable period of time. An initial draft was submitted to a number of colleagues for review late in 1965. The author is greatly appreciative of the comments received despite the additional work they caused. It is hoped that the report reflects some of the many constructive suggestions that were received.

The author is very pleased to acknowledge the counsel and criticism of W. B. Langbein, whose previous work outlined the premises upon which most of the report is based. The able assistance of M. E. Moss is acknowledged in the work of assembling and analyzing the mass of data used in the preparation of this report.

\section{RELATION BETWEEN SEDIMENT LOAD AND VELOCITY}

The relation between sediment load and velocity will be considered first, using data from experiments in flumes. The subject of sediment load was considered by Rubey (1938), and the following paragraph is a paraphrase of his statements.

Sediment loads must be observed by time averages; hence, the area over which equilibrium is to be studied also must be time averaged. If the velocity of flow near the bed is $V_{b}$, and $t$ is a unit of time, a characteristic area would have the dimensions of $V_{b} t$ and a unit width. The force on this characteristic area would be $\rho V_{b}^{2} V_{b} t$ or $\rho V_{b}^{3} t$, where $\rho$ is the mass density of the fluid, and the rate of expenditure of energy on this area would be $\rho V_{b}^{4} t$. This expenditure is held in equilibrium by a force-velocity product that is equal to the product of load per unit width in pounds per second, the time, $329-5100-69-2$ $t$, and a characteristic velocity that is related to tre settling velocity of the sediment, $w$, or together, Ltw. Hence, when $\rho_{s}$ is the mass density of the sediment,

$$
\rho V_{b}^{4} t \propto L t w\left(\frac{\rho_{s}-\rho}{\rho}\right) .
$$

Eliminating $t$,

$$
\rho V_{b}^{4} \propto L w\left(\frac{\rho_{s}-\rho}{\rho}\right)
$$

or

$$
V_{b} \propto\left[\frac{L w}{\rho}\left(\frac{\rho_{s}-\rho}{\rho}\right)\right]^{1 / 4}
$$

which can be expressed in dimensionless terms as

$$
\frac{V_{b}}{w} \propto\left(\frac{L}{\rho w^{3}}\right)^{1 / 4}\left(\frac{\rho_{s}-\rho}{\rho}\right)^{1 / 4} .
$$

The problem then resolves itself into determining the relation between the bed velocity, $V_{b}$, of Rubey (1938) and the mean velocity, $V$.

Support for the Rubey relations may be found in equations for the flow of sediment in pipes. Durand's (1953) equation for flow of sediment in pipes is

$$
\frac{J-J_{e}}{J_{e} C}=k\left(\frac{g D}{V^{2}}\right)^{3 / 2}\left(\frac{\rho w^{2}}{\Delta \gamma d}\right)^{3 / 4},
$$

where $J$ is the head loss for a sediment-water mixture, $J_{e}$ is the head loss for the same discharge of clear water, $C$, is the sediment concentration, $D$ is the pipe diameter, $g$ is the acceleration of gravity, and $\Delta \gamma=$ $g\left(\rho_{s}-\rho\right)$. Rearranging,

$$
V^{3}=C(g D)^{3 / 2}\left(\frac{\rho w^{2}}{\Delta \gamma d}\right)^{3 / 4} \frac{k J_{e}}{J-J_{e}} .
$$

Multiplying both sides by $\pi \rho V D^{2}$ to get the total loe,d in the pipe, $G$,

$$
\pi \rho V^{4} D=G w\left(\frac{\gamma D}{\Delta \gamma d}\right)^{1 / 2}\left(\frac{\rho w^{2}}{\Delta \gamma d}\right)^{1 / 4} \frac{k J_{e}}{J-J_{e}} .
$$

Because $L$, the load per unit of circumference, is $G / \pi D$, when both sides of the equation are divided by $\pi \rho D$,

$$
V^{4} \propto\left(\frac{L w}{\rho}\right)\left(\frac{\gamma D}{\Delta \gamma d}\right)^{1 / 2}\left(\frac{\rho w^{2}}{\Delta \gamma d}\right)^{1 / 4} \frac{k J_{e}}{J-J_{e}}
$$

or

$$
V \propto \frac{L w^{1 / 4}}{\rho}\left[\left(\frac{\gamma D}{\Delta \gamma d}\right)^{1 / 2}\left(\frac{\rho w^{2}}{\Delta \gamma d}\right)^{1 / 4} \frac{k J_{e}}{J-J_{e}}\right]^{1 / 4}
$$

The above equations illustrate some of the problems introduced through the use of dimensionless parameter. An examination of the terms in the bracket of the right-hand member of the last equation indicates that the greater the specific gravity of the sediment the 
greater the load for a given velocity. Actually, if $\Delta \gamma$ increases, $w$ must increase. Hence, in the Durand equation, the specific gravity of the sediment has no influence on the relation between velocity and load for sediment sizes larger than about $1 \mathrm{~mm}$. In this respect, the Durand relation differs from the Rubey relation because an increase in the specific gravity in the Rubey relation would, for a given velocity, reduce the load of coarse sediment.

In the Durand equation, when the head loss becomes constant for a given pipe, the Rubey relation of $L \propto \rho V^{4} / w$ holds. However, there is considerable additional evidence that load and velocity are uniquely related. Lacey (1940), Inglis (1949), Vanoni and Brooks (1957), Brooks (1958), Kennedy and Brooks (1963), Nordin and Beverage (1965), and Colby (1964) all have noted the relation between velocity and load. The same relation is implied in studies by Vanoni and Nomicos (1960) and Kennedy (1961). Colby (1964) recommended the use of velocity as the dominant measure in expressing bed-load movement and stated that it is as accurate as other measures and certainly the simplest to use.
Bogardi (1965) stated that at one time European practice was to consider the rate of sediment transport as proportional to the fourth power of the velocity. $\mathrm{He}$ referred to Velikanov (1949) as the author of the relation

$$
L \propto m d\left(V-V_{c}\right),
$$

in which $L$ is the rate of sediment movement per unit of width, $V$ and $V_{c}$ are, respectively, the mean velocity and critical velocity at which sediment motion begins, $m$ is proportional to $V^{3}$, and $d$ is the particle size. This type of relation differs from that proposed by Rubey (1938); hence, it appears that the relation between velocity and load cannot be described by one simple equation. This conclusion is confirmed by data from flumes having a wide range of characteristics.

The analysis of flume data as presented herein is divided into two major parts: that for unigranular material, and that for mixtures of sediment sizes. The relation between velocity and discharge of sediment per foot in both unigranular material and mixtures had to be approximated by using three characteristic ranges called the mid-velocity range, the low-velocity range,

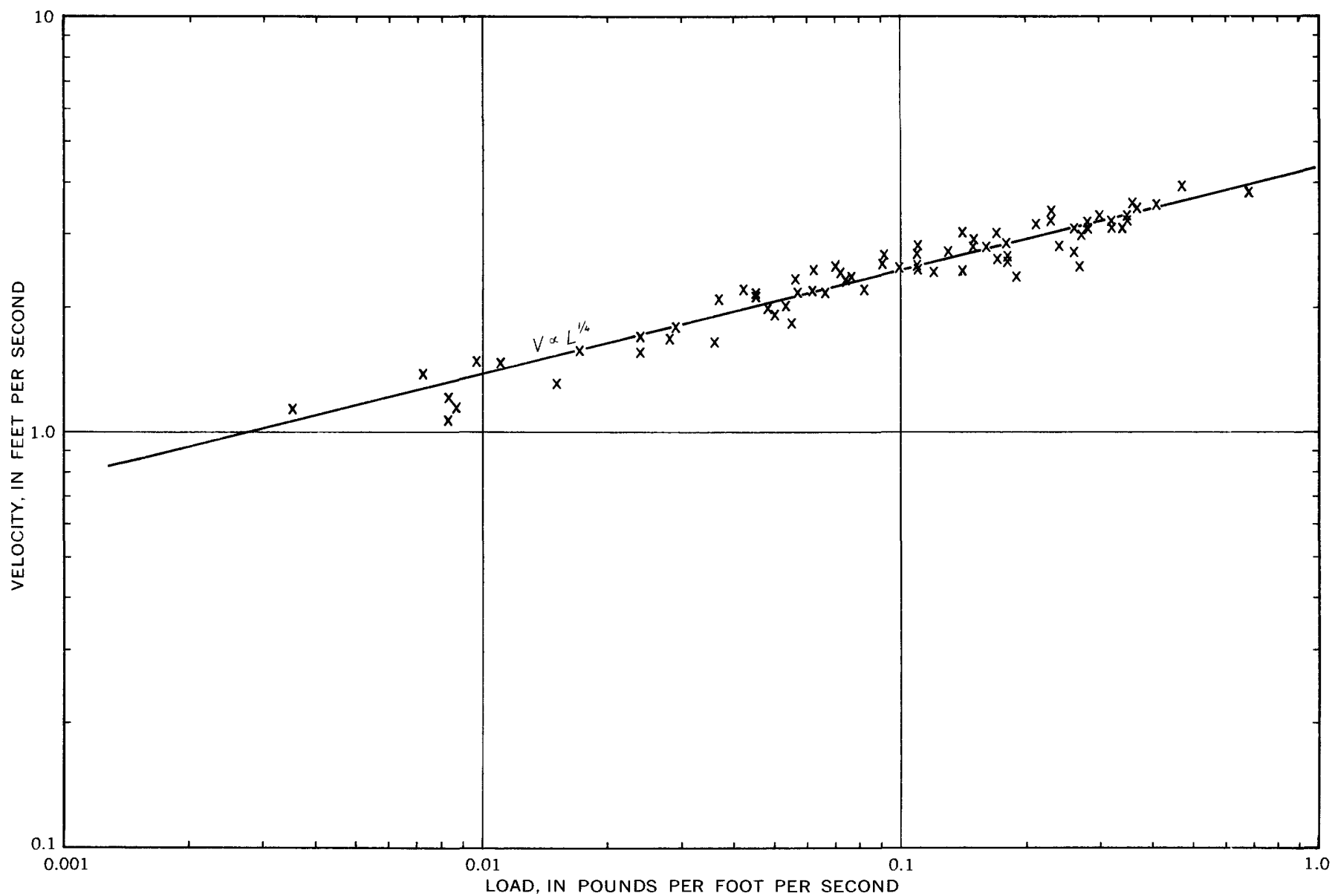

Figure 1.-Relation between velocity and load, sand B, Gilbert (1914) experiments. 
and the high-velocity range. These are presented in the order of their importance in natural streams and canals. The relations developed from flume data will be tested with field data from a few locations and compared with other equations for rates of sediment movement

\section{UNIGRANULAR MATERIAL}

Because of the uncertainties in the behavior of sediment mixtures, data from experiments with unigranular material were analyzed first. The best known and most widely used data of this kind are those from the studies of Gilbert (1914). I used some data from studies at the Waterways Experiment Station (1935), from Casey (1935), and from more recent experiments by Williams (1967) as supplements to the Gilbert data.

The relation between velocity and load for Gilbert's size $\mathrm{B}$ is shown in figure 1. ${ }^{1}$ The plot gives the relation $V \propto L^{1 / 4}$, which indicates a $1: 1$ relation for $V_{b}$ and $V$ in

1 Every other one of Gilbert's data on size B are plotted in figure 1, as is done when these same data are plotted in other figures. The same procedure is followed in plotting data from Gilbert's size C. All the data from Gilbert's sizes A, D, E, F, G, and $H$ are plotted unless otherwise noted. Data from runs having width-depth ratios from less than $41 / 2$ to 1 have not been plotted unless no other data are available in that size range. Load is total load; there is no distinction between bed load and suspended load if the bed material is made up of the same sizes as the sediment load.
Rubey's analysis. The same result holds true for sizes $A, C$, and $D$.

However, for size $\mathbf{E}$ (fig. 2), the data for low velocities tend to depart from the $V \propto L^{1 / 4}$ relationship. This departure is even noore pronounced for Gilbert's size G (fig. 3).

Careful observations by Williams (1967) using the Geological Survey flume at the Washington Gun Factory indicate that with a restricted range in sediment size the break between different velocity-load relations is well defined (fig. 4). Thus the $A B$ part of the curve will be called the low-velocity range, and the $B C$ part will be called the mid-velocity range.

The complete range of the velocity-load relations for a sediment mixture with a mean grain size of $0.19 \mathrm{~mm}$ is shown in figure 5 ; the $C D$ part of the curve is des:?nated as the high-velocity range. These data resulted from experiments by Simons and Richardson (1961) using the 8-foot recirculating flume at Colorado State University.

The relations between the Gilbert (1914) data and the Waterways Experiment Station (1935) data are shown in figure 6 . The mean grain sizes are the same.

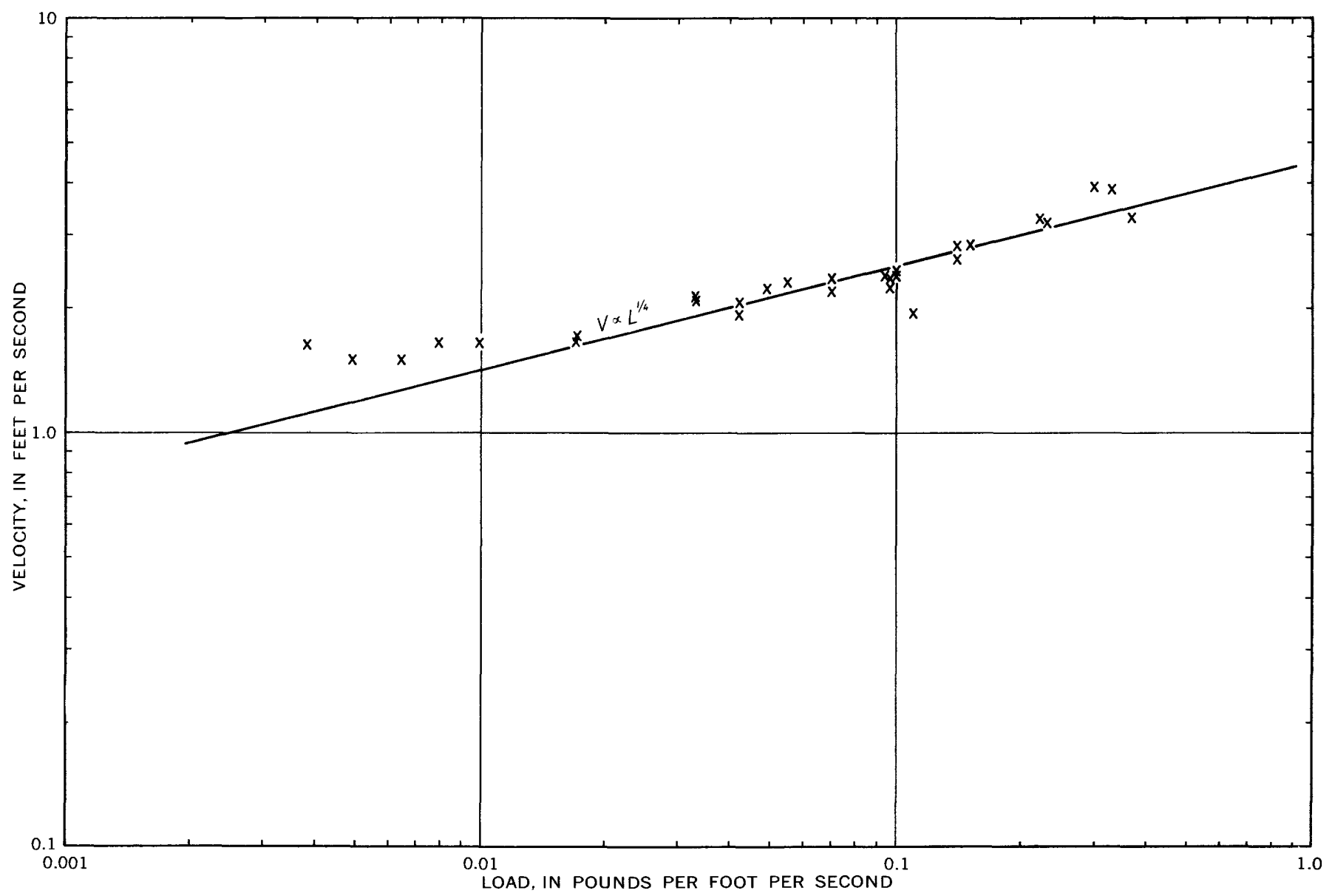

Figure 2.-Relation between velocity and load, sand E, Gilbert (1914) experiments. 


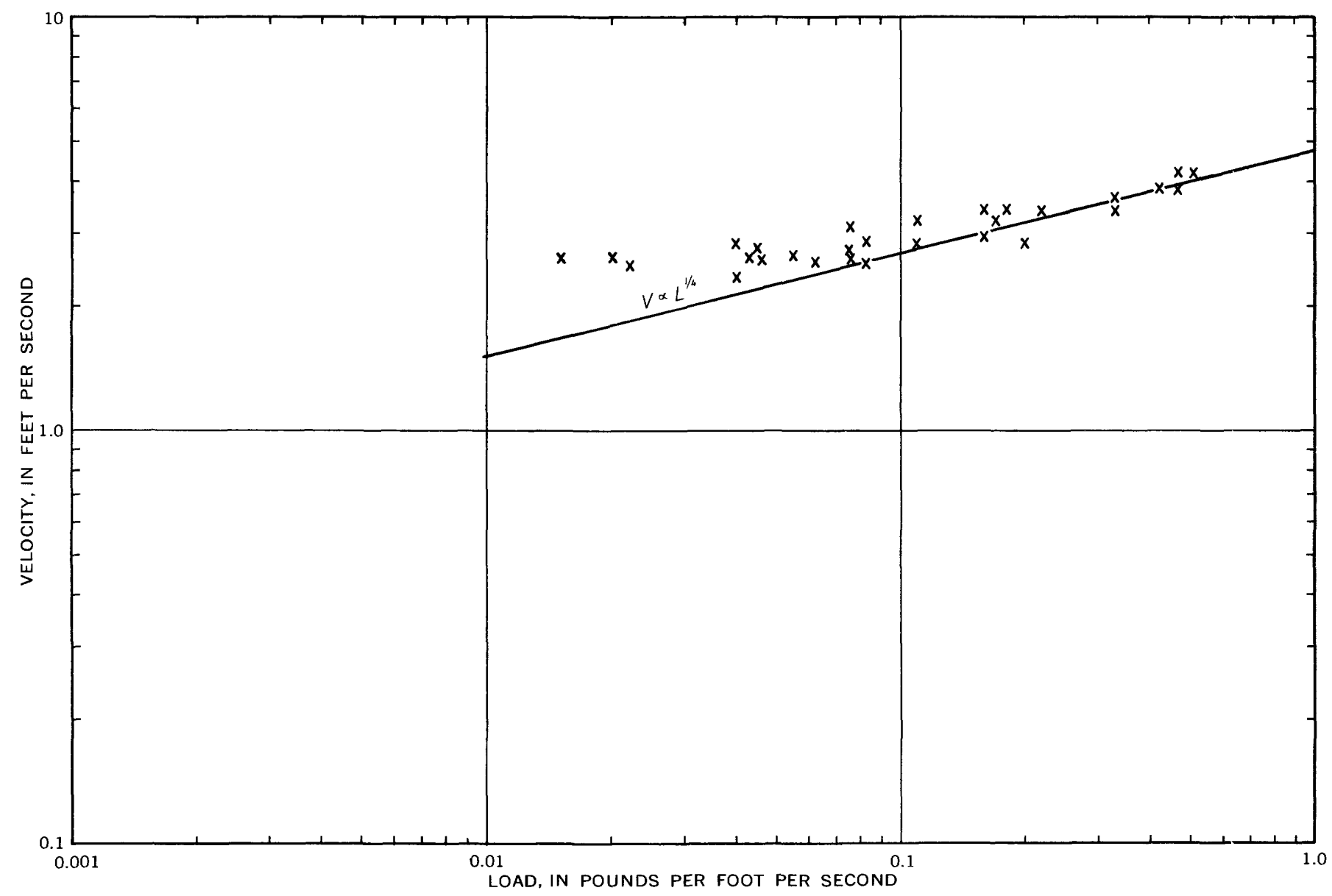

Figure 3.-Relation between velocity and load, sand G, Gilbert (1914) experiments.

The data from the Gilbert (1914), Williams (1967), Waterways Experiment Station (1935), and Simons and Richardson (1961) experiments all show the same pattern for the relation between velocity and load. (Compare figs. 1-6.)

\section{MID-VELOCITY RANGE}

If all the Gilbert data in the mid-velocity range are plotted in terms of $V / w$ instead of $V_{\mathrm{b}} / w$, as developed by Rubey, then a correction factor must be introduced into equation 2. The result is shown in figure 7 where $V / w$ is plotted against $L / \rho w^{3}\left(\frac{\gamma q}{\rho w^{3}}\right)$. I emphasize that in this report velocity is a dependent variable of sediment load and discharge; hence, the correction is related to discharge. The assumption or conclusion that shear velocity, $(\gamma D S)^{1 / 2}$, is directly related to the sediment load, moving either as bed load or suspended load, is specifically rejected. Furthermore, no distinction between modes of transport is made.

The complete equation for the mid-velocity range of the Gilbert data is (fig. 7),

$$
V=4.8 q^{1 / 16} L^{1 / 4} \frac{w^{1 / 16} \gamma^{1 / 16}}{\rho^{5 / 16}}
$$

To accommodate data from experiments with grain sizes smaller than those used by Gilbert, another correction factor must be used. This is a coefficient, $k_{1}$, and

$$
k_{1}=\exp \frac{1.55}{\pi} \operatorname{Cot}^{-1}\left(-5.55+3.8 \log \frac{\Delta \gamma d}{\rho w^{2}}\right)
$$

The equation of the line shown in figure 8 is

$$
V=1.13 k_{1} q^{1 / 16} L^{1 / 4}\left(\frac{\Delta \gamma d}{\rho w^{2}}\right)^{1 / 16} \frac{(w g)^{1 / 16}}{\rho^{1 / 4}} .
$$

A graph of the solution of equation 4 is shown in figure 9 ; the change in the value of $k_{1}$ falls between particle sizes of about $0.50 \mathrm{~mm}$ and $0.04 \mathrm{~mm}$. This is very close to the range of sizes where the relation between the fall velocity of the particle and its mean diameter changes from the square root of the diameter to the relation found under laminar conditiors insofar as the flow around the sediment particle is concerned. 


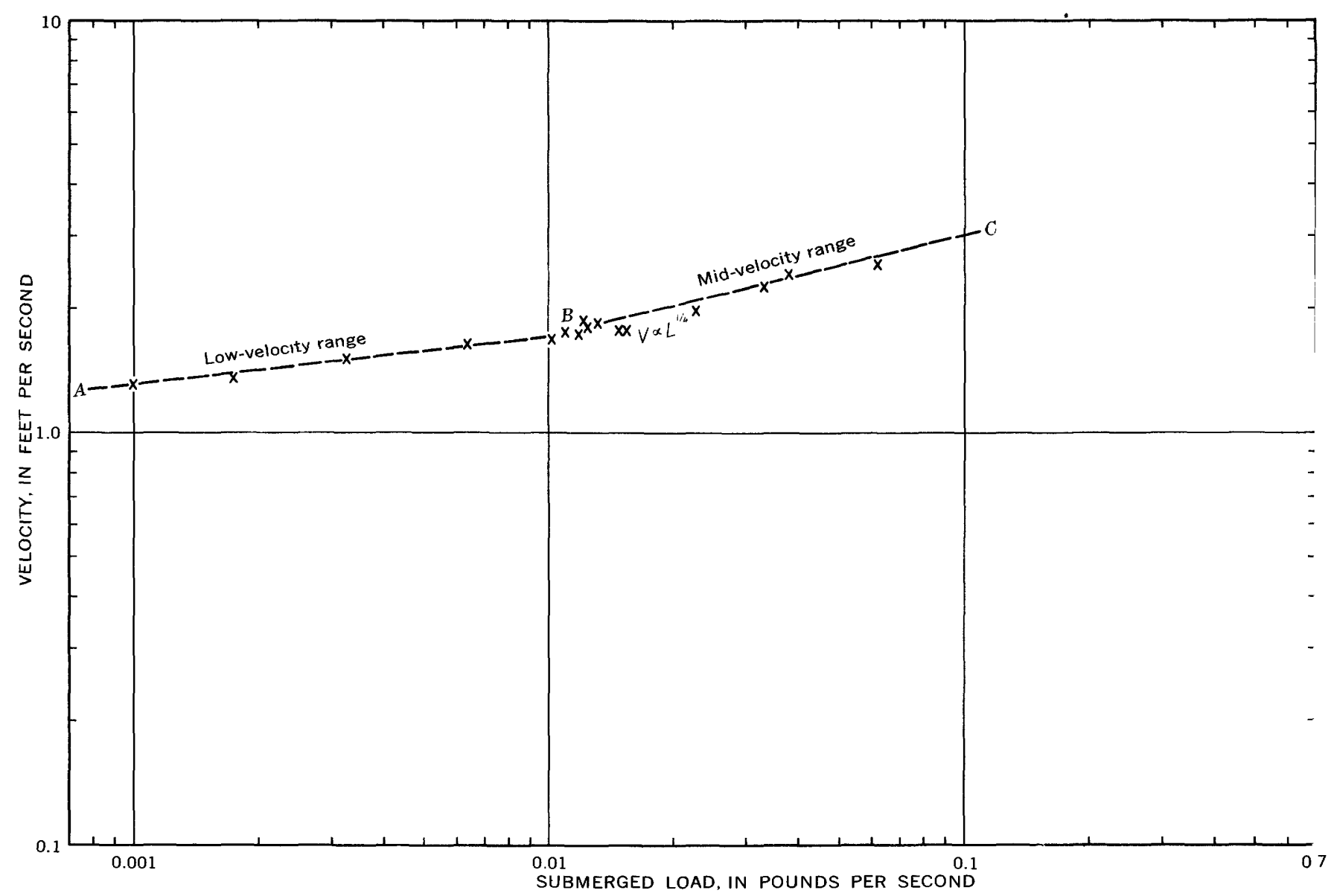

Figdre 4.-Relation between velocity and load. Data from Williams (1967) experiments. Sediment size: 0.25-2.00 mm, 1.40 mm mean. Width, 1 foot.

It is not unlikely that a change in the $V_{b} \propto V$ relations should occur simply because of differences in bed fornis. However, there is no prior reason why the cotangent function should be used, but it seems to fit the data best. I nust enphasize that all the equations presented are empiric, although they are dimensionally correct.

The velocity-load relation in the nuid-velocity range has been extended to nuuch snialler sizes than heretofore supposed possible - to the 0.01-nun sand of Kalinske and Hsia (1945) and the 0.04-mm sand of Laursen (1958) - by the introduction of the coefficient $k_{1}$. It results in a much larger load for a given velocity, relatively speaking, for a small size than for a large size of sediment in motion. These conclusions are limited to unimodal mixtures with standard deviations of less than 1.6 in the size conposition of the sand mixture; no data are available on bimodal size distributions.

\section{LOW-VELOCITY RANGE}

The relations between velocity and load in the low-velocity range were initially determined fron the
Simons and Richardson (1961) data for a number of sedinient nixtures. However, the forn of the equation proved wholly applicable to the Gilbert (1914) and Willianis (1967) data for essentially unigranular material. The basic form is also applicable to the Waterways Experiment Station (1935) data.

Because there is a velocity at which sedinient ceases to nove, velocity is not solely a function of load or vice versa. Consequently, in the analysis of the lowvelocity range, velocity is expressed in ternis of an effective load, $L_{e}$, defined as follows:

$$
L_{e}=\gamma q\left[C+7.5\left(\frac{\rho w^{2}}{\Delta \gamma d}\right)^{3 / 2}\right] 10^{-6} .
$$

Then for unigranular material,

$$
\frac{V}{w}=5.2\left(\frac{L_{e}}{\rho w^{3}}\right)^{1 / 9}\left(\frac{\Delta \gamma d}{\rho w^{2}}\right)^{1 / 2} .
$$

Equation 7 in the form of

$$
V \text { plotted against } \frac{L_{e}}{\rho w^{3}}\left(\frac{\Delta \gamma d}{\rho}\right)^{9 / 2}
$$




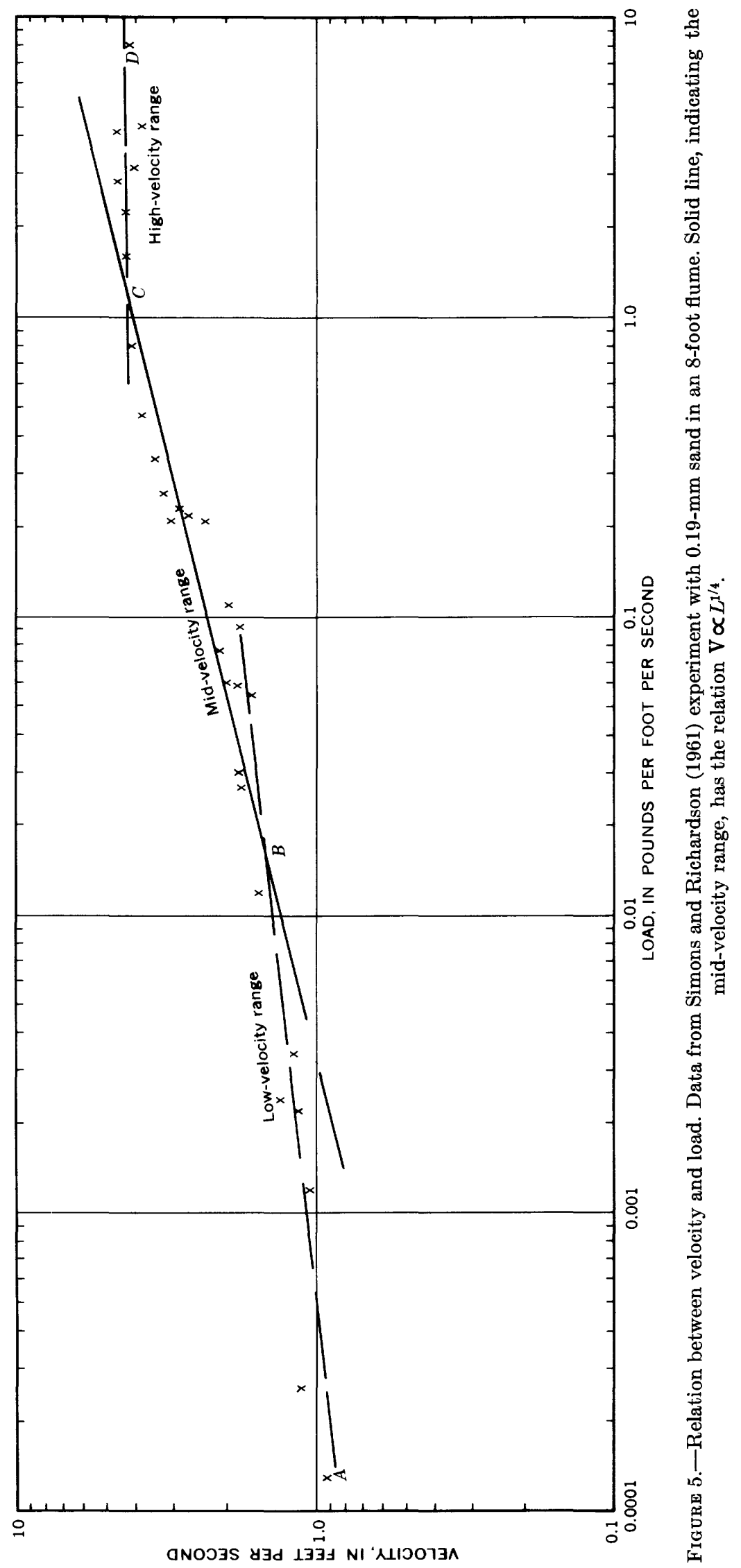




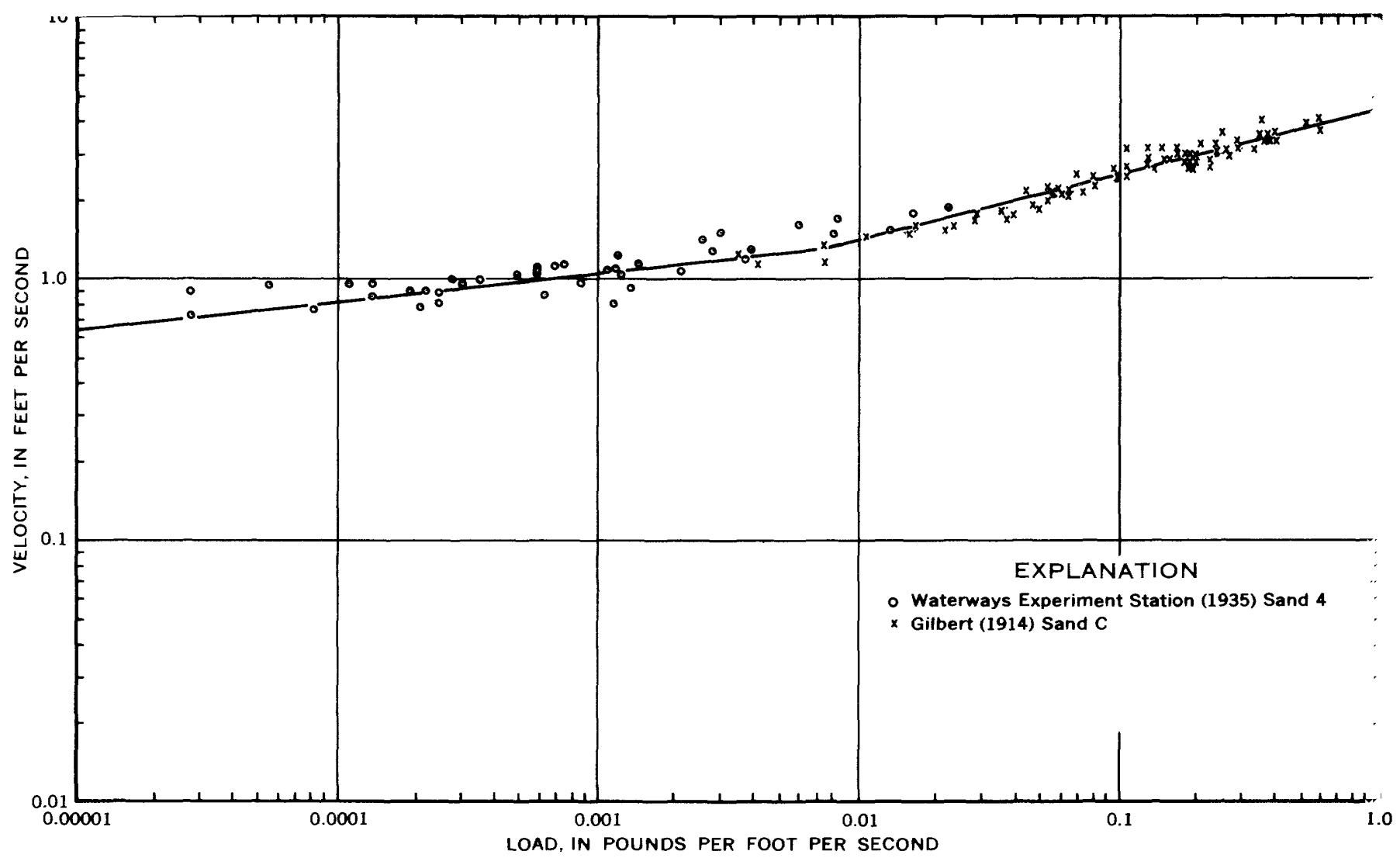

Figure 6.-Relation between velocity and load in the Waterways Experiment Station (1935) studies and in the Gilbert (1914) experiments, both using sand of 0.506-mm diameter.

is shown in figure 10 , which is a plot of the Gilbert (1914), Williams (1967), and Casey (1935) data.

When concentration of sediment becomes zero, equations 6 and 7 reduce to

$$
\rho^{3} V^{6} \propto(\Delta \gamma d)^{3} \frac{\gamma D}{\rho V^{2}}
$$

Equation 8 will be recognized as the well-known sixth-power law relating the weight of the particle to the velocity of the stream but with the addition of a velocity-depth correction.

Equation 7, for unigranular material and zero sediment concentration, can be expressed as

$$
V=9.6 d^{0.375} D^{0.125} \text {. }
$$

It can be compared with Laursen's (1958) relation of $V=5.47 C d^{1 / 3} D^{1 / 6}$ for zero sediment transport, where $C$ is a coefficient; with Kondrat'ev's (1962, p. 10) relation, which, when converted from the metric system, is $V=6.95 d^{1 / 3} D^{1 / 6}$; with Ho's (1935) relations, $V=5.1 d^{0.5} D^{0.13}$ and $V=3.9 d^{0.47} D^{0.22}$, in which $d$ is in inches and $D$ is in feet; and with the Meyer-Peter, Favre, and Einstein (1934) relation, $V \propto d^{3 / 8} D^{1 / 8}$, if the friction factor is constant. The relations of equation 9 are representative of the condition when sediment movement ends because they are an extrap?lation on a specific type of bed-one deformed by general sediment motion.

Equation 9 can be written as

$$
d=0.0024 \frac{V^{2.66}}{D^{0.33}} .
$$

Fahnestock (1963) reported that the maximum size of material in transport found in the White River below Emmons Glacier, Wash., varied with velocity to the 2.6 power. Equation 10 fits Fahnestock's observations reasonably well.

The point of intersection of the low-velocity load curve (eq 7) and the mid-velocity load curve (eq 5) is

$$
V=\frac{A^{12 / 7}}{\left(B k_{1}\right)^{16 / 21}}\left(\frac{\Delta \gamma d}{\rho}\right)^{1 / 2}\left(\frac{\Delta \gamma d}{\rho w^{2}}\right)^{11 / 42}\left(\frac{\Delta \gamma d}{\gamma D}\right)^{1 / 21}
$$

where $A$ is the intercept of the low-velocity load curre and $B$ is the intercept of the mid-velocity load curre. In computing the above value of velocity, the correction factor $7.5\left(\rho w^{2} / \Delta \gamma d\right)^{3 / 2}$ in equation 6 has been ignored 


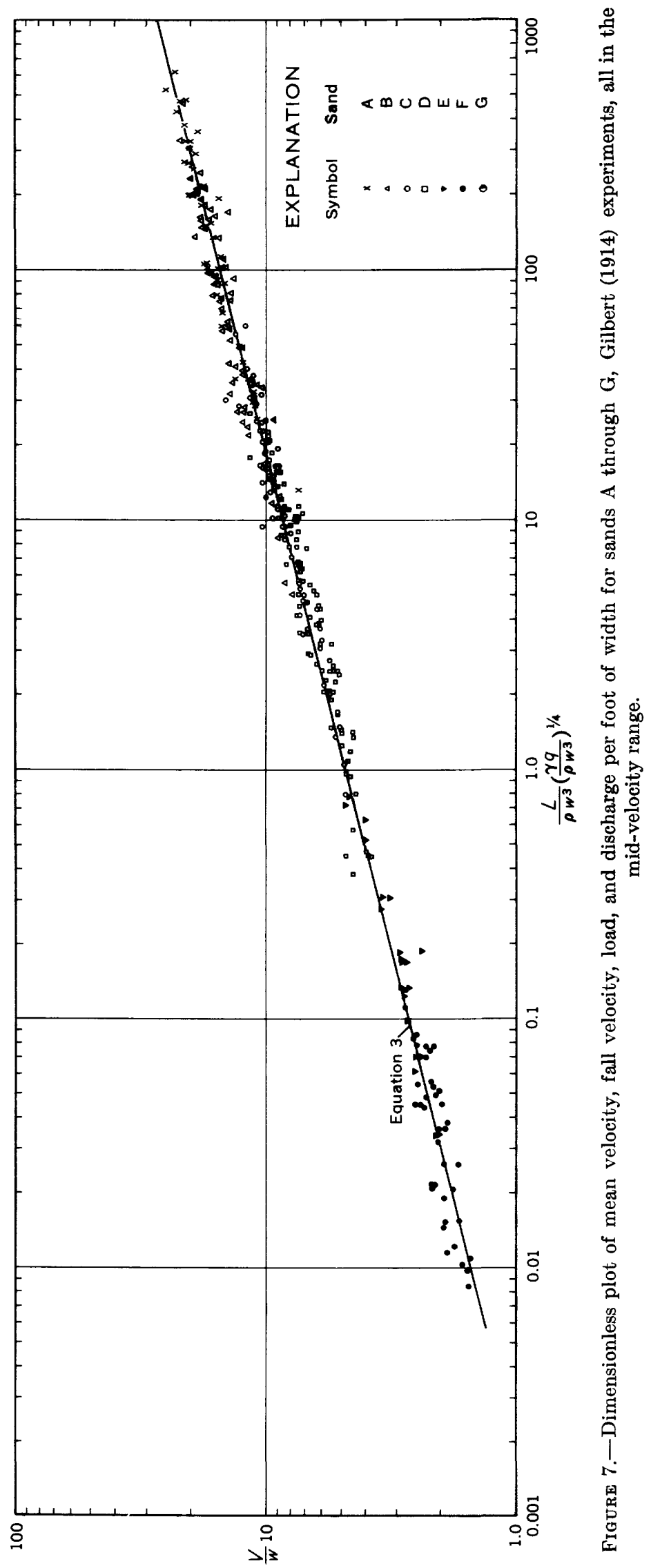




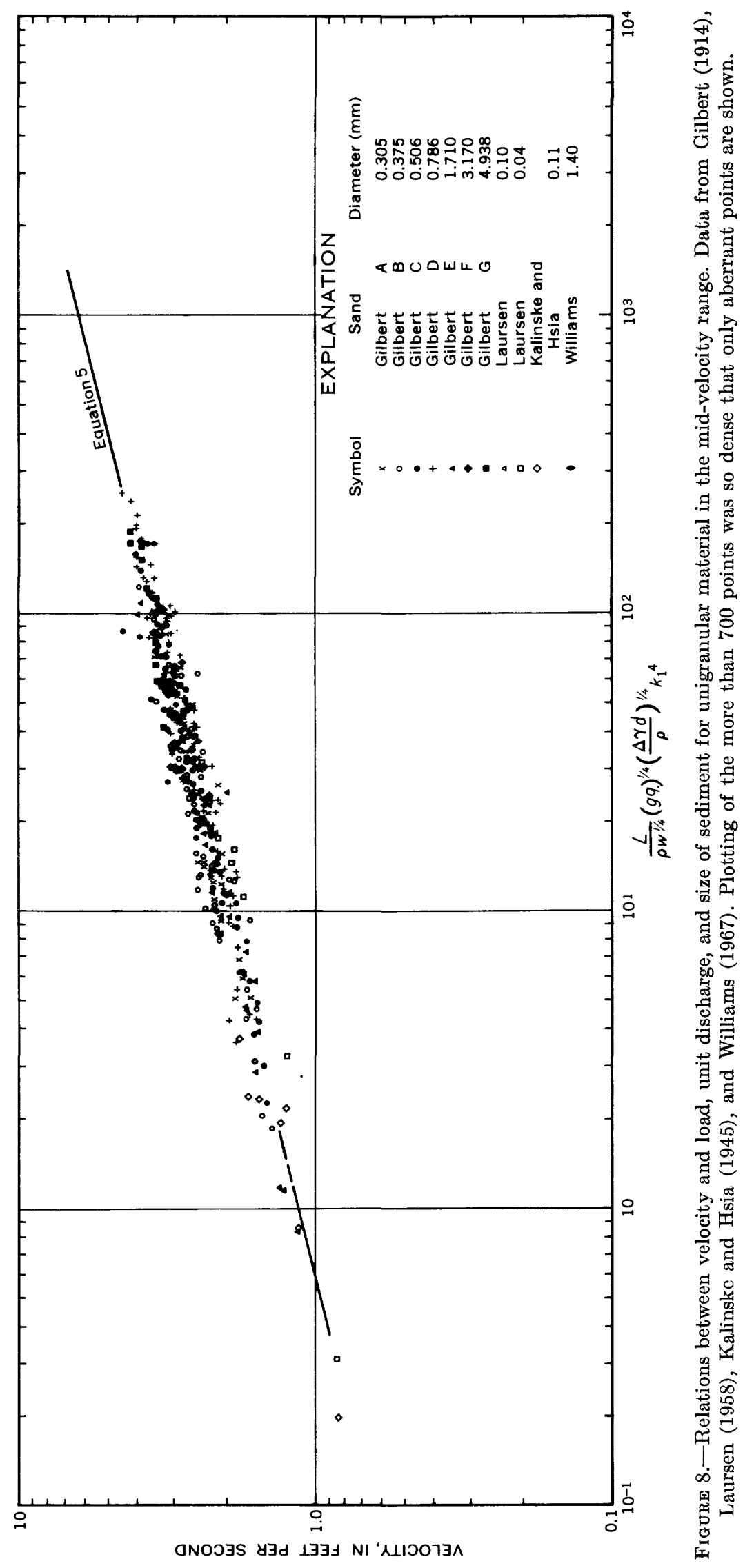

$329-5100 \longrightarrow 69-3$ 


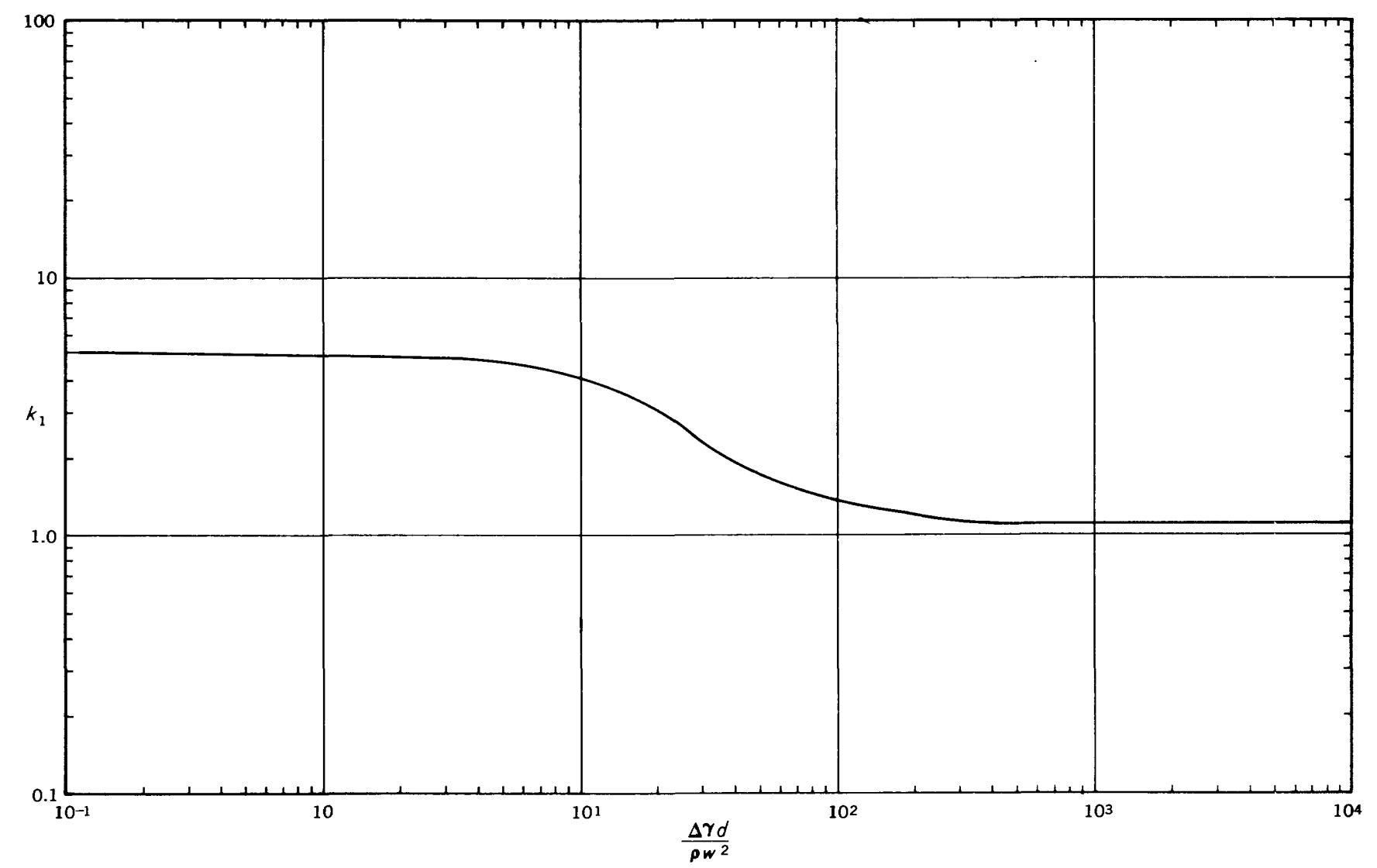

Figure 9.-Values for the coefficient $k_{1}$ in equations 4 and 5 with variations in the diameter and fall velocity of sediment particles.

as being unimportant. In each computation, the value of the correction factor at the point of intersection has been less than 5 percent of the value of the sediment concentration, $C$. For all practical purposes the velocity at this point is a function only of size of sediment. The velocity is at a minimum for a sediment in the sand size and increases with both smaller and larger sediment sizes.

\section{HIGH-VELOCITY RANGE}

For some time there has been field evidence of a limiting high velocity-one beyond which a channel becomes unstable. Such a high velocity was not readily discernible from the analysis of the Gilbert (1914) data. The Simons, Richardson, and Albertson (1961) data showed some evidence of a limiting high velocity, and Stein (1965) confirmed this. Further study however, indicated that some of the data from Gilbert's (1914) sand sizes A, B, C, and D belonged in a high-velocity range (fig. 11). The equation of the line in figure 11 is

$$
L=13 \gamma q S^{5 / 3}\left(\frac{\Delta \gamma d}{\rho w^{2}}\right)^{1 / 2}
$$

Equation 12 can be written in the form

$$
S=a\left(\frac{L}{\gamma q}\right)^{3 / 5}\left(\frac{\rho w^{2}}{\Delta \gamma d}\right)^{3 / 10}
$$

and can be compared with Craven's (1953, p. 73) equation for the flow of sediment in pipes of

$$
S=0.606 \frac{\Delta \gamma}{\gamma}\left(\frac{Q s}{Q}\right)^{2 / 3}
$$

where $Q_{s}$ is the sediment discharge and $Q$ th , water discharge. In the two equations the exponents of the ratio of sediment discharge to water discharge (concentration) are almost identical. Both equations indicate that, for coarse material, slope is a furction of sediment concentration.

Equation 12 seems valid for high concentrations and, therefore, is particularly applicable to small flumes with low discharges on steep slopes. The relation in equation 12 is not the equivalent of the limiting highvelocity range (fig. 4), which appears to be what Stein called a "breakaway" velocity and is related to loads 
BEHAVIOR OF STRAIGHT OPEN CHANNELS WITH MOVABLE BEDS

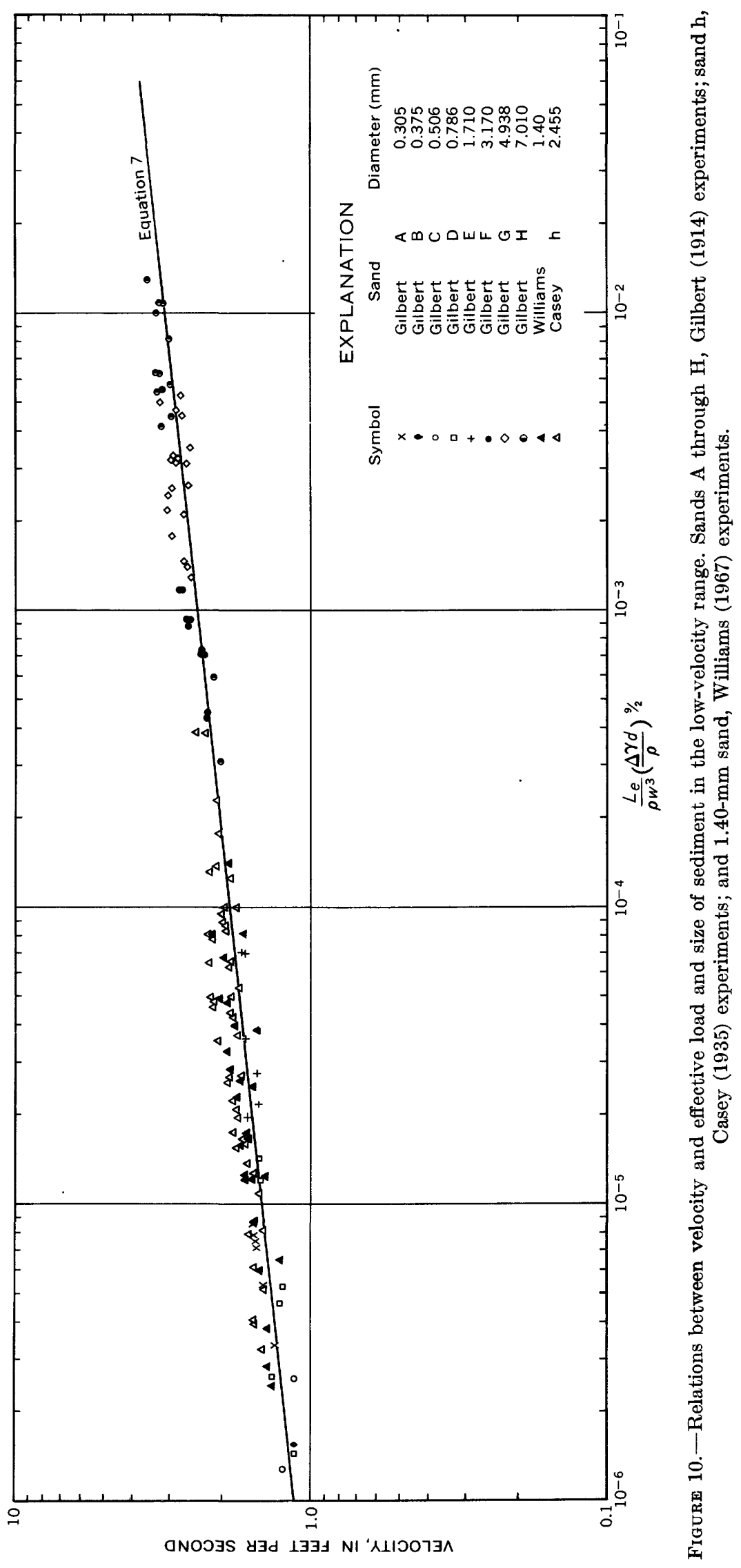




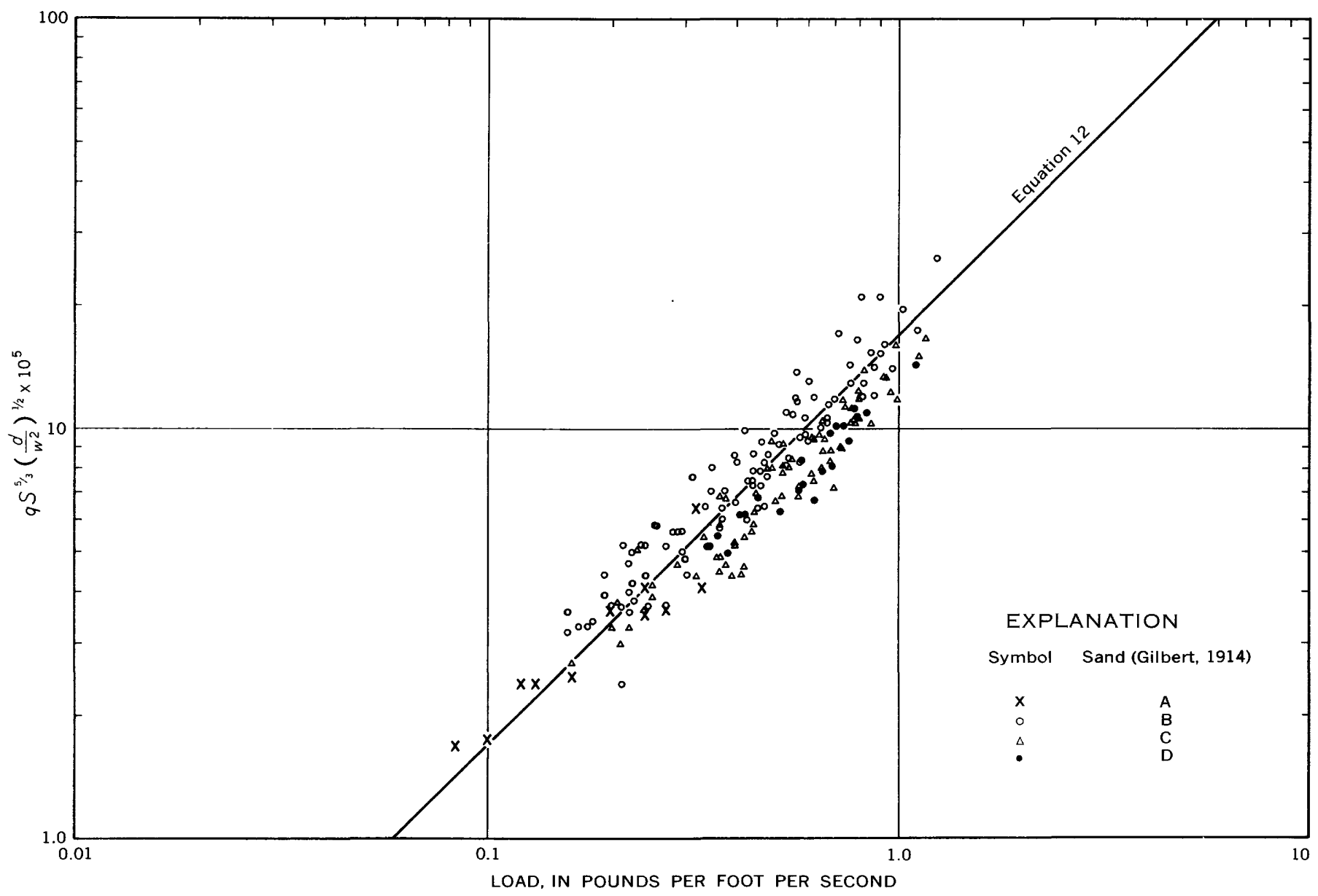

FIGURE 11.- Relations between load and discharge, slope, and sediment size in the high-velocity range; sands A through D, Gilbert (1914) experiments.

derived from the stream bed. A field example of a limiting velocity is shown in figure 31, where data are plotted for the Colorado River at Yuma, Ariz. There, maximum velocities under natural conditions were between 6 and 7 feet per second for discharges between 25,000 and 100,000 cfs (cubic feet per second). The question of a maximum velocity will be discussed at greater length in the following section on mixtures of sediment sizes.

\section{MIXTURES OF SEDIMENT SIZES}

Although the relations describing the movements of unigranular sediments are good, those describing the movements of sediment mixtures are indeterminate. In fact, this is the first area of indeterminacy encountered in the study of the behavior of alluvial channels. In most, but not all, flume studies the size distributions of the transported material and of the bed material are the same. In most natural streams these two size distributions are not the same, and the differences between them may vary widely. Even if the size distributions were the same in natural streams, the fact would be difficult to substantiate because the size distribution of material caught in a suspended load sampler is always deficient in some of the coarser sizes of the sediment load. These pass beneath the sediment sampler and constitute much of the unmeasured load of the stream. Consequently, in some flumes and in most natural streams, the selection of a proper size is ver difficult on the basis of available information. This difficulty increases as sediment concentrations decline and as the range of sizes increases.

The effect of size mixtures on the velocity-load relation is indicated in figure 12 . The mixture of sediment sizes seems to have the effect of exterding the relation $V \propto L_{e}^{1 / 9}$ by permitting, for a given mean velocity of fluid, an increased dune velocity, an increased dune height, or both. In figure 12 the velocityload relation of the mixture eventually comes back to the line $B C$; there is insufficient data to establish the relation for the high-velocity range, the curve $C D$, but 


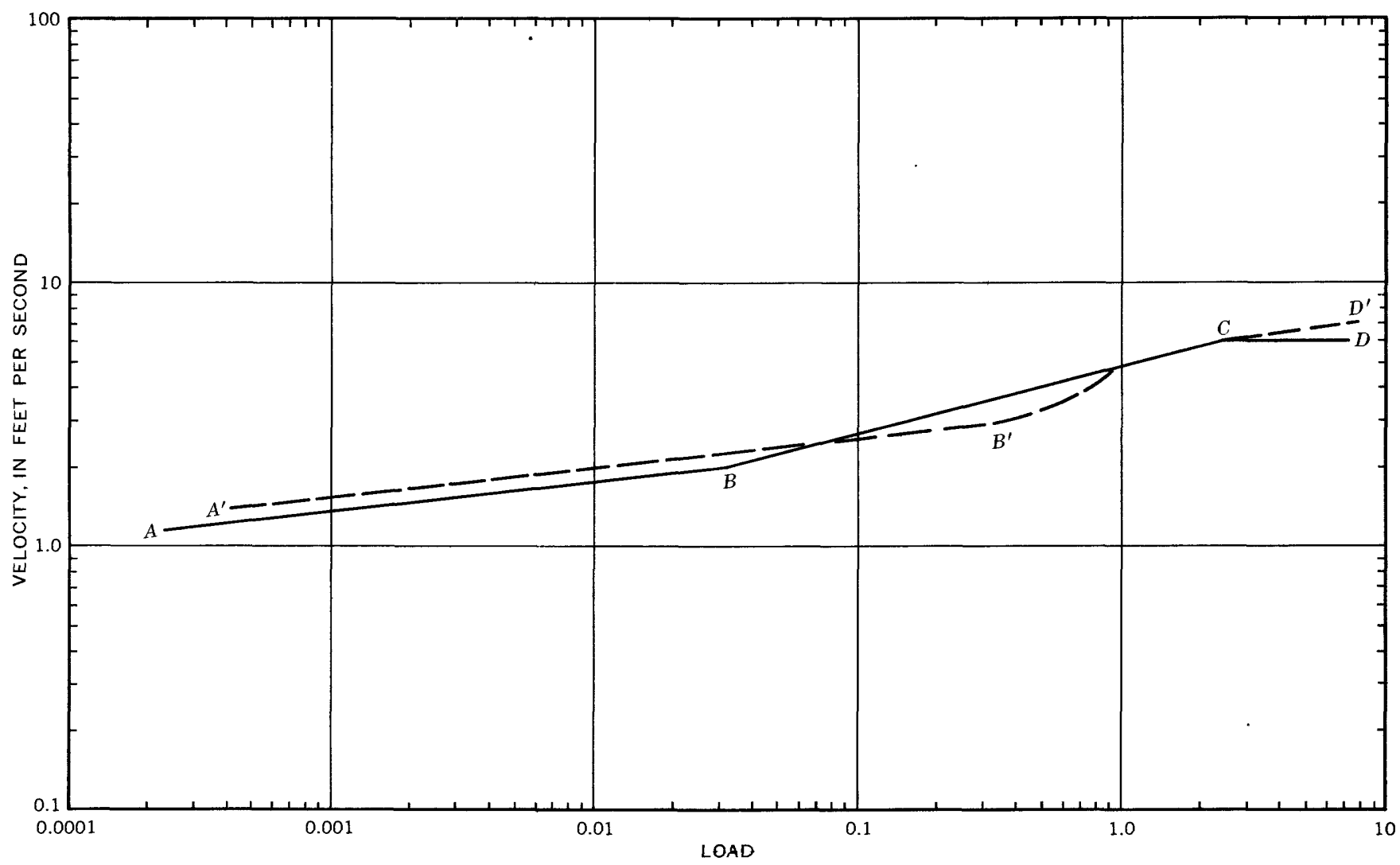

Figure 12.-The velocity-load relation for unigranular material and a unimodal mixture. Solid line $A B C D$, relation between velocity and load for a unigranular material. Dashed line $A^{\prime} B^{\prime} C D^{\prime}$, relation between velocity and load for a unimodal mixture with a mean diameter equal to the diameter of the unigranular material.

the slope of the line $C D^{\prime}$ is presumed to be a function of the size composition of the sediment mixture. The distance from $B^{\prime}$ to the line $B C$ appears to be related to the range of sizes in the mixture - a wide range of sizes, a wide departure - and particularly to the range of particle-fall velocities.

Thus, the behavior of mixtures of sediment sizes in alluvial channels is considerably more complex than that for unigranular material. Rubey (1938) assumed that in any mixture with a wide range of sediment sizes, the largest size moved would vary approximately as the bed velocity. Because the largest size would have an important bearing on the characteristic settling velocity of the sediment mixture, there would be some degree of relation between the bed velocity and the fall velocity. Rubey then concluded that, roughly $V_{b} \propto w$ and $V_{b}^{3} \propto L$.

Rubey (1938) undoubtedly was influenced by Gilbert (1914) for, as shown in figure 13, if all of Gilbert's data are taken together, they do show the same rough relation. Thus, Rubey's conclusion is most applicable to the mid-velocity range because the Gilbert data are typical of it. However, even in the mid-velocity range the effects of the range of sizes within a mixture and of size variation with time are still uncertain, and in the other velocity ranges these effects are even more uncertain.

\section{MID-VELOCITY RANGE}

The relation between velocity and load for sedimert mixtures in the mid-velocity range is shown in figure 14. Clearly, equation 5 can be used only with caution and with a change in coefficient. The equation of the line shown in figure 14 is

$$
V=0.95 k_{1} q^{1 / 16} L^{1 / 4}\left(\frac{\Delta \gamma d}{\rho w^{2}}\right)^{1 / 16} \frac{(w g)^{1 / 16}}{\rho^{1 / 4}}
$$

Because of the small influence of the size parameter in equation 13 , it is doubtful if the fit of the equation can be improved by trying to adjust the mean diameter of the mixture. The better approach seems to be to adopt the Rubey (1938) hypothesis and ignore the size parameter in mixtures. The results are almost as good as those for unigranular material, and the procedure is far simpler.

The resultant equation, which is simply

$$
V=6.0\left(\frac{L}{\rho}\right)^{1 / 3}
$$




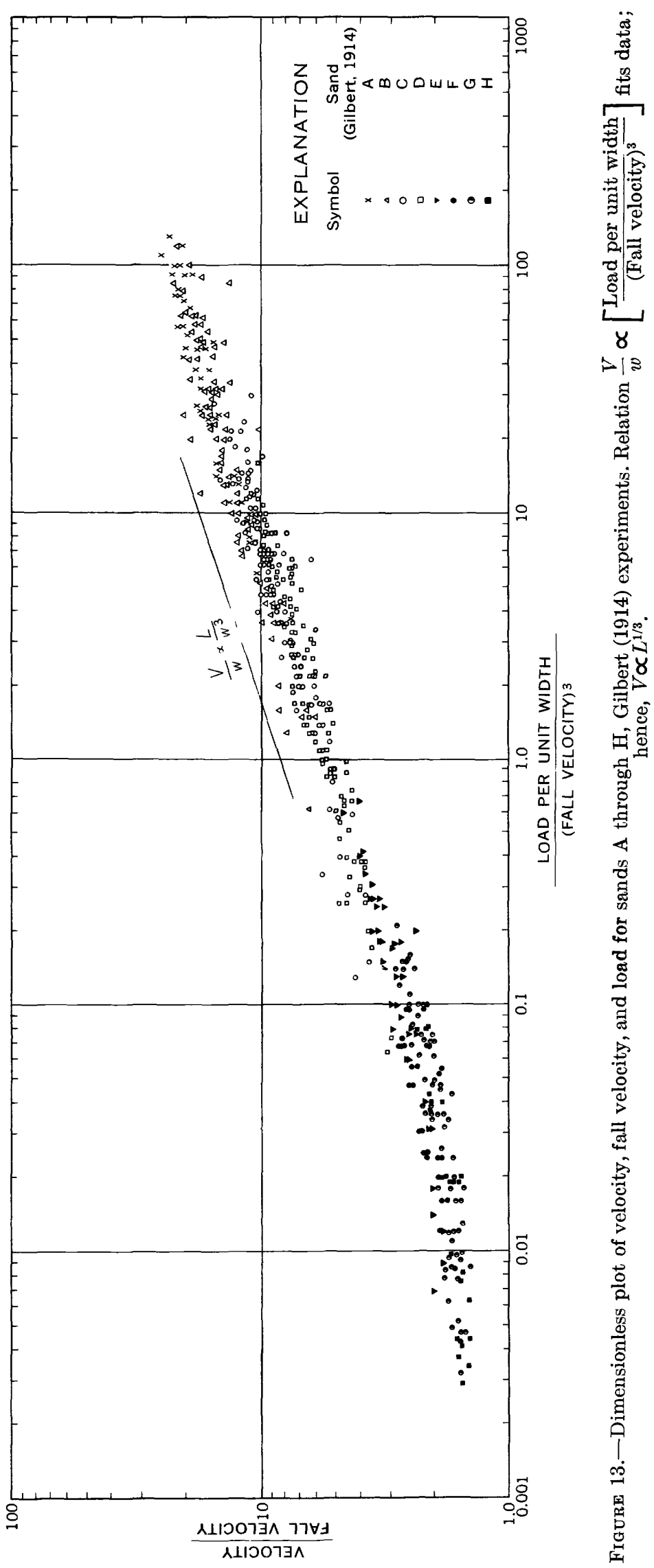




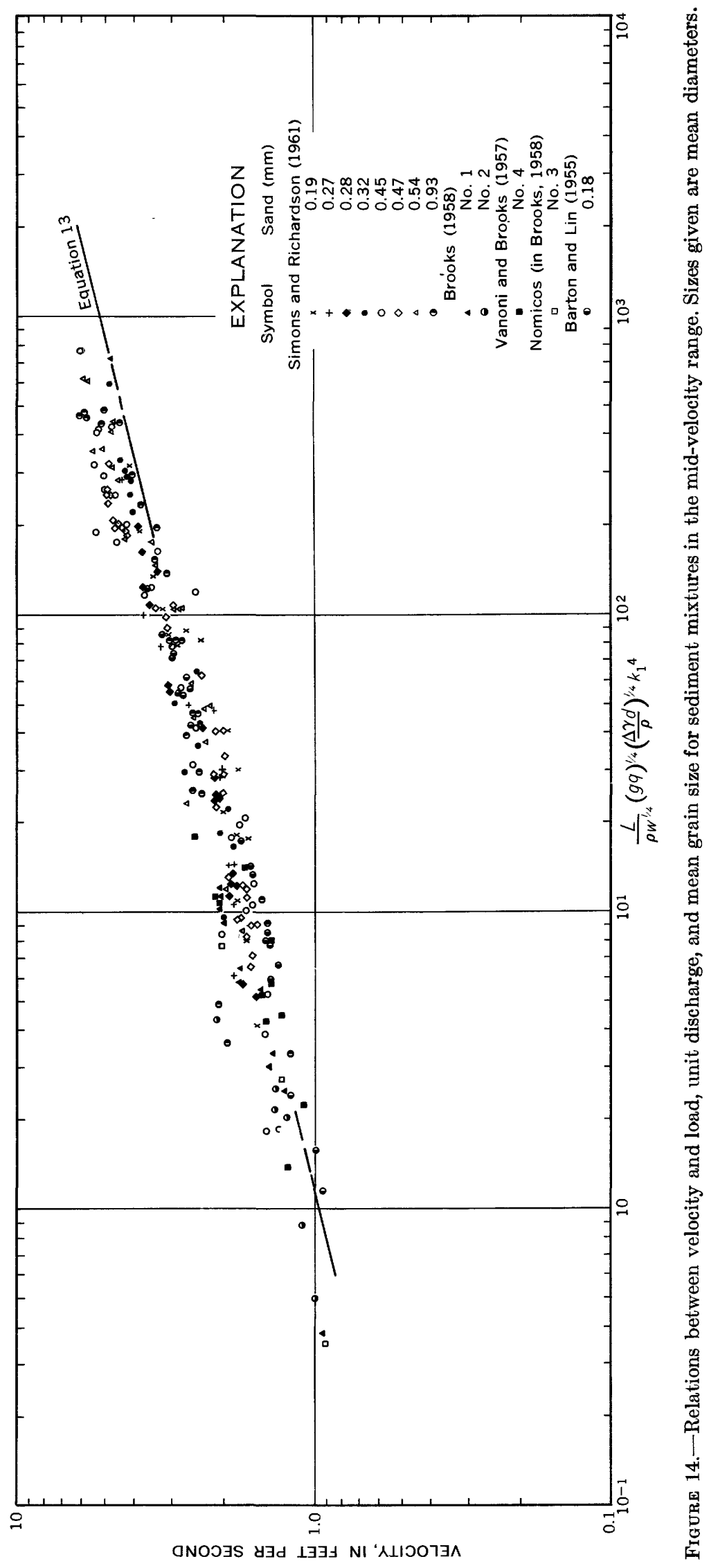




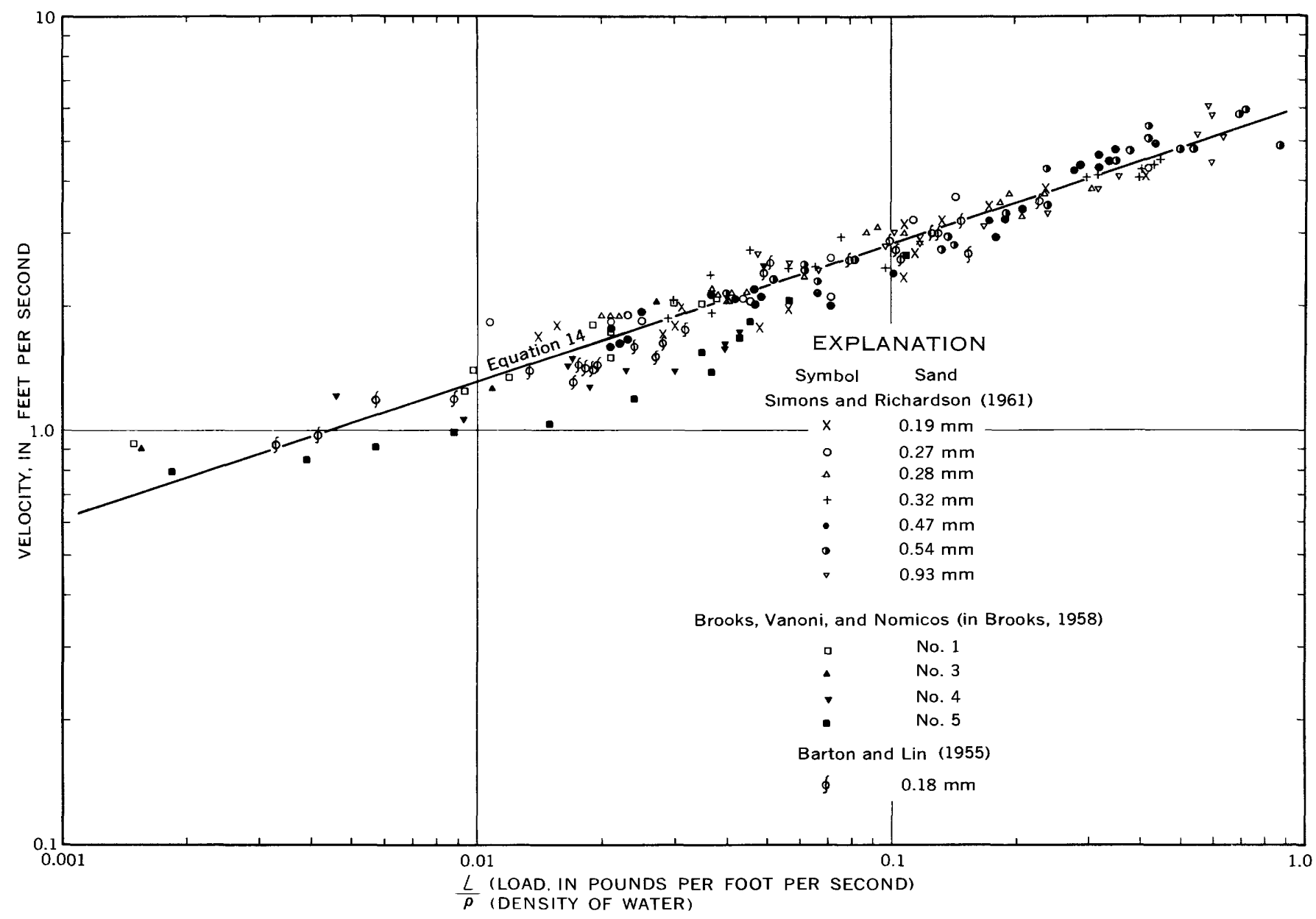

Figure 15.-Relations between velocity and load for sediment mixtures. Flume data. Sizes given are mean diameters.

is shown in figure 15 together with data from recirculating flumes.

In comparison with unigranular material the load of a sediment mixture is higher, for a given velocity, in the lower part of the mid-velocity range and there is little difference in loads in the higher velocities of the midvelocity range.

The mid-velocity range of sediment of any specific size encompasses the velocities usually found in nature and is particularly important in canal design. We must remember, however, that there is an upper and a lower limit for each size. Therefore, it is never possible to have the same load for the same velocity of, say, a $0.10 \mathrm{~mm}$ and a $1.0 \mathrm{~mm}$ sand over a wide range of velocities. Some parts of the velocity and load-size spectrum will coincide but not all.

A word of caution must be introduced about the use of the velocity-load relations, particularly equations 13 and 14. Load is a function of some power of velocity. Consequently, if the velocity distributions throughout the water prism vary greatly, the coefficients of the equations must vary to some unknown extent. The situation is somewhat analogous to the determination of the energy coefficient. Chow-Ven $(1959$, p. 28) indicated that the value of the energy coefficient for natural streams (and presumably this would be true of canals) exceeds that for flumes. The coefficients of exuations 13 and 14 should have an inverse relation to the energy coefficient; consequently, the coefficient of equation 13 , and particularly equation 14, should be reduced for large streams and canals. Data indicate that equation 14 for canals and many rivers should be

$$
V=5\left(\frac{L}{\rho}\right)^{1 / 3} \text {. }
$$

Because at this time there is no way of evaluating the effect of change in velocity distribution in the water prism, the coefficient of equation 14 should be determined on the basis of local evidence.

\section{LOW-VELOCITY RANGE}

The velocity-load relations in the low-velocity range for the Simons and Richardson (1961) data, using the effective load as defined in equation 6 , are 


$$
\frac{V}{w}=6.3\left(\frac{L_{e}}{\rho w^{3}}\right)^{1 / 9}\left(\frac{\Delta \gamma d}{\rho w^{2}}\right)^{1 / 2}
$$

This equation is shown in figure 16, where the Simons and Richardson (1961) data are plotted as

$$
V \text { plotted against }\left(\frac{L_{e}}{\rho w^{3}}\right)\left(\frac{\Delta \gamma d}{\rho}\right)^{9 / 2} \text {. }
$$

In the low-velocity range the effect of a reduction in the fall velocity is a reduction in the sediment load if the velocity of the fluid remains constant (eqs 7 and 15). Thus, part of the variation in the coefficient in these equations and the spread of the data plotted in figures 16 and 17 can be eliminated by the use of fall velocity weighted in accordance with the variation in sizes of the mixture. However, as indicated by data for the $0.45-\mathrm{mm}$ runs of Simons and Richardson (1961) in figure 16 , the size composition of the material actually being moved may change considerably from time to time, but when the size composition of the material in the bed and that of the material in motion are the same the relations are as good as those for unigranular material. Variation between the sizes of the bed material and the transported material was also observed in the Waterways Experiment Station (1935) studies. The relations velocity and effective load and mean grain size are shown in figure 17.

Two problems exist in dealing with sediment mixtures: The first is to establish the relation between the mean diameter of the mixture and the variations in sediment size. The second is to predict the variation between the sizes of material in motion and the sizes of the material in the bed-that is, the sorting problem.

In view of the uncertainties about the correct value of the characteristic fall velocity of a group of particles and other unknowns about sediment mixtures, such as sorting and size separation, it is considered adequate, for the present, to express variations in the velocityload relations in the low- and mid-velocity ranges by two sets of equations (eqs 5 and 14 for unigranular materials and eqs 7 and 15 for sediment mixtures). Fall velocities used in this report are those for quartz spheres of a diameter $d$.

As will be shown later, low sediment loads are not important in determining velocity. Thus, errors are likely to be concentrated in the estimates of the rate of sediment movement rather than the estimates of velocity. Fortunately, such errors, while large percentagewise, are small in terms of the actual quantity of sediment moved by a stream at various discharges. There are large changes in the amount of sediment in movement for small variations in velocity, and the stream adjusts readily to variations in load with small changes in the velocity. Low sediment loads are not important in canal design. Under such conditions, sediment size becomes a dominating characteristic. Except for flumes having small discharges, there is not much interest in either the determination or the effect of very low rates of sediment movement.

\section{HIGH-VELOCITY RANGE}

As noted in the section on unigranular material, little information is available about the high-velocity range. An analysis of the Simons and Richardson (1961) data, confirmed in part by the use of data from Stein (1965) with respect to his "breakaway" velocity, indicates that the limit of the velocity parameter is

$$
V=18 \frac{(\Delta \gamma d)^{2 / 3}}{\rho^{2 / 3} w^{1 / 3}}
$$

which reduces to

$$
V=250 \frac{d^{2 / 3}}{w^{1 / 3}}
$$

It is hypothesized that in a channel with a bed of incoherent unigranular material which, with increasing discharge, is to be a source of sediment there is a velocity above which channel stability will not existthat is, a channel will simply erode and enlarge its sections, keeping velocity essentially constant. Equations 16 and 17 are based on data from mixtures. In a mixture, however, each size should be considered separately, and the actual limiting velocity should be based on the largest sizes present in appreciable amounts. The slope of the high-velocity load curve $C D$ in figure 5 is presumed to be dependent on the range of sizes of sediment present in the sediment mixture.

According to equation 17, maximum velocity will be constant at about 4 feet per second for all sediment sizes of less than about $0.10 \mathrm{~mm}$ and will be proportional to $d^{1 / 2}$ for sizes greater than about $5 \mathrm{~mm}$. According: to my own estimate, based on the relations in equation 17, the size of sand that stabilized the predam flow of the Colorado River at Yuma, Ariz., was about $0.8 \mathrm{~mm}$. The mean size was smaller than this, but, presumably, the largest size appearing in any quantity in the mixture was about $0.8 \mathrm{~mm}$. The behavior of the sediment load of the river is shown in figure 18.

Because there was little variation of width with discharge at the Yuma gaging station, the sediment concentration decreased with increasing discharge and the load remained constant. Thus, the load was constant while the depth-slope product increased consideral ${ }^{l} y$. Hill (1925) excluded flow from the Gila River in his data on the Colorado River, and at that time the Gila River was largely uncontrolled. A suggested reason for 


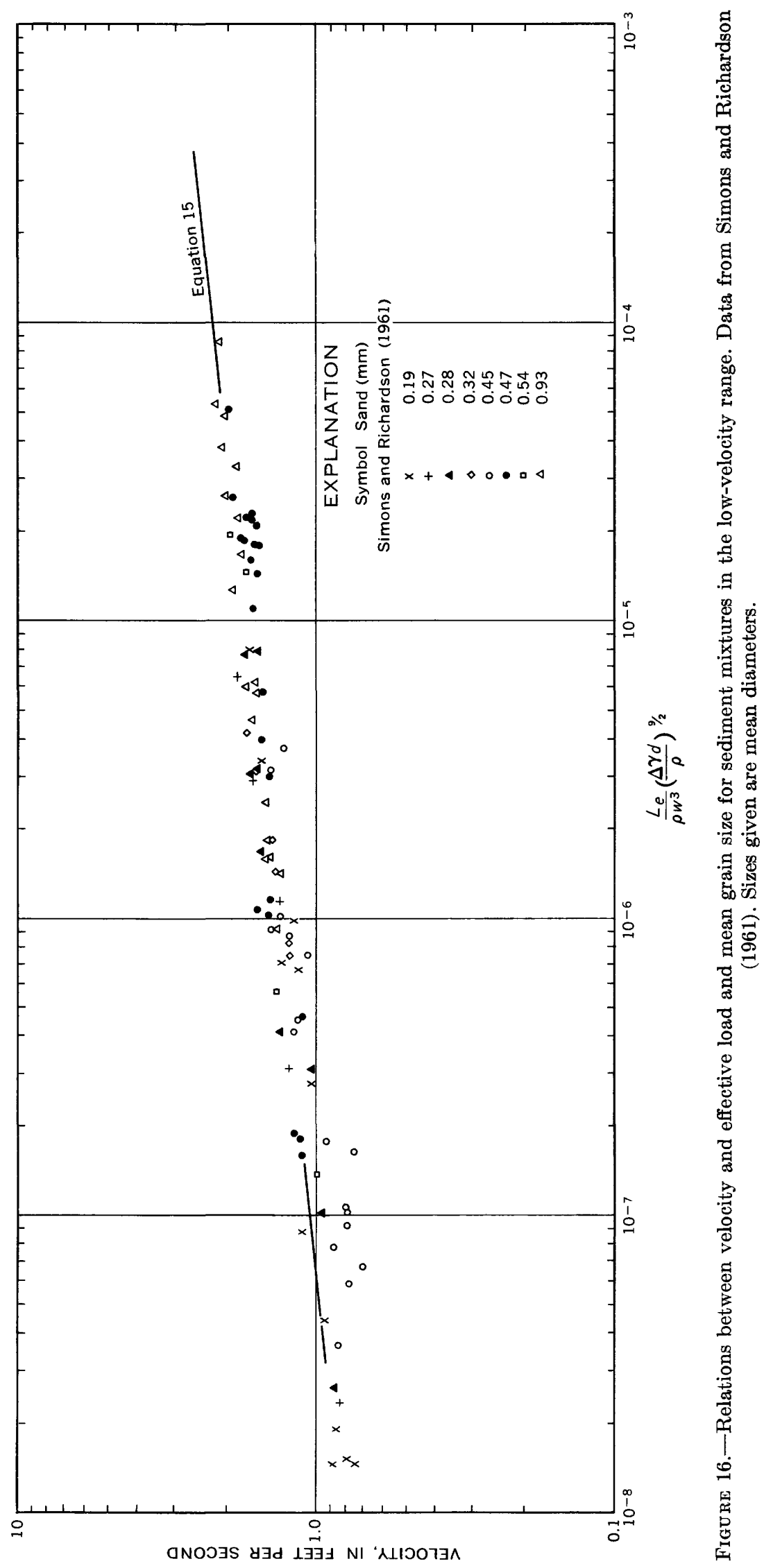


BEHAVIOR OF STRAIGHT OPEN CHANNELS WITH MOVABLE BEDS

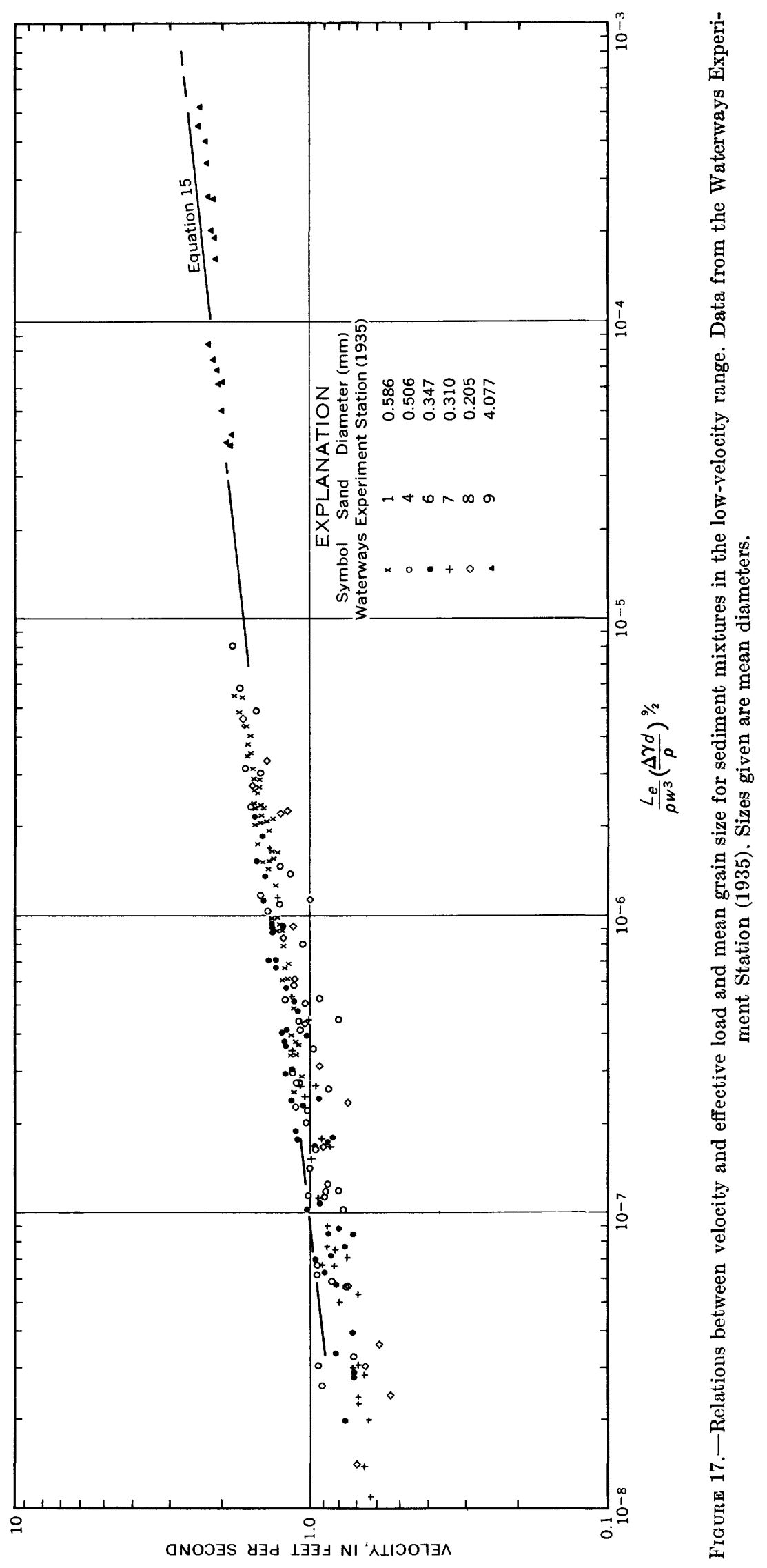




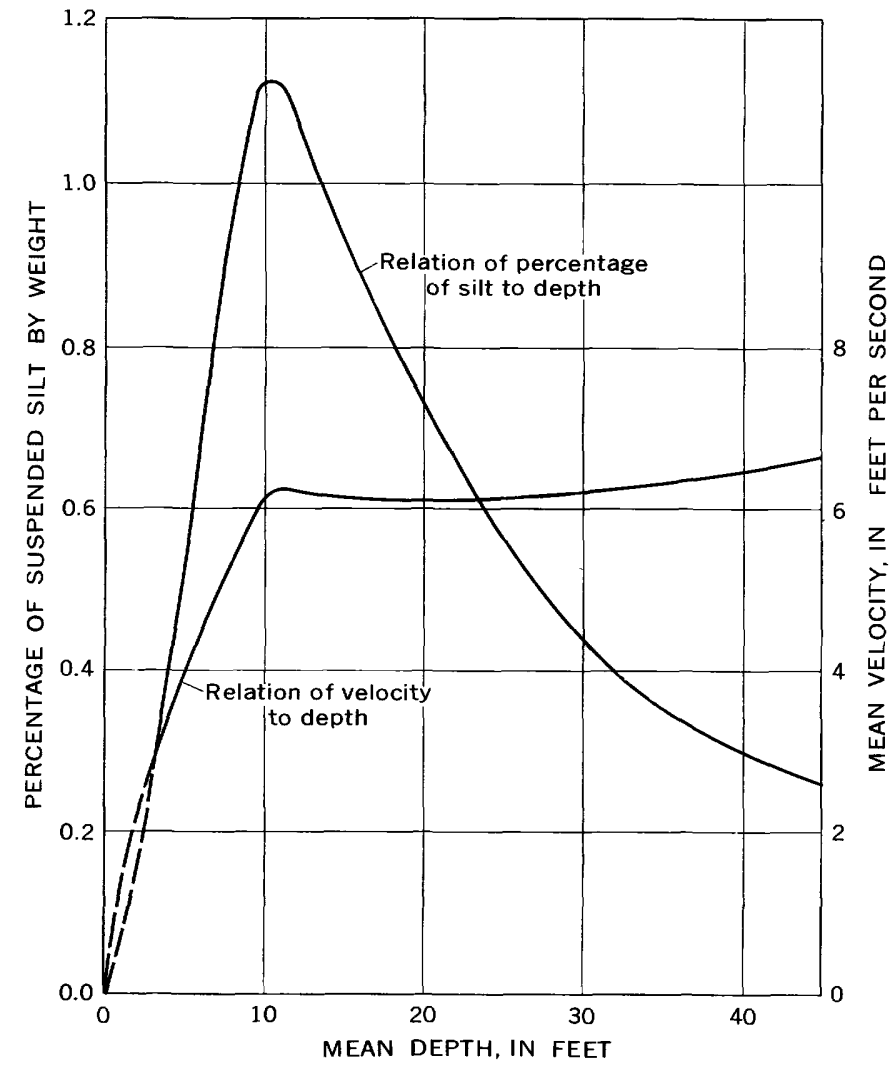

$A$

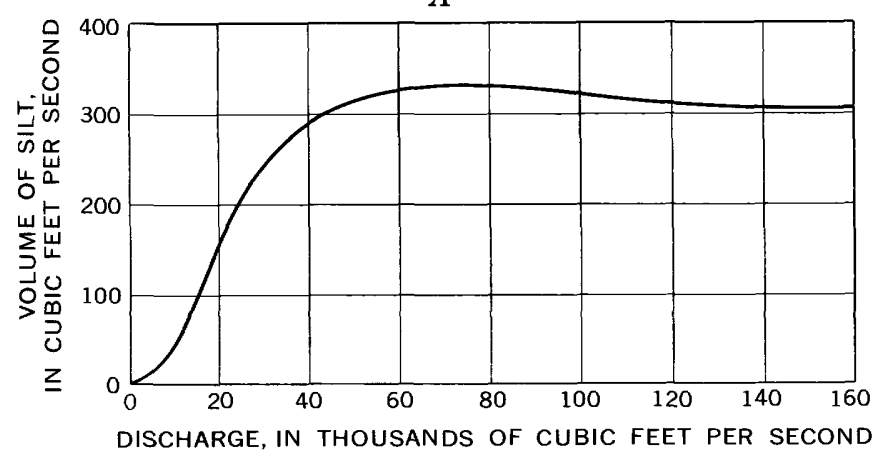

$B$

Figure 18.-Behavior of the sediment load of the Colorado River at Yuma, Ariz. A, Relation of percent of sediment and mean velocity to mean depth (from Hill, 1926, p. 963). These curves are based on about 3,000 measurements at the Yuma gaging station, taken when there was no flow in the Gila River. $B$, Relation between sediment discharge and water discharge (from Hill, 1925, p. 420). The curve is based on about 3,000 samples taken during the period 1908-16 at the gaging station, Yuma, Ariz., at times when there was no flow in the Gila River. One cubic foot of deposited silt assumed as weighing 83 pounds.

the exclusion is that the Gila River had a slope about three times that of the Colorado River, and the Gila moved considerably larger sizes of sediment. Consequently, floods from the Gila River at the Yuma gaging station had higher velocities, for the same discharge, than did the Colorado River.

The coefficients of equations 16 and 17 are based on the results of a small number of experiments. Consequently, the coefficients are subject to error and, perhaps, to a difference in interpretation, but the equations seem to describe field conditions and should b? worthy of further study.

Testing the Simons and Richardson (1961) data for the choked-flow conditions yields

$$
L=23 \gamma q S^{5 / 3} \frac{\Delta \gamma d}{\rho w^{2}}
$$

which should be compared with equation 12 from the Gilbert data (p. A12).

The scatter of the Simons and Richardson data shown in figure 19 is much greater that that of the Gillort data, which indicates, perhaps, that many of the Simons and Richardson runs were not in a choked-flow state. What is clearly indicated is that mixtures result in much higher loads than do unigranular materials for a given discharge, slope, and median grain size of sediment; this result was not unexpected.

\section{EXTRAPOLATION FROM FLUME STUDIES}

Sediment movement in alluvial channels has been related to three parameters-a shear stress, $\gamma D S$; a mean velocity; and a combination of the two, a stream power, $\gamma q S$. Field evidence led Leopold and Maddock $(1953 \mathrm{a}, \mathrm{b})$ to conclude that load was not ralated to either $\gamma D S$ or $\gamma q S$, which was simply a confirmation through observations at other locations of what Hill $(1925,1926)$ had observed almost 30 years earlier. Flume evidence of the nonuniqueness of the $\gamma D S$ parameter was first reported by Brooks (1958) and was confirmed by Stein (1965) in detail. Thus, the relation between velocity and load is the only one that, to any degree, can be said to be unique. The comr'exity of this relation is obvious from the preceding discussion. However, the fact that load is not uniquely related to slope means that for a given discharge on a given slope different loads will be moved if it is possible to change velocities accordingly. The effects of different loads are very difficult to determine in small flumes having shallow depths. The introduction of sediment into a small flume already moving sediment blocks the whole sediment load and scour occurs downstream (R. E. Rathbun and H. P. Guy, unpub. data, 1967). Thus, the behavior of flumes and natural streams can be very different.

Particularly, the different ways of measuring velocity and load in flumes and natural streams mus t be considered. Velocity in a flume is usually calculated by dividing the discharge by the product of the width and the average depth over a considerable length of 


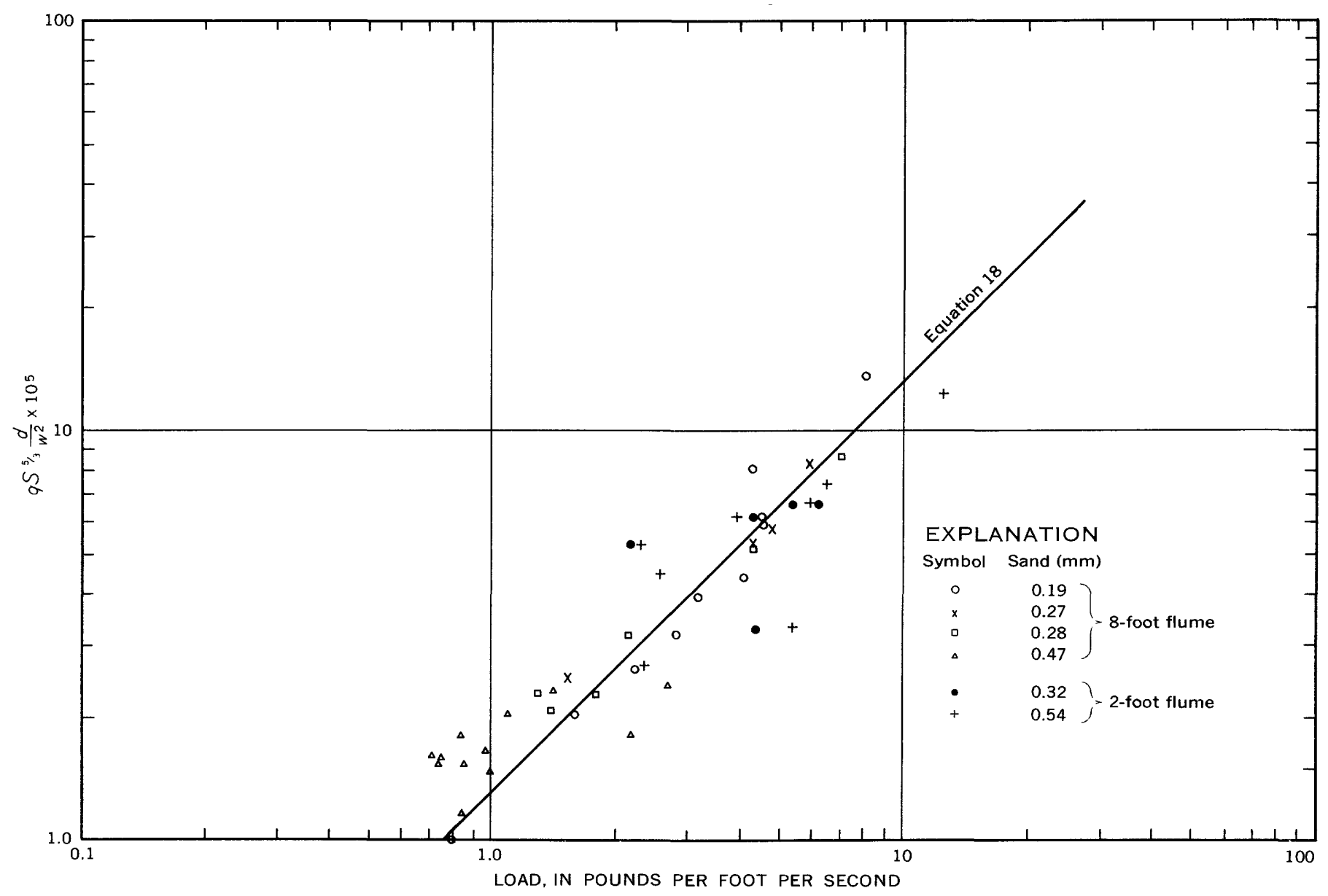

FigURE 19.- Relations between load and unit discharge, slope, and sediment size for sand mixtures in the high-velocity range. Simons and Richardson (1961) data.

the flume. Load is determined by frequent samplings during a long period of time. The mean velocity of a natural channel is usually computed by dividing the discharge, determined by summing the products of depth and velocity (determined by current meter) of a group of discharges of unit width, by the product of the width and average depth. The sediment load is determined by measuring the concentration of a small group of water samples taken at one cross section. Considering the potential for variation, the results of sampling are remarkably consistent. In terms of actual variation, however, a half $\log$ cycle variation is the most that can be expected under normal conditions. Consequently, considerable variation is to be expected in comparing flume and field observations.

At the present time, it appears that the equations developed from flume studies may be extrapolated to larger streams if the following conditions are met: (1) The sediment in motion is unigranular in size or the sizes of the material in the bed and the sizes of the sediment in motion are the same; (2) the vertical velocity distributions are symmetrical about the center line of the stream cross section; and (3) the sediment is moving in the same manner across all the bed.

Where vertical velocity distributions are not symmetrical about the center of the stream but are skewed, the stream will carry a relatively larger load for a given mean velocity in the mid-velocity range and a smaller load for a given mean velocity in the lowvelocity range. Thus, for most natural streams that have nonsymmetrical velocities, the exponents of equations 13 and 14 must be decreased and increased, respectively, by about 10 percent.

One must realize, however, that the average rate of sediment movement is computed from flume data. Actually, the different instantaneous measuremerts that make up the average vary considerably. Consequently, sediment measurements must be taken over fairly long periods of time to provide an adeque.te estimate of the rate of sediment movement in large natural streams. Until there is some certainty about the reliability of present estimates, the proper evaluation of the coefficients of equations 13 and 14 will be in doubt. 
The relation between discharge of water and sediment in natural streams is usually a poorly defined sediment rating curve. Nevertheless, if the relation between velocity and discharge or depth and discharge is good the relation between water discharge and sediment discharge will be reasonably good also.

In the next section of this report a means will be given for estimating velocity, given discharge per unit of width, slope, and size of bed material. This is for an average condition because no great variation in slope is possible on a given reach of a stream and changes in sediment load are accommodated by changes in the friction factor. These change the velocity-unit discharge relation.

The relations between discharge per foot of width and depth for Mountain Creek, N.C., and West Goose Creek, Miss., are shown in figures 28 and 29 respectively. Also shown in each of the graphs is a relation

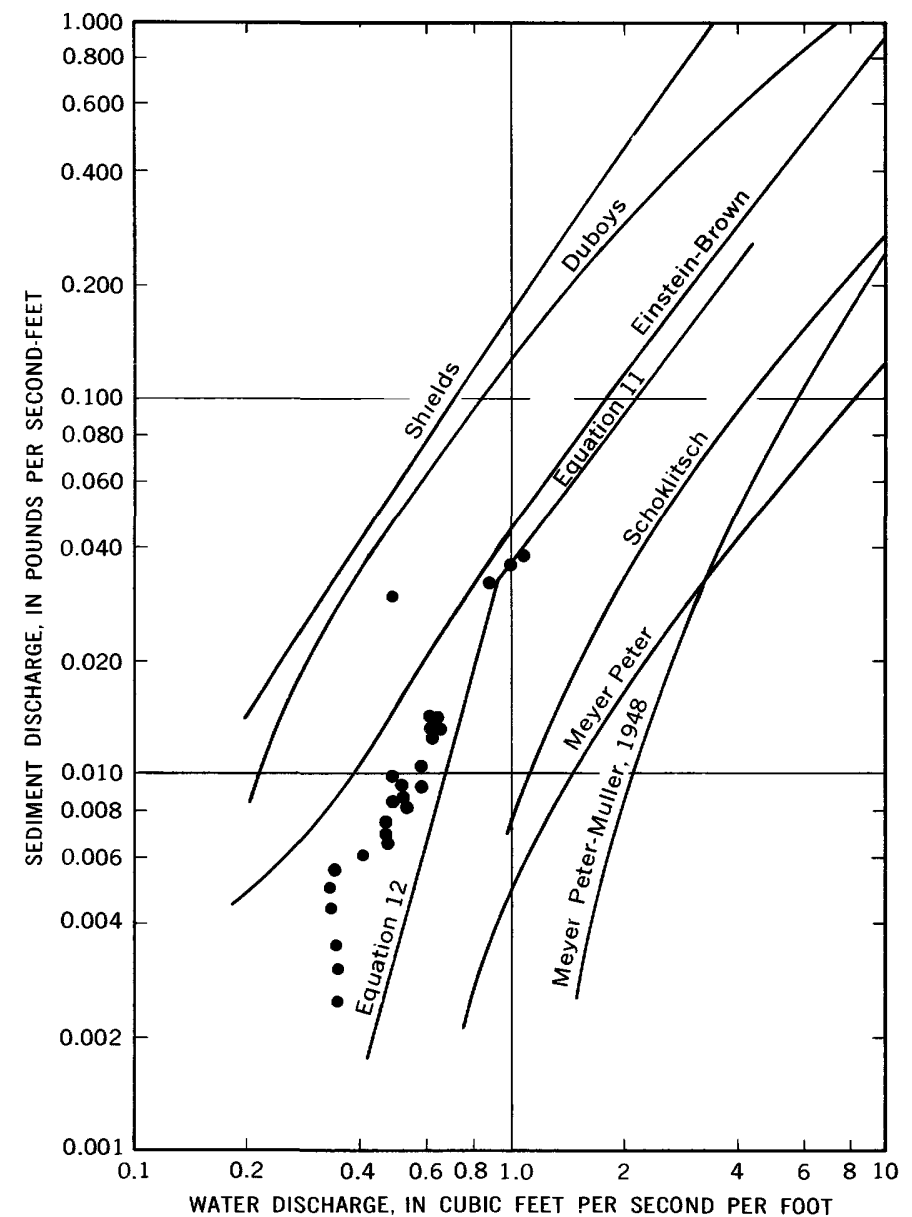

computed using the Einstein-Barbarossa (1952) method and another relation computed from equation 35. Using the equations for the two locations, relations between sediment discharge and water discharge were computed by use of equations 13 and 15 . The results are shown in figure 20 , together with computations from. various authors as noted. These graphs as well as the graphs showing the results of the Einstein-Barbaross? (1952) method are found in Vanoni, Brooks, and T ennedy (1961), and their use is greatly appreciated.

Another field example is the water and sediment discharge of the Colorado River at Yuma, Ariz., prior to the construction of major dams. Figure 34 shows the velocity-discharge relation as $V=0.046 Q^{1 / 2}$. A ssuming a constant width of 500 feet, this reduces to $V=1.04 q^{1 / 2}$. Substituting into equation 13 with a mean grain size of $0.10 \mathrm{~mm}$ gives $L=0.015 q^{1.75}$ in pounds per foot per second. This is reduced to tons per day for the

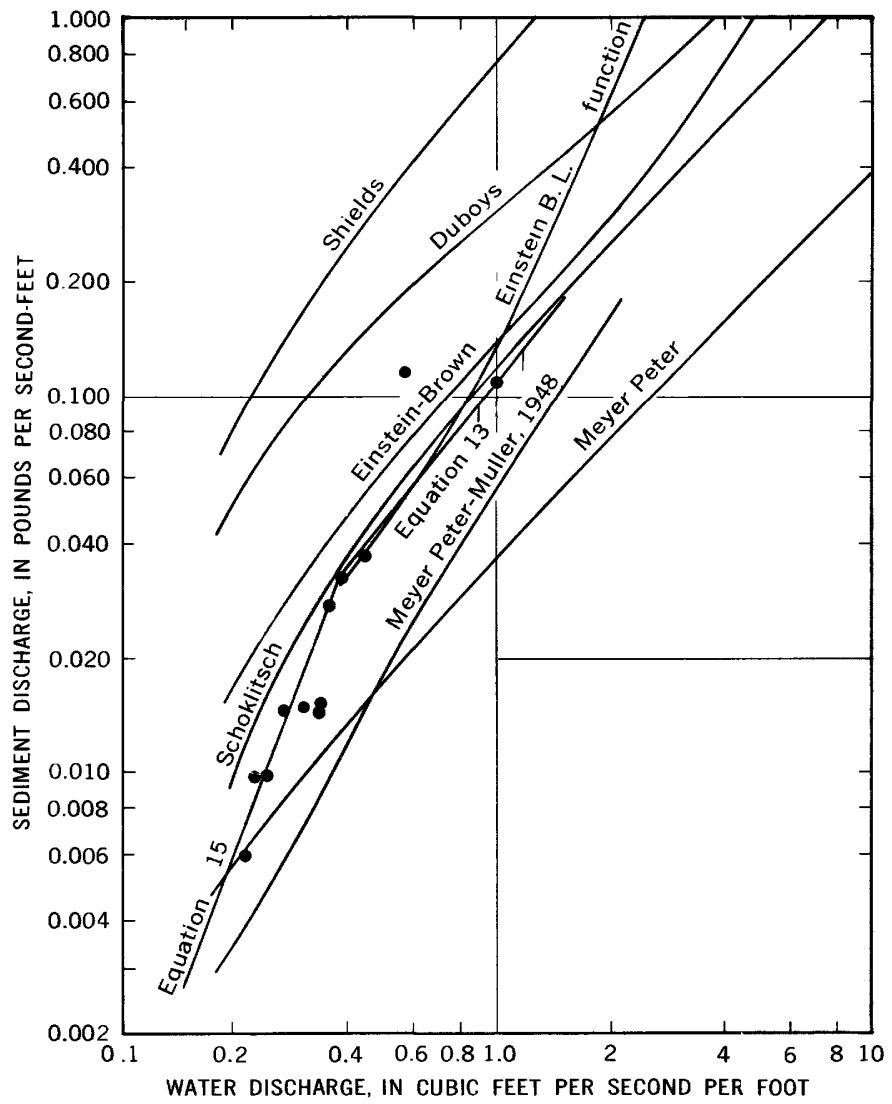

Figure 20.- Relation between sediment discharge and water discharge. From Vanoni, Brooks, and Kennedy (1961). Left, Mountain Creek near Greenville, N.C., showing observed values (black dots) and values computed by equations 11 and 12 and by methods of authors as noted (solid lines). Slope, 0.00157 foot per foot; geometric mean, $0.86 \mathrm{~mm} ; \sigma g, 1.8$; temperature, $78^{\circ} \mathrm{F}$. Right, West Goose Creek near Oxford, Miss., showing observed values (black dots) and values computed by equations 13 and 15 and by methods of authors as noted (solid lines). Slope, 0.00305 foot per foot; geometric mean, $0.287 \mathrm{~mm} ; \sigma g, 1.5 ;$ temperature, $68^{\circ} \mathrm{F}$. From Vanoni, Brooks, and Kennedy (1961, p. 7.8 and 7.9). 
whole width of the stream, and the result is shown in figure 21 together with data on the suspended load of the Colorado River at Yuma in 1933 and 1934 as given by Corfitzen (1940). Samples at Yuma and samples from flow over the crest of Laguna Dam upstream from Yuma showed essentially the same sediment content; hence, it is presumed that the suspended load measurements closely approximate the total load.

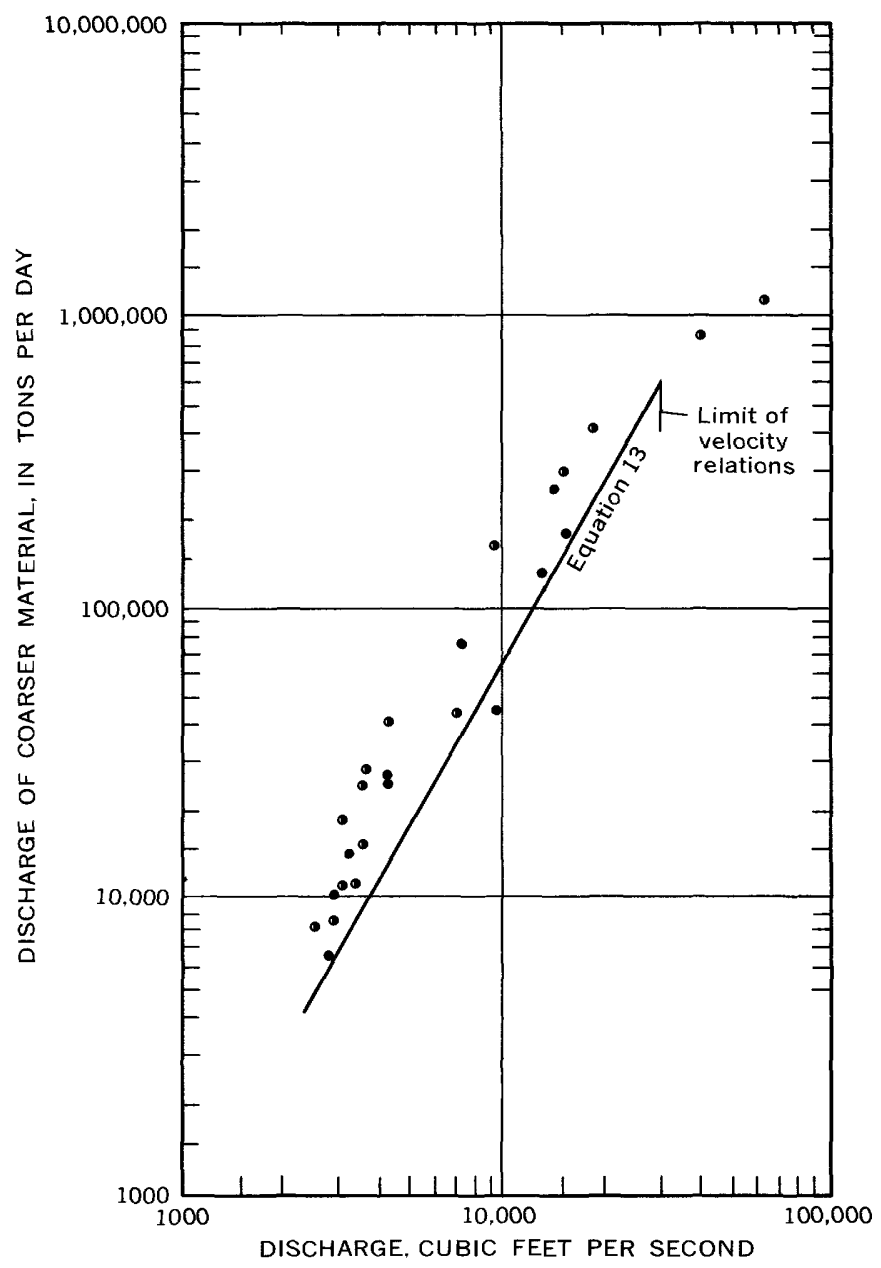

Figure 21.- Relation between discharge of coarser grades (Nos. 1, 2, 3, 4, and 5; $0.25-0.01 \mathrm{~mm}$ ) of sediment and water discharge of the Colorado River at Yuma, Ariz., showing observed values (black dots) and values computed by equation 13 (solid line). From Corfitzen (1940).

The Colorado River at Yuma is an example of a stream in which the relation between velocity and discharge is controlled by the load. As will be noted later, a constant slope stream is expected to have a $V \propto q^{0.4}$ relation if load is a dependent variable. The exponent of " $/ 2 / 2$ " indicates that sediment load is increasing unusually rapidly for an increasing discharge. That this increase in load falls off with increase in discharge above about $30,000 \mathrm{cfs}$ has been discussed previously.

\section{TWO-DIMENSIONAL FLOW}

The hydraulics of channels with rigid boundaries and high width-depth ratios has been established reasonably well in terms of the relation between the friction factor and the ratio of the water depth to the height of roughness elements. The effects of the spacing and the form of the roughness elements, particularly when they are lorge in terms of depth, are still not completely known. Nerertheless, given any two of depth, velocity, and slope, the other may be computed with reasonable accuracy on the assumption of a channel roughness.

The problem of hydraulics of channels with moveble beds is that even if the relative roughness of a specific bed form is known, there is no assurance that this bed form would exist given any two of depth, velocity, and slope. Thus, although it has been shown that tl are is a reasonably good and consistent relation among velocity, depth, and load, there is no fully consistent relation among these values and slope. As long as flume experiments are performed in precisely the same manner, relations tend to be consistent, however, the results of different kinds of experiments are considers.bly different.

Some of the procedures and results of differont experiments will be considered. Langbein's (1964, 1ธ 35 ) procedure for identifying the behavior of depencent variables associated with changes in independent variables will be discussed. Then the principal constraints upon this relation will be evaluated; the most important of these is the tendency of the friction factor and the shear stress to be minimized, either jointly, when constraint is a minimum, or individually, when the response is limited by flume operation. Each type of constrint evaluated by Langbein's procedure will then be tested by field data. The discussion of two-dimensional flow will be closed by a summary of slope as an element in stream behavior.

\section{SLOPE}

Consider the differences in the manner in which the different flume studies have been conducted. Gilbert (1914) introduced water and sediment into a flume and let the bed and water surface seek an equilibrium slope. An unknown degree of regulation by a tail gate, affected the final result. In the Waterways Experiment Station (1935) experiments a channel was constructed on a given slope. Water was introduced in increasing anounts into the channel until erosion began. When erosion was noticeable, just enough sediment was introduced into the channel to keep the original bed and water-surface slopes; depth was free to adjust. Once equilibrium was established, discharge was increased, and, again, just enough sand was introduced to maintain equilibrium. The procedure was carried 
on for a number of discharges. The Casey (1935) experiments were performed in essentially the same manner, except that measurements were made with both increasing and decreasing discharges without modifying the bed configuration. In the Williams (1967) experiments, values of depth and load were selected. Estimates of a probable discharge and an equilibrium slope were made. The flume was set at the estimated slope, and sediment was spread evenly over the floor of the flume. The sediment infeed and the discharge were started. If the flow depth was not within the range selected, discharge was altered to raise or lower the depth. Once the desired depth and a uniform flow had been established, the slope was allowed to adjust until it became stabilized. For the majority of runs, no changes in slope occurred, which indicates that the equilibrium slope was the slope of the flume itself.

Three different sets of relations among velocity, discharge, and slope are found in the four experiments just described. The first, from the Gilbert experiments, is shown in figure 22 and has the equation

$$
V=4.7 \frac{\left(g^{1 / 2} \gamma^{1 / 2} q S\right)^{1 / 2}}{(\Delta \gamma d)^{1 / 4}}\left(\frac{\rho w^{2}}{\Delta \gamma d}\right)^{1 / 8}
$$

The second, represented by Waterways Exroriment Station sands 1 and 9 and by Casey's sand $h$, is a condition where grain roughness appears to control the relations (fig. 23). Williams data represent a condition of grain roughness control at small discharges or the effect of flow at a controlled depth (fig. 24). The third set of relations is shown in figure 23 by data from Waterways Experiment Station sands 4, 6, 7, and 8. The exuation for these groups of data is

$$
V=4.4\left[\frac{\gamma q S}{\rho^{1 / 2}}\left(\frac{w}{\Delta \gamma d}\right)^{1 / 2}\right]^{0.4},
$$

and it represents the situation when the channel roughness is controlled by the deformed bed.

In the Gilbert data and particularly in the Nilliams data shown in figures 22 and 24 , there is no rariation in the relations between velocity and discharge and slope for the high- and low-velocity ranges. Although

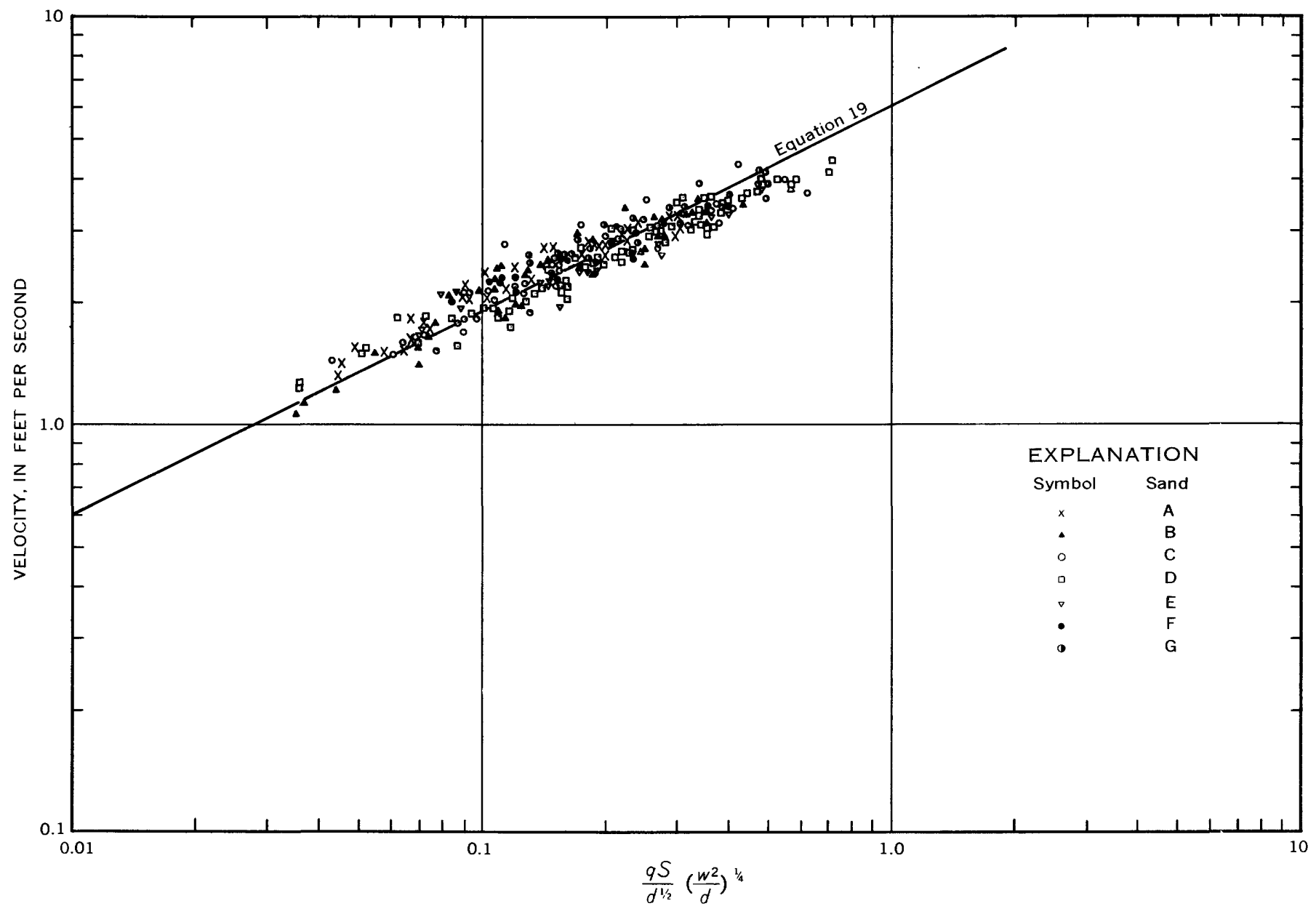

FIGURE 22.--Relations between velocity and unit discharge, slope, and size of sediment for unigranular material in the mid-velocity range. Data from Gilbert (1914). Discharge and load are independent variables. 


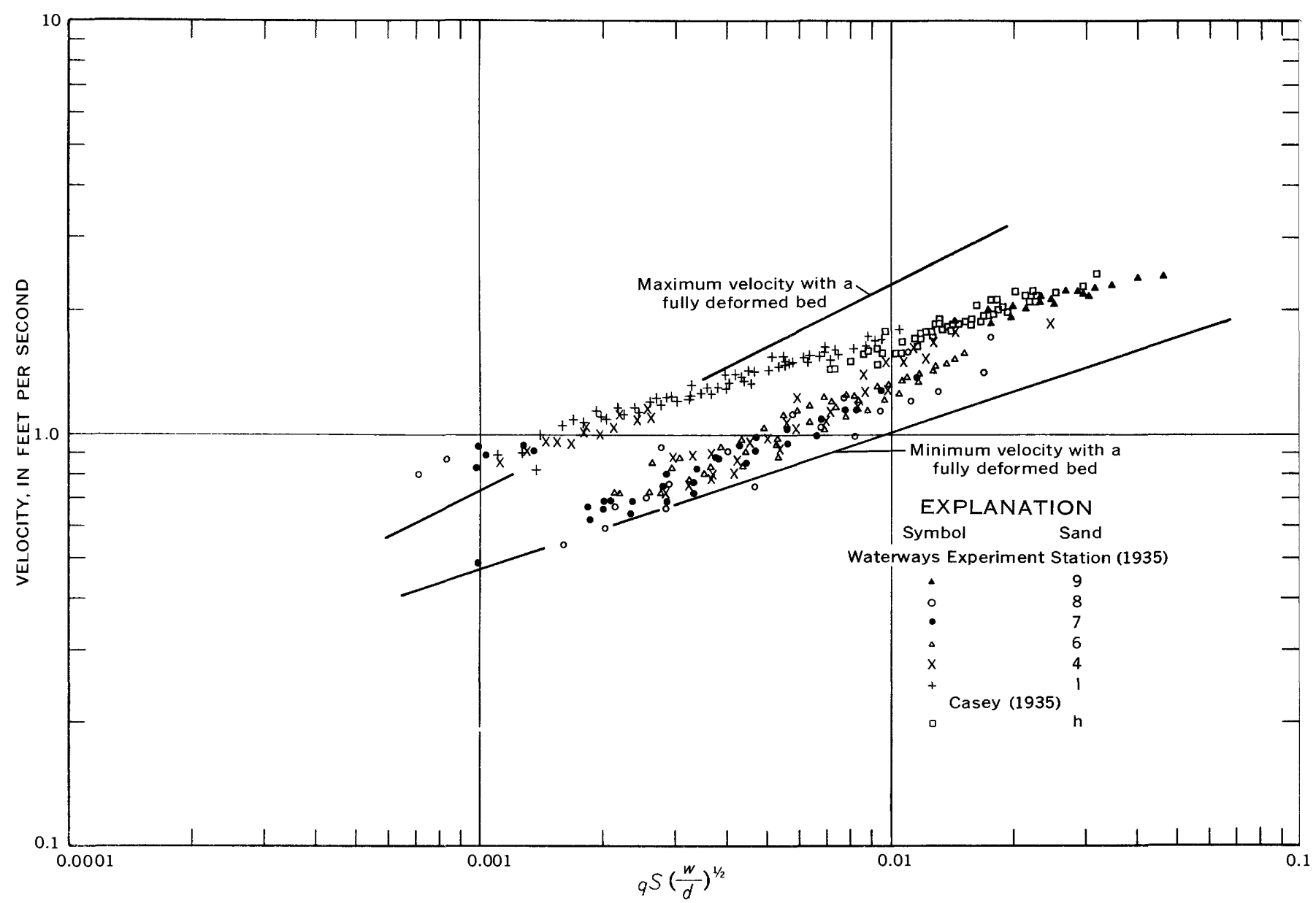

FIGURE 23.- Relations between velocity and unit discharge, slope, and mean grain size of sediment mixture in the low-velocity range. Data from Waterways Experiment Station (1935) and Casey (1935). Slope is an independent variable.

the sediment load is explicitly stated in these experiments, it has no direct association with the velocitydischarge-slope relation and, consequently, with the velocity-depth-slope relation.

Figure 23 also shows two envelope curves which represent the maximum and minimum velocities to be expected with a fully deformed bed. These curves are for a size of sediment of about $0.3 \mathrm{~mm}$. Their position will vary with the size of sediment. There is a considerable degree of uncertainty about the actual nature of the envelope curves, and future experimental data may yield different results.

Recirculating flumes, in general use since World War II, are supposed to be more representative of the behavior of natural channels than the older experiments of Gilbert and the Waterways Experiment Station. Actually, they are not because too much depends on how the flume is operated and on flume characteristics.

Laursen (1958), Brooks (1958), Vanoni and Brooks (1957), Vanoni and Nomicos (1960), and Stein (1965) $329-51100-69-5$ all operated flumes at a constant depth under varying discharges with slope free to vary. They found slop? to be constant over a wide range of discharges.

Simons and Richardson (1961) operated recirculating flumes under a range of slopes, discharges, and sizes of sediment. The procedure was described by Guy, Simons, and Richardson (1966, p. 14) as follows:

The procedure followed for some runs involved recirculating a given discharge of water-sediment mixture in the flume at a preselected slope until equilibrium conditions were estaklished. Equilibrium here should be defined as a condition of statistically uniform velocity, concentration and slope with respect to time and space in the flume where the variables are observed. Even though discharge can be held relatively constant, depth, slope, and sediment discharge condition (several hours or days after the start of the run) could be considerably differert from. those in the initial condition. For some runs depth wess kept constant either by adjusting the tailgate slope [sic] or discharge. For some other runs slope was kept constant by adjusting the tailgate or the discharge, or both.

The independent and dependent variables are most uncertain, and consequently, the relations among the 


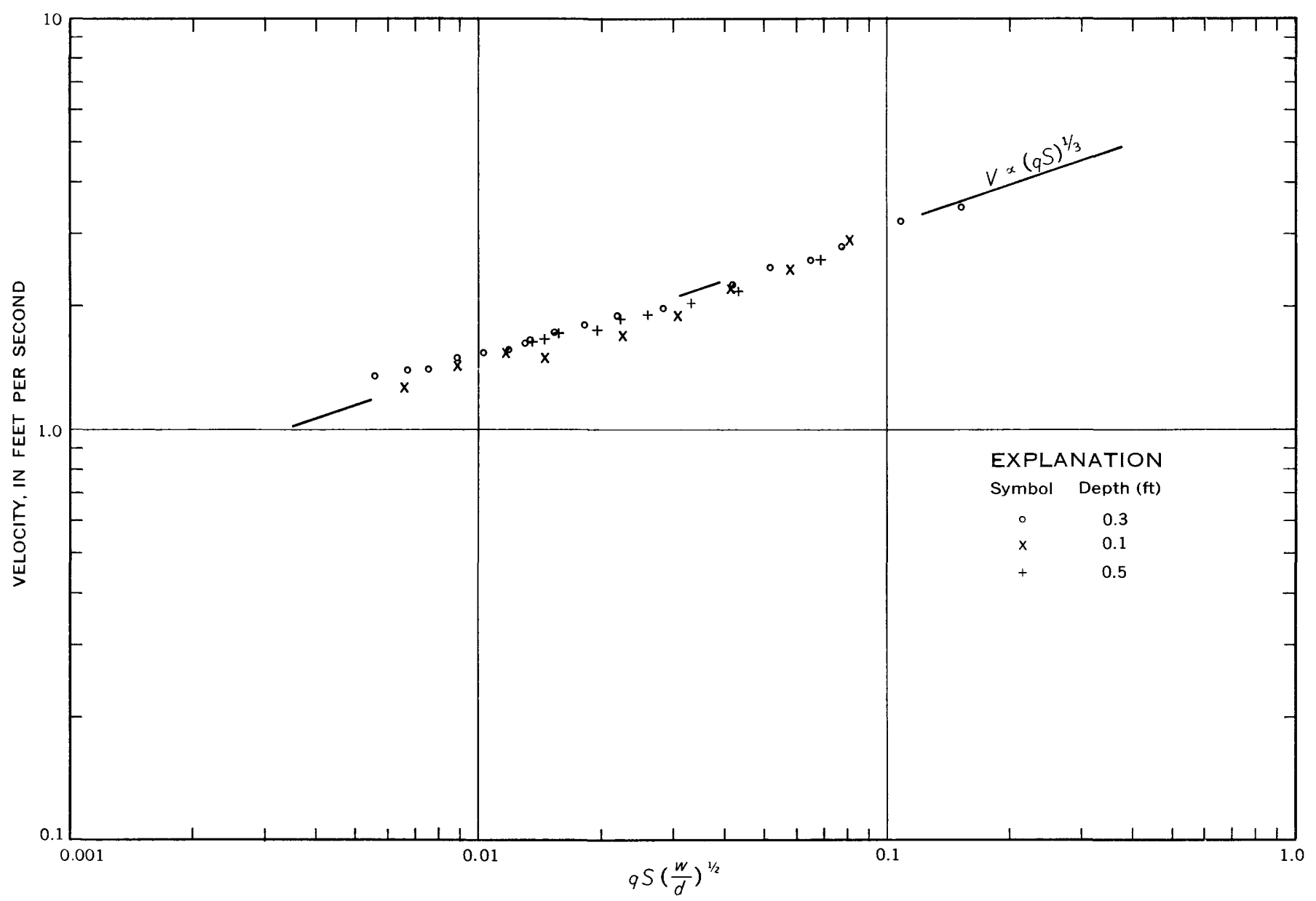

Figdre 24.-Relations between velocity and unit discharge, slope, and mean grain size of sediment mixture in the low-velocity range. Flume data from Williams (1967). Depth and load are independent variables.

variables are uncertain. These relations will be discussed later.

Guy, Rathbun, and Richardson (1966), experimenting in a 20 -cm-wide flume with a $0.3-\mathrm{mm}$ median fall diameter using both a recirculating and a sand-feed system, concluded that there was no difference between the two systems. The relation of equation 19 prevailed.

Clearly there are wide variations in flume behavior which are related to slope; the problem is to find an explanation for such behavior. A likely hypothesis appears to be that for any specific sediment mixture exposed to increasing unit discharges, there is a relation between velocity and the product of depth and slope. The actual relation is dependent on the width-depth ratio of the channel, the median-diameter particle size of the sediment mixture, and the maximum size of particles found in appreciable amounts in the sediment in motion. Thus, at low discharges, the flume and the grain size control roughness. Once the product of unit discharge and slope exceeds a specific value and the width-depth ratio exceeds a value of about four, the relation between the velocity and the product of depth and slope for a given sediment mixture is indeterminate. The boundaries of this indeterminacy are limited by the range in roughness of the deformed and plane bed. How can this statement of indeterminacy be reconciled with the statements of equatiors 19 and 20 ? The answer is that in nature certain cc rstraints are in operation that make some relations more probable than others. Langbein $(1964,1965)$ concluded that these constraints are the results of minimization or maximization processes and that the results will differ depending on the selection of independent and dependent variables. Combining the idea of minimization or maximization of the functions of certain dependent variables with the results of the previous section on the relations between velocity and load, the behavior of flumes can be predicted as described in the following section.

\section{INDEPENDENT VERSUS DEPENDENT VARIABLES}

If sediment sizes remain constant, the pertinent 
variables in two-dimensional flow are: discharge, velocity, depth, slope, and load. Discharge nearly always is independent - that is, the discharge is selected or determined independent of the channel. This is always true in natural streams, but there is no prior reason why discharge should be independent in flume studies. Potentially, there are four degrees of freedom among the remaining variables. However, these are constrained by interrelationships; for example, velocity $X$ depth $=$ discharge. Also, velocity and load have specific relations, as previously discussed. Considering these two constraints, only two degrees of freedom remain. If the degrees of freedom are to be reduced to one, only one of velocity, depth, slope, and load also may be an independent variable. Because of the nature of the constraints, this statement can be narrowed down to the following. If discharge is an independent variable, one of velocity, depth, or load may be chosen as the other independent variable. The two remaining variables become dependent variables, and the solution is unique. The problems of channels on movable beds are due to the fact that when slope is a variable, either dependent or independent, the solutions are not unique but are subject to other constraints.

Table 1 shows the behavior of flumes under twodimensional flow with different independent and dependent variables but with unchanging sediment sizes. In each example, two independent variables are chosen, and the table indicates whether the solution is unique or, if not, what is required for a unique solution. Meaningful relations are those that occur

TABLE 1.-Behavior of flumes of unit width and same sediment sizes with different independent and dependent variables

\begin{tabular}{|c|c|c|c|c|}
\hline \multirow{2}{*}{ No. } & \multicolumn{2}{|c|}{ Variables } & \multirow{2}{*}{$\begin{array}{l}\text { Usable relations with two inde- } \\
\text { pendent variables }\end{array}$} & \multirow{2}{*}{$\begin{array}{l}\text { Required for } \\
\text { unique solution }\end{array}$} \\
\hline & $\begin{array}{c}\text { Inde- } \\
\text { pendent }\end{array}$ & $\begin{array}{c}\text { Depend- } \\
\text { ent }\end{array}$ & & \\
\hline 11 & $q, L$ & $V, D, S$ & $\begin{array}{l}V \text { and } D \text { unique, } S \text { usable only if } \\
\text { some } f(S) \text { is minimized or maxi- } \\
\text { mized. }\end{array}$ & $\tau, S$ or $F$ \\
\hline 22 & $q, D$ & $V, L, S$ & $\begin{array}{l}V \text { and } \dot{L} \text { unique. } D S \text { and } F \text { each } \\
\text { becomes constant for certain } \\
\text { discharges. }\end{array}$ & Nothing. \\
\hline 3 & $V, D$ & $q, L, S$ & $\begin{array}{l}q \text { and } L \text { unique. } D S \text { becomes con- } \\
\text { stant for certain discharges. }\end{array}$ & Do. \\
\hline 34 & $q, s$ & $V, D, L$ & $\begin{array}{l}\text { Only if a funetion of } V, D \text {, or } L \text { is } \\
\text { minimized or maximized. }\end{array}$ & $\begin{array}{l}\text { Any one dependent } \\
\text { variable. }\end{array}$ \\
\hline 5 & $D, S$ & $q, V, L$ & Only if a function of $V, D$, or $L$ is & Any one dependent \\
\hline 6 & $V, S$ & $D, q, L$ & $\begin{array}{l}\text { Load essentially unique. } D \text { or } q \\
\text { only if a function of } D \text { or } q \text { is } \\
\text { minimized or maximized. }\end{array}$ & $D$ or $q$. \\
\hline 7 & $L, S$ & $q, V, D$ & $\begin{array}{l}V \text { essentially unique. } D \text { or } q \text { only } \\
\text { if a function of } D \text { or } q \text { is mini- } \\
\text { mized or maximized. }\end{array}$ & $D$ or $g$. \\
\hline 48 & $D, L$ & $V, q, S$ & $\begin{array}{l}V \text { and } q \text { essentially unique. } F \text { and } \\
D S \text { each become constant for } \\
\text { certain discharges }\end{array}$ & Nothing. \\
\hline 9 & $\boldsymbol{I}, L$ & $D, q, S$ & $\begin{array}{l}\text { None possible. } \\
\text { Nold i }\end{array}$ & $D$ and $S, q$ and $S$. \\
\hline
\end{tabular}

1 Gtlbert (1914) experiments. $f(S)$ minimized, relations consistent. 2 Brooks (1958), Kennedy (1961), Laursen (1958), and Stein (1965)

3 Waterways Experiment Station (1935), sediment sizes $3-8, f(S)$ minimized. For sizes 1-2 and 9, grain size controlled results. Some data from Simons and Richardon (1961) confirmed this behavior. Usable relations doubtful.

4 Williams flume (1967).

Note.--Unique means fully predictable by two independent variables. without a forced constraint caused by flume characteristics or method of flume operation.

Langbein (1964) postulated that the observed cheracter of flow is such that changes in the independent variables are reflected by the minimization, not of functions of slope themselves, but of the variance of these functions. He also proposed an effective way to evaluate the variance of any function of slope.

The problem is to express the width, depth, and velocity of a stream in terms of the applicable incependent variables, one of which is discharge. Because of the interrelations of the variables and their product, it appears that an exponential relation between each dependent variable and the independent variable, as used by Leopold and Maddock (1953a), is a simple form that proves satisfactory. If discharge is the independent variable, then width, depth, and velocity may be expressed as functions of discharge. Thus,

$$
\begin{aligned}
& \text { velocity } \propto Q^{m}, \\
& \text { depth } \propto Q^{f}, \text { and } \\
& \text { width } \propto Q^{b} \text {. }
\end{aligned}
$$

Since

$$
\text { discharge }=\text { width } \times \text { depth } \times \text { velocity, }
$$

from equation 21 ,

and

$$
\begin{aligned}
& Q=Q^{b} Q^{r} Q^{m}, \\
& 1=b+f+m .
\end{aligned}
$$

Equation 21a can be stated as

$\log$ discharge $=\log$ width $+\log$ depth $+\log$ velocity.

Although these equations are all true in a hydraulic sense, they also have a purely statistical significance.

For example,

$\log$ width $=\log a+b$ (log discharge),

$\log$ depth $=\log c+f$ (log discharge),

$\log$ velocity $=\log k+m$ (log discharge $)$.

Because $a, c$, and $k$ are found by experiment to be essentially constant and have little variance, the standard deviations can be written as

$\sigma \log W \propto b \sigma \log Q, \sigma \log V \propto m \sigma \log Q$, etc.,

and finally

$$
\begin{gathered}
b=\frac{\sigma \log W}{\sigma \log Q}, \\
f=\frac{\sigma \log D}{\sigma \log Q}, \\
m=\frac{\sigma \log V}{\sigma \log Q}
\end{gathered}
$$

in which the population is all observed values of $Q$ and their respective values of $V, D$, and $W$. Langbin (1964) shows that this reduces to 


$$
1=b+f+m
$$

in a purely statistical sense.

The exponents of the independent variables describing the elements of discharge therefore, are indices of the standard deviations of the dependent variables. Further, the variance of the dependent variable can be expressed by the square of the indices or the proper combinations thereof. For example, the variance of velocity can be expressed by $m^{2}$, and, because $m=1-b-f$ in equations $21 \mathrm{a}$ and $21 \mathrm{~b}$, the variance may also be expressed as $(1-b-f)^{2}$. The variance of a Froude number can be expressed as $(2 m-f)^{2}$ or $(2-2 b-3 f)^{2}$.

The measures of the relative changes in velocity, width, and depth, as represented by equation $21 \mathrm{a}$, are most nearly equal when the sum of the squares of the discharge indices-that is, the sum of the variances-is a minimum. Under these conditions, $m^{2}+f^{2}$ $+b^{2}$ would be a minimum. We can easily show that if all elements are free to vary and have the same probability, $m=f=b=1 / 3$. The continuously reforming streams on the valley train beneath Emmons Glacier on Mount Rainier, Wash., are representative (Fahnestock, 1963).

In flumes, width is a constant, and in most streams width is great enough to consider the flow as two-dimensional. Under these conditions, the unit discharge, $q$, is used instead of the total discharge $Q$. Thus,

$$
q=\frac{Q}{W}=V D,
$$

and $V$ and $D$ are expressed as functions of $q$. Hence, $V$ $\propto q^{m}$ and $D \propto Q^{f}$. When $q$ is a variable, $m+f=1$, and when $q$ is a constant, $m=-f$. Expressing the variance of $V$ as $m^{2}$ and the variance of $D$ as $f^{2}$, the variance of the Froude number, if unit discharge is the independent variable, is $(f-2 m)^{2}$ or $(1-m-2 m)^{2}$. If the variance of the Froude number is to be minimized, the first derivative of $(1-3 m)^{2}$ must be set equal to zero. Then

$$
\begin{gathered}
18 m-6=0 \\
m=1 / 3 .
\end{gathered}
$$

Thus, the variance of the Froude number is minimized when $V=q^{1 / 3}$. Since $D=q^{2 / 3}$ when $V=q^{1 / 3}$, it follows, $\mathrm{F} \propto q^{2 / 3} / q^{2 / 3}$ or $\mathrm{F}=$ constant. When the Froude number is constant, its variance is zero.

Discharge is but one of the independent variables, and, as already stated, there must be a second. We now assume that any dependent variable can be expressed as any independent variable raised to some exponent in precisely the same way as we assumed with discharge and that the evaluation of the relations between these exponents and the variance of the dependent variables will be the same as was developed for discharce.

Definite experimental evidence exists that the variance of slope itself is never minimized in flumes. The two important functions of slope are the shear stress, $\gamma D S$, and the friction factor $g D S / V^{2}$. Analyses of the Gilbert (1914) and Waterways Experiment Station (1935) data indicate that neither the shear stress nor the friction factor alone were minimized in the performance of the experiments (eqs 19 and 20). This is in accord with the theory presented herein. The effects of any change in the independent variable affecting both the shear stress and the friction factor should not be concentrated in either one but should be split between the two. Only if one of the two terms is held constant should all the change be concentrated in the other. Furthermore, according to the theory presented, the variability of each tends to be a minimum. Because both terms cannot be a minimum at the same time for the same discharge, the most probeble condition occurs when the sum of the two varianc?s is at a minimum.

\section{CONSTRAINTS}

In accordance with Langbein's (1964) concepts, we will analyze the behavior of alluvial channels under different combinations of independent and dependent variables that are under different kinds of constraints. These constraints are (1) the joint minimization of the shear stress and the friction factor, (2) the joint minimization of the velocity and the friction factor, and (3) the joint minimization of the concentration and the friction factor. The constraints are exclusively statistical relations that do not give directions for deciding which dependent variables are relevant. Such information, which is to be included in the variance statement, can only come from the mechanics of the processes involved or as inferred from the data. Following each analysis, the applicable flume and field (river and canal) observations will be compared with the theoretical forecast.

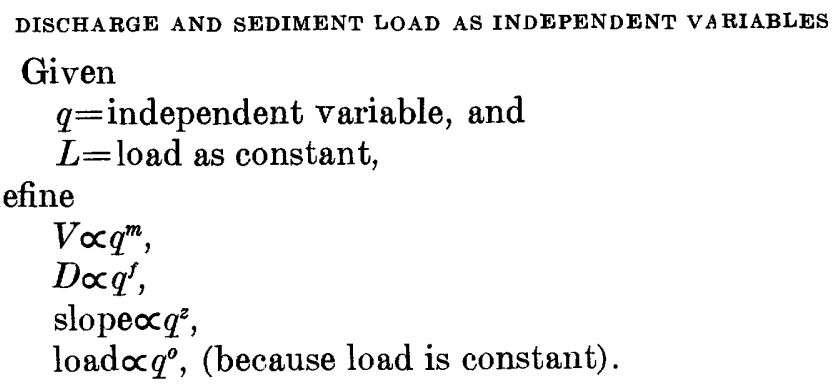

As shown in the first part of this report, load, the sediment transport per unit of width, is a function of 
velocity and discharge that can be simplified to the relation

$$
L \propto V^{\alpha} q^{j} .
$$

This relationship always exists in the same sense as $q=D V$, whatever the dependent or independent variables. Because load has a unique relation to velocity and dis charge and $\alpha$ and $j$ are given, then

$$
q=V D=q^{m} q^{r},
$$

or

$$
m+f=1 \text {. }
$$

Further,

$$
q^{\circ} \propto q^{m \alpha} q^{j},
$$

or

$$
m \alpha+j=0,
$$

or

$$
m=-\frac{j}{\alpha} \text { and } f=1+\frac{j}{\alpha} \text {. }
$$

Now the variance of the shear and friction factor in combination is minimized. First, we note that

variance of shear stress $=(f+z)^{2}$, and variance of friction factor $=(f+z-2 m)^{2}$.

The variances are added and minimized:

$$
\left(1+\frac{j}{\alpha}+z\right)^{2}+\left(1+\frac{3 j}{\alpha}+z\right)^{2} \rightarrow \text { a minimum. }
$$

Squaring, as indicated, and setting the derivative equal to zero,

$$
z=-1-\frac{2 j}{\alpha},
$$

or

$$
\frac{1}{S} \propto(q)^{1+\underline{2 j}} \text {. }
$$

Now, consider $q$ as constant and $L$ as the independent variable. By definition

$$
\begin{aligned}
& V \propto L^{1 / \rho}, \\
& D \propto L^{x} \\
& \text { slope } L^{\beta}, \\
& q \propto L^{0} \\
& L \propto L^{1}
\end{aligned}
$$

where

$$
q=V D \text {, }
$$

or

$$
\frac{1}{\alpha}+x=0 \text {, }
$$

and

$$
x=-\frac{1}{\alpha} .
$$

Minimizing the variance of shear and friction factor in combination as before,

$$
\begin{aligned}
& (x+\beta)^{2}+(x+\beta-2 m)^{2} \rightarrow \mathrm{a} \text { minimum, } \\
& \left(\beta-\frac{1}{\alpha}\right)^{2}+\left(\beta-\frac{1}{\alpha}-\frac{2}{\alpha}\right)^{2} \rightarrow \mathrm{a} \text { minimum, }
\end{aligned}
$$

or

$$
\beta=\frac{2}{\alpha}
$$

Thus,

$$
\text { slope } \propto L^{2}
$$

If there is no correlation between the independent variables, discharge and load, the two relations above may be combined as

$$
S \propto \frac{L^{\frac{2}{\alpha}}}{q^{1+\frac{2 J}{\alpha}} .}
$$

But since

$$
\begin{gathered}
L \propto V^{\alpha} q^{j}, \\
S \propto \frac{V^{2}}{q},
\end{gathered}
$$

or

$$
V \propto(q S)^{0.5} .
$$

The exponents disappear in the analysis, although they are based on an explicit statement of sediment transport in the form $L \propto V^{\alpha} q^{j}$. The relation, then, is independent of the nature of the transport equation, as long as load is a unique function of velocity and discharge.

The Gilbert equations have the same independent variables, discharge and load, and the same dependent variables, velocity, depth, and slope, as were set forth in the hypothetical example. Equation 19, developed from an empirical analysis of these data was

$$
V=4.7 \frac{\left(g^{1 / 2} \gamma^{1 / 2} q S\right)^{1 / 2}}{(\Delta \gamma d)^{1 / 4}}\left[\frac{\rho w^{2}}{\Delta \gamma d}\right]^{1 / 8},
$$

which confirms equation 29. (Note in figure 22 that eq. 19 relates to an average or a most probable condition.) Because this is a statistical evaluation, these relations are not expected to be precise. This will be true for all relations developed by this type of analysis; however, the coefficient of equation 19 is related to stream behavior. A high value of the coefficient is associated with a stream that is carrying a high load for a given slope or a stream that has a tendency toward aggradation. A low value of the coefficient is associated with low loads and tendencies toward derradation. Thus, the range in coefficient represents the 
range of change of roughness due to change in bed form. To aid in the solution of equations 19 and 20, values of the parameters $w^{1 / 4} / d^{3 / 8}$ and $(w / d)^{1 / 2}$ for given values of the particle diameters are shown in figure $25 A$ and $B$.

Because natural streams exhibit the reaction of load and discharge on a long-term basis (Rubey, 1952), equations 19 and 29 would be expected to describe them.

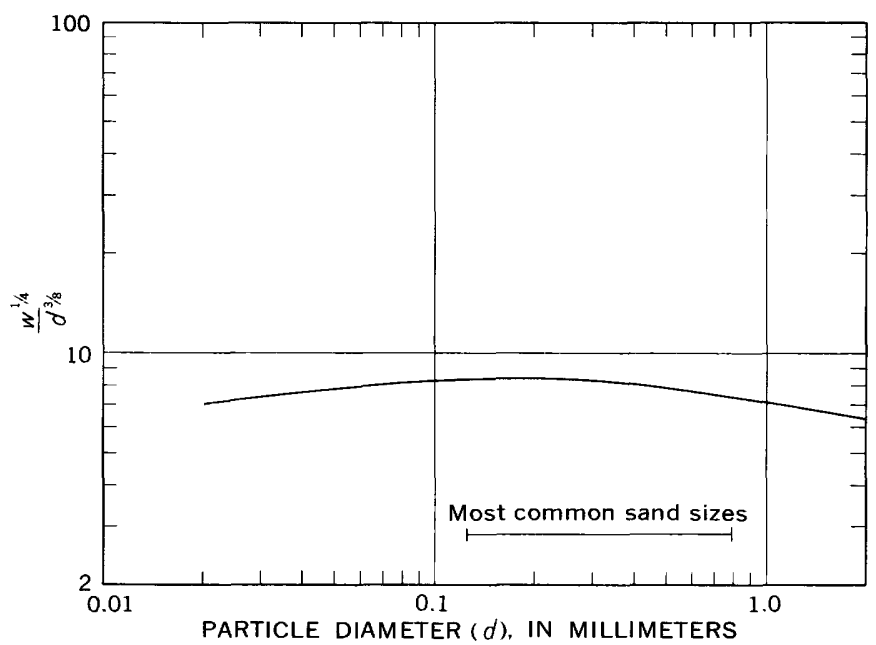

$A$

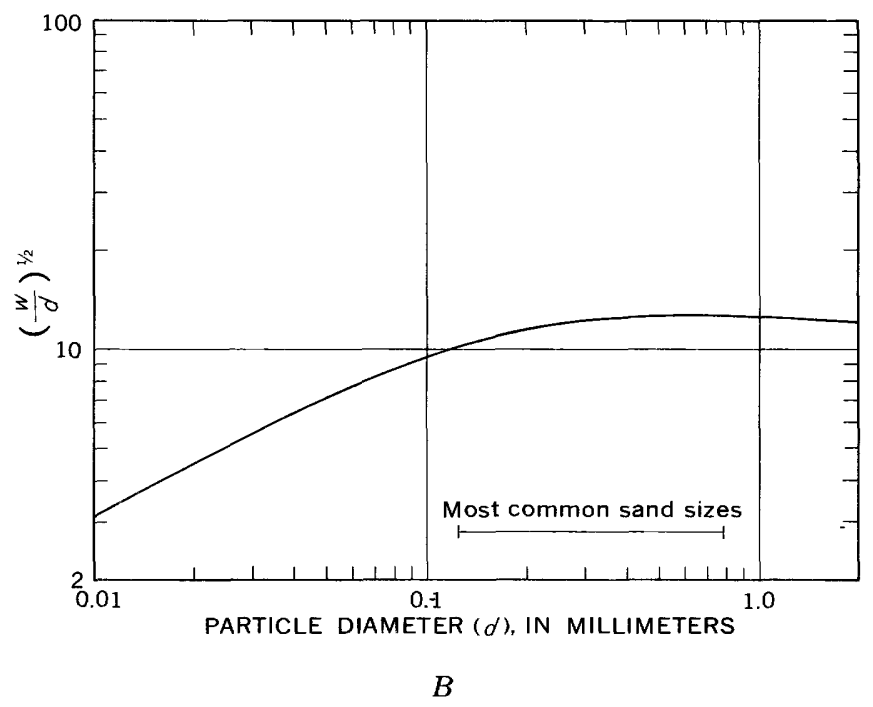

Figure 25.-Values of sediment size parameters from equations 19 and 20. $A$, Values of $w^{1 / 4} / d^{3 / 8}$. B, Values of $(w / d)^{1 / 2}$. Values for $A$ and $B$ computed for quartz spheres in water at $25^{\circ} \mathrm{C}$.

Blench (1966) gave three equations basic to "regime" channels. These are $V^{2} / D=F_{b}, V^{2} / g D S=3.63(V b / \nu)^{1 / 4}$, and $V^{3} / b=F_{s}$. Combining the last two

$$
\frac{V^{2}}{g D S}=3.63\left(\frac{V^{4}}{F_{s \nu}}\right)^{1 / 4}
$$

or

and

$$
V^{2}=3.63 \frac{g q S}{\left(F_{s} \nu\right)^{1 / 4}}
$$

$$
V=1.9 \frac{(g q S)^{1 / 2}}{\left(F_{s} \nu\right)^{1 / 8}}
$$

This is the same basic relation as equations 19 and 29. As will be shown later, the term $3.63(\mathrm{Vb} / \nu)^{1 / 4}$ is not a unique measure of the friction factor in rivers. In the form of equation 30, it is an expression of specific channel behavior through the use of the coefficient $F_{s}$. Equation 30 differs from equation 19 in that it contains no size parameter. Blench's size parameter is contained in his first equation $V^{2} / D=F_{b}$. In the author's system, $V^{2} / D=C$, or concentration of sediment in the mid-velocity range and size is unimportant.

The Lacey equations are also variants of equation 19. Let the equation be written

$$
\frac{V^{2}}{g D}=B^{4} \frac{\gamma D}{\Delta \gamma d} S^{2}\left(\frac{\rho w^{2}}{\Delta \gamma d}\right)^{1 / 2}
$$

Lacey used a silt factor $f$, which is defined as either $f \propto V^{2} / \nu$ or $f^{2} \propto V S$. In each equation, $f^{2} \propto d$. In the sand range, the relation between particle diameter and $w / d^{3 / 2}$ varies from about $w / d^{3 / 2} \propto d^{-1 / 2}$ to $w / d^{3 / 2} \propto d^{-1}$. Consequently, substituting $f$ for $w / d^{3 / 2}$ the range would be from $f^{-1}$ to $f^{-2}$. Substituting the two silt factors when $w / d^{3 / 2} \propto f^{-2}$

$$
\frac{V^{2}}{D} \propto \frac{B^{4} D S^{2}}{V S}
$$

or

$$
V \propto B^{4 / 3} D^{2 / 3} S^{1 / 3}
$$

The other relation is

$$
\begin{gathered}
\frac{V^{2}}{D} \propto \frac{B^{4} D S^{2}}{\left(\frac{V^{2}}{D}\right)^{2}} \\
V \propto B^{2 / 3} D^{2 / 3} S^{1 / 3} .
\end{gathered}
$$

Both of these expressions are equivalent to Lacey's $V=16 R^{2 / 3} S^{1 / 3}$.

When

$$
\begin{gathered}
\frac{w}{d^{3 / 2}} \propto f^{-1} \\
\frac{V^{2}}{D} \propto B^{4} \frac{D S^{2}}{(V S)^{1 / 2}}
\end{gathered}
$$

or 
the other relation is

$$
\frac{V^{2}}{D} \propto \frac{B^{4} D S^{2}}{\frac{V^{2}}{D}}
$$

or

$$
V \propto B D^{1 / 3} S^{1 / 2}
$$

The latter is equivalent to Lacey's $V=60 R^{3 / 4} S^{1 / 2} / f^{1 / 4}$. It would appear however that Lacey's general relationship should be $V \propto D S / d^{1 / 2}$ and that $B$ is essentially a constant.

From equation 30 , Blench's side factor $F_{s}$ is related to $B$, that is, $B \propto F_{s}^{-1 / 8}$. Since $F_{s}=V^{3} / W$ and $V^{3} \propto Q C / W$, $F_{x} \propto Q C / W^{2}$ and $B \propto\left(W^{2} / Q C\right)^{1 / 8}$. Thus, according to Blench there will be very little variation in the coefficient $B$.

In a discussion of departure from "regime," Inglis $(1949$, p. 99$)$ uses two values of $f$. Lacey's $f=\left(V^{2} / D\right)^{1 / 2}$ becomes $f_{z r}$, and $f \propto\left(D^{1 / 2} S\right)^{2 / 3}$ becomes $f_{r s}$. Note that $f_{v r} /\left(f_{r s}\right)^{3 / 2}=B^{4}$, which appears to confirm Inglis' statement that $\left(f_{o r} / f_{r s}\right)^{1 / 2}$ was a measure of the deviation from regime. From a practical standpoint, however, it is obvious that the $f$ in the Lacey equations is a most elusive parameter.

The relations among the coefficients of these equations will be discussed more fully in the sections on regime channels and stable channels.

Recently, Engelund (1966) proposed a series of equations that Maddock (1966) showed to reduce to

$$
V \propto\left(\frac{q S}{d^{1 / 4}}\right)^{1 / 2}\left(6+2.5 \ln \frac{0.39 D S}{(s-1) d^{2}}\right)^{1 / 2} .
$$

Engelund apparently developed the logarithm term from analysis of flume experiments. Consequently, it is doubtful if the term will fit all flume and field data. Nevertheless, the basic form is the same as that of equation 19.

Einstein and Barbarossa (1952) proposed a similar but more complicated relation, in which the friction factor due to the bed forms is related to the shear stress on the grains of sediment and to the size of grain. For values of $1.68 D_{35} / R^{\prime} S$ in excess of about 2 the relation becomes

$$
\frac{V}{\left(g R^{\prime \prime} S\right)^{1 / 2}}=\left[\frac{g R^{\prime} S}{d_{35}(s-1)}\right]^{1 / 2},
$$

which, for all practical purposes, seems to be another variant of equation 19. The feed system flume data of Guy, Rathbun, and Richardson (1966) also have this same basic relation.

In conclusion, all the standard approaches to the roughness of alluvial channels have the specific limitation that the depth, velocity, and slope are all supposed to vary with changing discharge. This may occur $\mathrm{k}$ cause sediment load is an independent variable, as it was in the development of equation 29 , or because small discharges, narrow flumes, or coarse material limit the possible combinations in a recirculating flume. Equation 29 and the Blench (1964) and Engelund (1966) equations are independent of the form of the relation 1 ?tween velocity and sediment load; the Lacey (1946) and, perhaps, the Einstein-Barbarossa equations ere not. No precise relation exists in equation 19 or any other equation relating to slope; the relation may be the most probable or may reflect channel behavior, and consequently these equations are all "regime"equations.

DISCHARGE AND SLOPE AS INDEPENDENT VARIABLES

\section{Variance of shear stress and friction factor}

First, consider discharge as an independent varial le and slope as constant:

$$
\begin{aligned}
& V \propto q^{m}, \\
& D \propto q^{f},
\end{aligned}
$$

slope $\propto q^{2}$ where $z=0$ (slope constant),

$$
m+f=1 \text {. }
$$

Minimizing the sum of the variances of shear stress and the friction factor

$$
\begin{aligned}
& (f+z)^{2}+(f+z-2 m)^{2} \longrightarrow \text { minimum, } \\
& (1-m)^{2}+(1-m-2 m)^{2} \longrightarrow \text { minimum. }
\end{aligned}
$$

We perform the necessary operations,

$$
\begin{gathered}
m=0.40, \\
V \propto q^{0.40} .
\end{gathered}
$$

Secondly, consider discharge as constant and slope as an independent variable.

Define

$$
\begin{aligned}
& V \propto S^{t}, \\
& D \propto S^{u}, \\
& S \propto S^{1}, \\
& q \propto S^{o}, \\
& t+u=0 .
\end{aligned}
$$

Minimizing the sum of the variance of shear stress and

$$
(u+1)^{2}+(u+1-2 t)^{2} \longrightarrow \mathrm{a} \text { minimum, }
$$

and, as before,

$$
\begin{gathered}
t=0.4 \\
V \propto S^{0.4}
\end{gathered}
$$




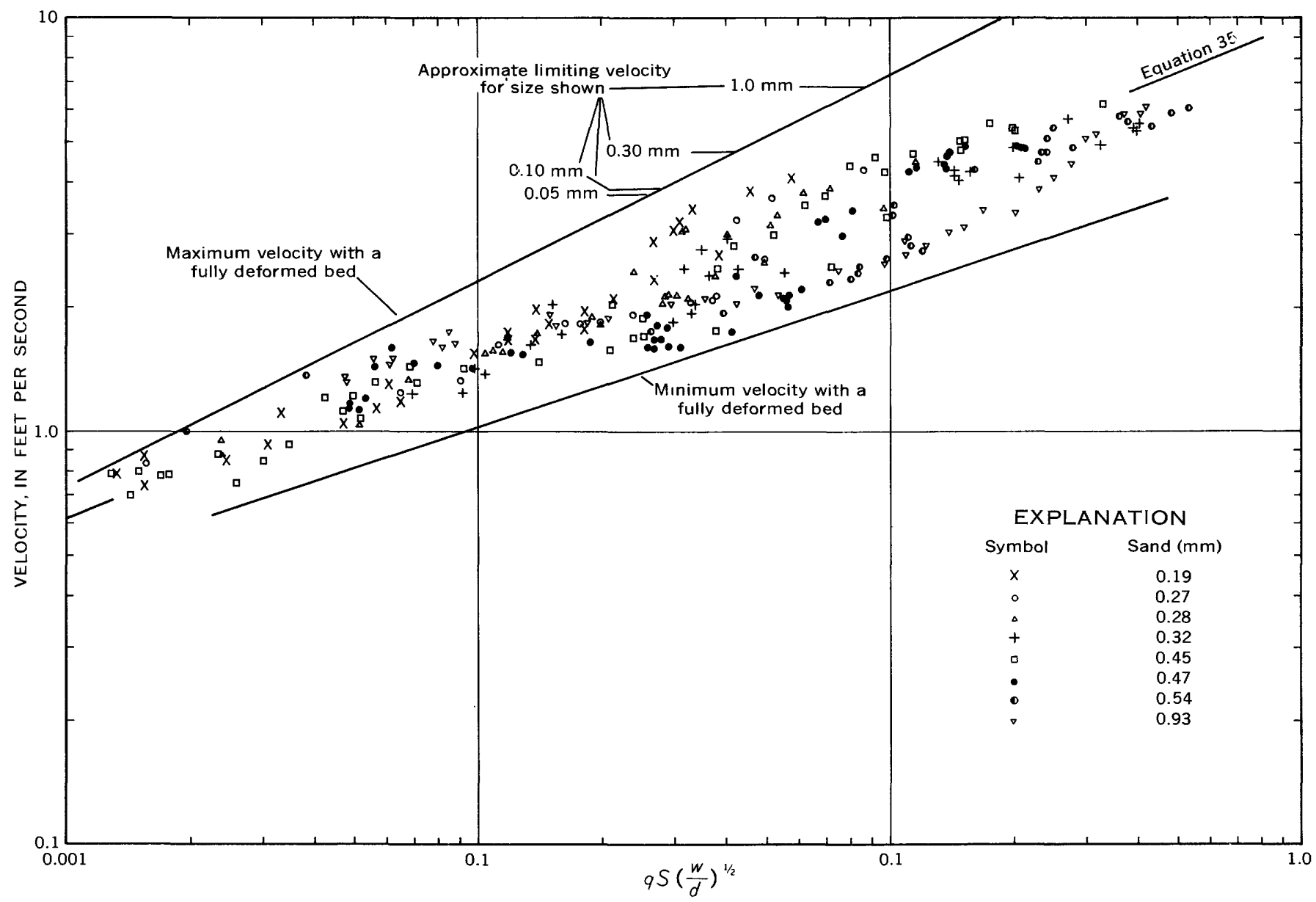

Frgure 26.-Relations between velocity and unit discharge, slope, and mean grain size of sediment, Simons and Richardson (1961) data from recirculating flumes.

Again, if there is no correlation between the two independent variables, equations 32 and 33 may be combined in the form

$$
V \propto(q S)^{0.40}
$$

Obviously, there are many situations where slope is not going to change with discharge, and both flume and field data are available to confirm this relation. As was previously noted, equation 20 was developed from the Waterways Experiment Station (1935) data with slope as an independent variable.

The Simons and Richardson (1961) experiments provide data for a much greater range in the value of slopes than those of depth and unit discharge. (The highest value for slope is about 100 times greater than the lowest value; the highest values for depth and unit discharge are about four times greater than the lowest values.) That these data are essentially the result of a slope-independent variable operation is shown in figure 26 , where the equation of an average line is

$$
V=5.5\left[\frac{\gamma q S}{\rho^{1 / 2}}\left(\frac{w}{\Delta \gamma d}\right)^{1 / 2}\right]^{0.4}
$$

Equations 20 and 35 are identical except for the coefficients, 4.4 and $\mathbf{5 . 5}$.

Data from Hubbell and others $(1956,1960)$, Simons (1957), Nordin and Beverage (1965), and the Harza Engineering Co., International (1963), are shown in figure 27. Again the relation of the data to equation 35 is evident.

The difference between the coefficients of equations 20 and 35 is attributed to the fact that the prosedures of the Waterways Experiment Station (1935) studies had the effect of minimizing the sediment load and, consequently, the velocity. The range in observed values about equation 35 represents the change in the coefficient due to variation of bed forms largely associated with sediment load. Differences in the sizes of transported and bed materials may account for a small part of the difference. 


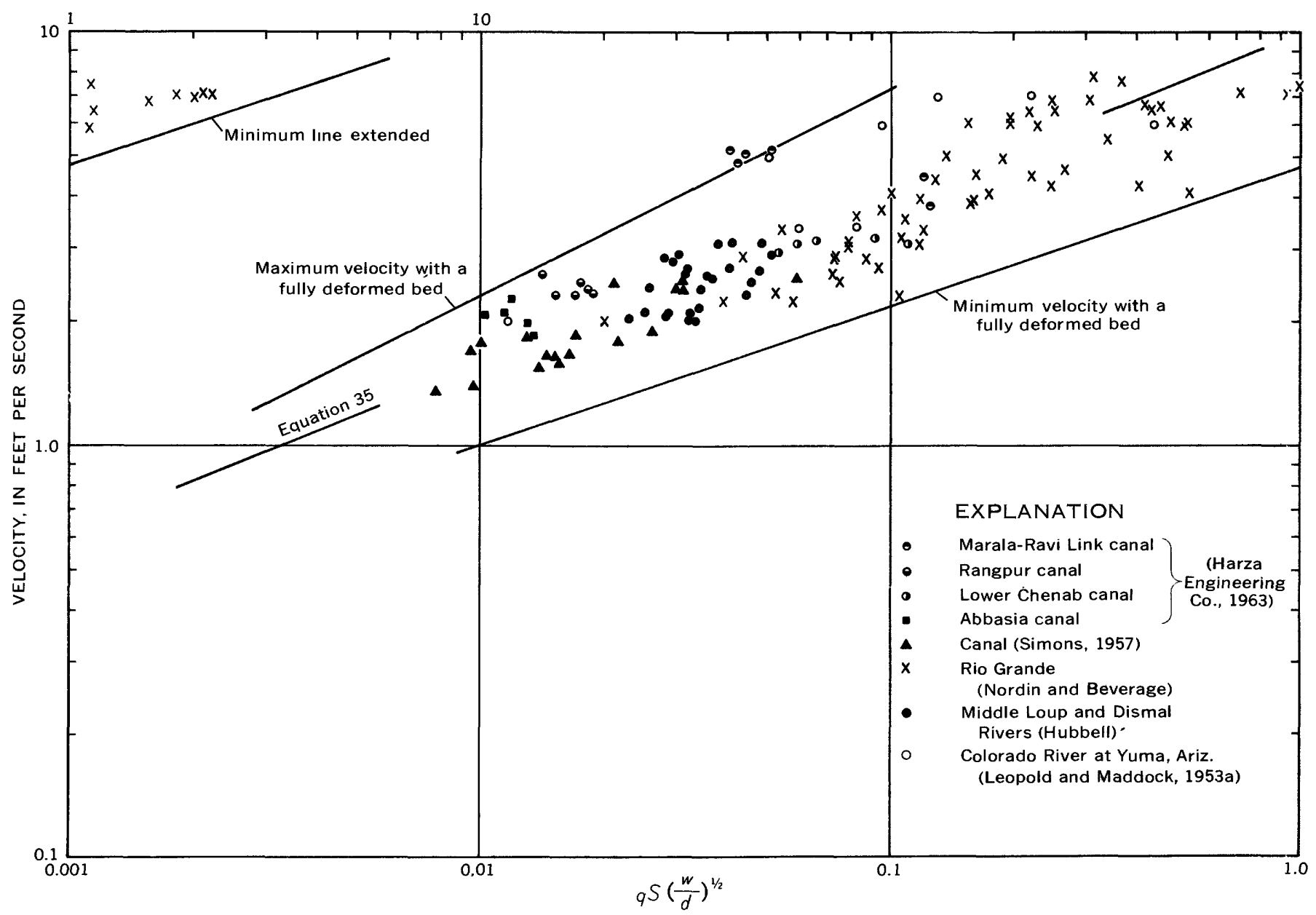

Figure 27.-Relations between velocity and unit discharge, slope, and mean grain size of sediments for certain canals and natural streams.

The envelope curves shown in figures 26 and 27 are approximations of the limit of change in roughness for any value of $q S$ for a mean grain size of about $0.3 \mathrm{~mm}$. The position of the upper limit at least, will vary with changing grain size. Figure 26 also shows the approximate maximum velocities for given sizes of sediment. These, together with the envelope curves, circumscribe the behavior of any alluvial channel.

Figures 28 and 29 are taken from Vanoni, Brooks, and Kennedy (1961) and show the relation between equation 35 and observations for two natural streams at constant slope. In contrast, figure 30 (Culbertson and Dawdy, 1964) shows observations for a stream having a variation in slope and in the sediment load. The figure shows the potential variation, due to changes in slope, in the relation between the hydraulic radius and velocity. The other variations as shown by the plotted points may be due to changes in load and size of the sediment in transit.

\section{Variance of velocity and friction factor}

Rubey (1938) noted that for the movement of smaller sizes of sediment shear stress seemed to be the governing factor, but in the larger sizes, velocity seemed to be most important. If this is true, variance in velocity possibly should be minimized. Furthermore, it would seem natural that a stream would resist variations in velocity to minimize change in momentum. Decisions as to whether variance in load or velocity are being minimized may be difficult. Consequently, the effect of minimization of velocity together with the friction factor must be determined.

If $q$ and $S$ are independent variables, and if $q$ is varied while $S$ is constant, and

$$
\begin{aligned}
& V \propto q^{m}, \\
& D \propto q^{f}, \\
& q=V D \text { and } m+f=1, \\
& S=\text { constant }=q^{\circ} .
\end{aligned}
$$




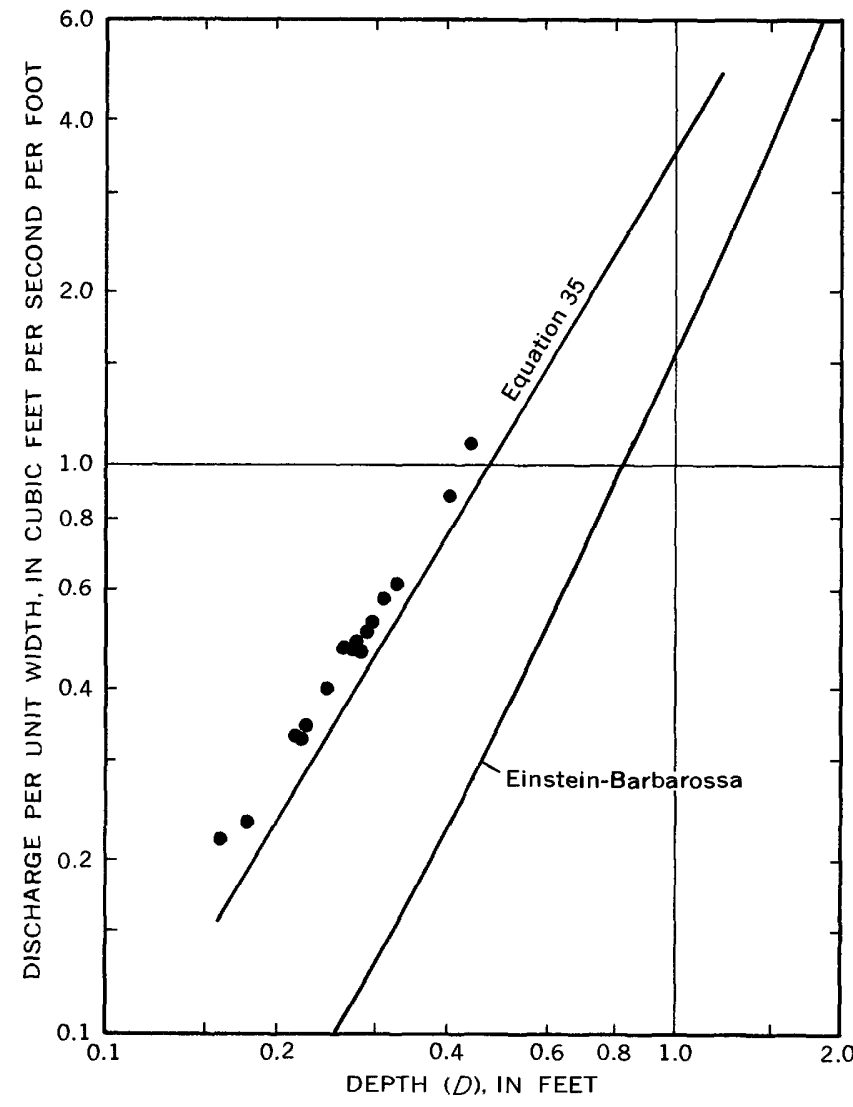

FIGURE 28.-Relation between unit discharge and depth for Mountain Creek near Greenville, N.C., showing observed values (solid circles) and values computed by equation 35 and by the Einstein-Barbarossa method. From Vanoni, Brooks, and Kennedy (1961).

To minimize the variance of $V$ and the friction factor in combination

or

$$
\begin{aligned}
& m^{2}+(1-3 m)^{2} \rightarrow \text { minimum, } \\
& 2 m+18 m-6=0, \\
& m=0.3 \\
& V \propto q^{0.3}
\end{aligned}
$$

If $S$ is varied where $q$ is constant and

then

$$
V \propto S^{i}, D \propto S^{u}, S \propto S^{1},
$$

$$
q=V D=\text { constant and } t+u=0, u=-t \text {. }
$$

To minimize the variance of $V$ and the friction factor in combination

or

$$
t^{2}+(1-3 t)^{2} \rightarrow \text { minimum }
$$

$$
\begin{aligned}
& 2 t+18 t-6=0, \\
& t=0.3, V \propto S^{0.3}
\end{aligned}
$$

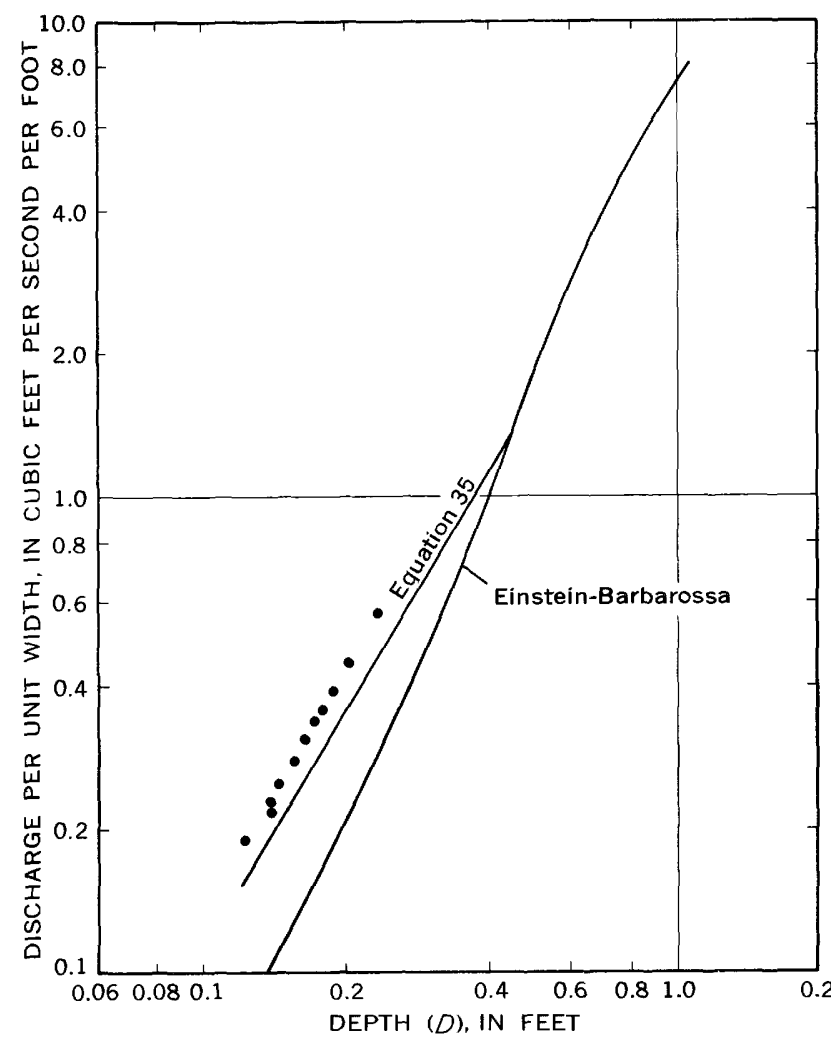

Figure 29.-Relation between unit discharge and depth for West Goose Creek near Oxford, Miss., showing observed values (solid circles) and values computed by equation 35 and by the Einstein-Barbarossa method. From Vanoni, Brooks, and Kennedy (1961).

Under conditions of independence of $q$ and $S$, equations 35 and 36 may be combined, and

$$
V \propto(q S)^{0.3} .
$$

The relation between velocity and $q S$ for stations on the Colorado River below Glen Canyon Dam is shown in figure 31 . The high flows, usually associrted with periods of scour, are for the Colorado River at Grand Canyon, Ariz., from 1961 to 1965. Other data are from locations below Davis Dam reported by the Bureau of Reclamation. In this section of the river, the stream derives its load from its bed and banks, as incoming natural load has been cut off by dams. Considerable diurnal variation occurs in the releases from Davis Dam, and the flow during flood periods was unsteady.

The relation shown in figure 31 is

$$
V=14.4(q S)^{0.3} \text {, }
$$

as might be expected from the analysis leading to equation 37.

Figure 32 is taken fron Vanoni, Brooks, and Kennedy (1961) and shows the adaptation of equation 38 to the 


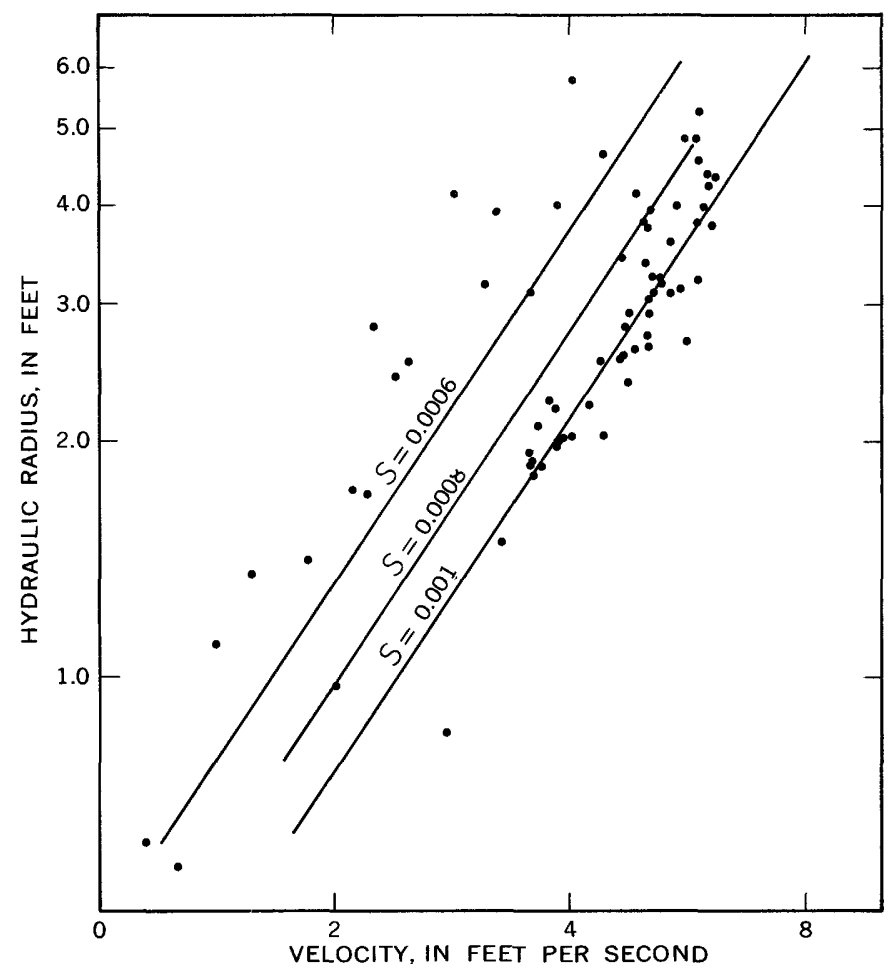

Figure 30.-Relation of velocity to hydraulic radius for San Francisco riverside drain near Bernardo, N. Mex. Different values of slope computed from equation 35. From Culbertson and Dawdy (1964).

Colorado River at Taylors Ferry, Ariz. Figure 33 shows the behavior of the Colorado River at Yuma, Ariz., before and after the construction of Hoover Dam. The original slope was an aggrading, self-formed slope, so a high coefficient was used for equation 19. After dam closure and with only a small amount of sediment from the desilting works of the All-American Canal, the channel was still self-formed but degrading, hence, a smaller coefficient was used for equation 19. The higher releases in the post-dam period, however, were for sluicing purposes; hence, discharge was irregular and sediment load was secured locally. Consequently, equation 38 applies as shown.

\section{Variance of concentration and friction factor}

Observation indicates that the concentration of sediment tends to be conservative, not the load, which is a rate of sediment movement per width of channel. Thus, changes in width, which result in changes in load with concentration and stream discharge constant, are readily accepted by a stream, but changes in concentration appear to be resisted. The heads of flumes and even canal systems, particularly with low discharges and with coarse sediments, seem to illustrate this condition.

If slope and discharge are independent variables and if $L \propto V^{\alpha} q^{j}$, then $C \propto V^{\alpha} q^{j-1}$. If the variance of the concentration and friction factor are to be minimized and $V \propto q^{m}$, the former procedures yield, when slope is constant,

$(\alpha m+j-1)^{2}+(1-m-2 m)^{2} \longrightarrow$ minimum, $\alpha^{2} m^{2}+2 \alpha m(j-1)+(j-1)^{2}+9 m^{2}-6 m+1 \rightarrow$ minimum. Setting the first derivative equal to zero

or

$$
2 \alpha^{2} m+2 \alpha(j-1)+18 m-6=0,
$$

$$
\begin{gathered}
m=\frac{3-\alpha(j-1)}{\alpha^{2}+9} \\
V=q^{\frac{3-\alpha(j-1)}{\alpha^{2}+9}} .
\end{gathered}
$$

If $S$ is a variable and $q$ is constant, $V \propto S^{t}$ and $C \propto S^{\alpha t}$. Further, D $\propto S^{u}$ and, because $q$ is constant, $u=-t$. Again, to minimize jointly the variance of the concentration and the friction factor

$$
(\alpha t)^{2}+(1-3 t)^{2} \longrightarrow \text { minimum }
$$

and, setting the derivative equal to zero,

$$
\begin{gathered}
2 \alpha^{2} t-6+18 t=0, \\
t=\frac{3}{\alpha^{2}+9},
\end{gathered}
$$

or

$$
V=S^{\frac{3}{\alpha^{2}+9}}
$$

With the restriction of complete independence of $q$ and $S$, equations 32 and 33 may be combined in the form

$$
V=q^{\frac{3-\alpha(j-1)}{\alpha^{2}+9}} S^{\frac{3}{\alpha^{2}+9}}
$$

The exponents of this equation will vary, depending upon which of the velocity-load equations are chosen. If equations 10 or 11 are chosen, $\alpha=4$ and $j=-1 / 4$, whence

$$
V \propto q^{8 / 25} S^{3 / 25} \propto q^{0.32} S^{0.12} .
$$

If equations 6 and 12 are used, $\alpha=9$ and $j=0$, and

$$
V \propto q^{2 / 15} S^{1 / 30} \propto q^{0.133} S^{0.033} .
$$

Because the variance in concentration is minimized, these equations show little variation in velocity with discharge in the low-velocity range or with slope in either the low- or mid-velocity ranges. However, this condition seems more likely to be found in the lowvelocity range than in the high-velocity range. In the studies of Guy, Simons, and Richardson (1966, p. I 33) using $0.45-\mathrm{mm}$ sand, flow was increased from 4.24 efs in run 19 to $12.12 \mathrm{efs}$ in run 21. Slopes in the two runs were 0.00112 and 0.00114 , respectively. The report states: "This increase in flow caused the depth of flow 


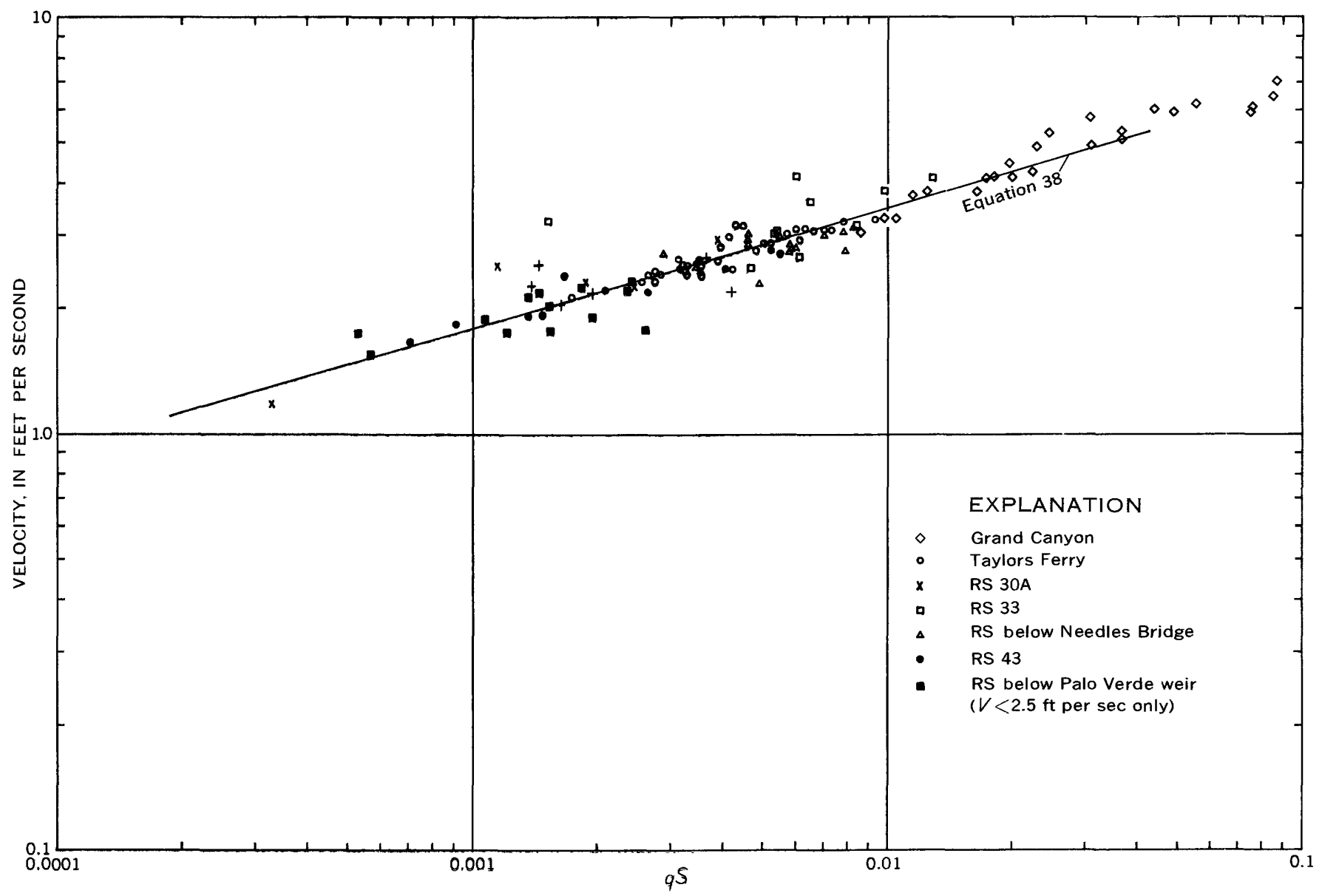

FIGURE 31.-Relations between velocity and the produot of unit discharge and slope for locations on the Colorado River at Grand Canyon, Ariz., and below Davis Dam. Discharge measurements at Grand Canyon by U.S. Geological Survey; all other data from U.S. Bureau of Reclamation (1958). RS, River station.

to more than double and caused the velocity to increase from 1.30 to $1.58 \mathrm{fps}$." This appears to be a confusion of cause and effect. The flume by itself could not increase the depth. Nearly 5,000 gallons of water had to be added to the recirculating system. Undoubtedly, a considerable manipulation of the flume's tailgate was required. The point is that the slope of run 19 could not have been maintained with the discharge of run 21 without holding the scour at the lower end of the flume to a minimum and maintaining sediment concentration. Tailgate manipulation had this effect. Actually, the sediment concentration did increase from $208 \mathrm{ppm}$ to $380 \mathrm{ppm}$, although the mean particle size declined. Thus, the velocity rose to $1.58 \mathrm{fps}$ (feet per second) rather than to 1.45 , which would have resulted if the variation in the sediment concentration had been minimized.

The Simons and Richardson experiments using a $0.93 \mathrm{~mm}$ sediment also are reported by Guy, Simons, and Richardson (1966). The results of these experi- ments are shown in figure 34. Relations between velocity and $q S$ for $q S$ values of less than .001 are mostly dependent on grain size or a limited rariation in concentration with low discharges. Once the bed is deformed, however, other considerations take hold. Equation 43 in the form

$$
V=2.33 q^{0.133} S^{0.033}
$$

was applied to runs with values of $q S$ betwe?n 0.001 and about 0.004, which appears to be the end of the low-velocity range. The results are as follows:

\begin{tabular}{|c|c|c|c|c|}
\hline \multirow[b]{2}{*}{ Run } & \multicolumn{2}{|c|}{ Velocity } & \multirow[b]{2}{*}{ Difference } & \multirow[b]{2}{*}{ Percen } \\
\hline & Observed & Computed & & \\
\hline $15 \ldots$ & 1. 93 & 2. 00 & +0.07 & 3. 61 \\
\hline $16 \ldots$ & 2. 03 & 2. 06 & +.03 & 1. 47 \\
\hline $35 \ldots \ldots$ & 1. 80 & 1. 87 & +.07 & 3. 87 \\
\hline $17 \ldots \ldots$ & 2. 10 & 2. 08 & -.02 & .95 \\
\hline $10_{\ldots} \ldots$ & 1. 88 & 1. 86 & -.02 & 1. 06 \\
\hline $36 \ldots \ldots$ & 2. 04 & 1. 96 & -.08 & 3. 92 \\
\hline
\end{tabular}




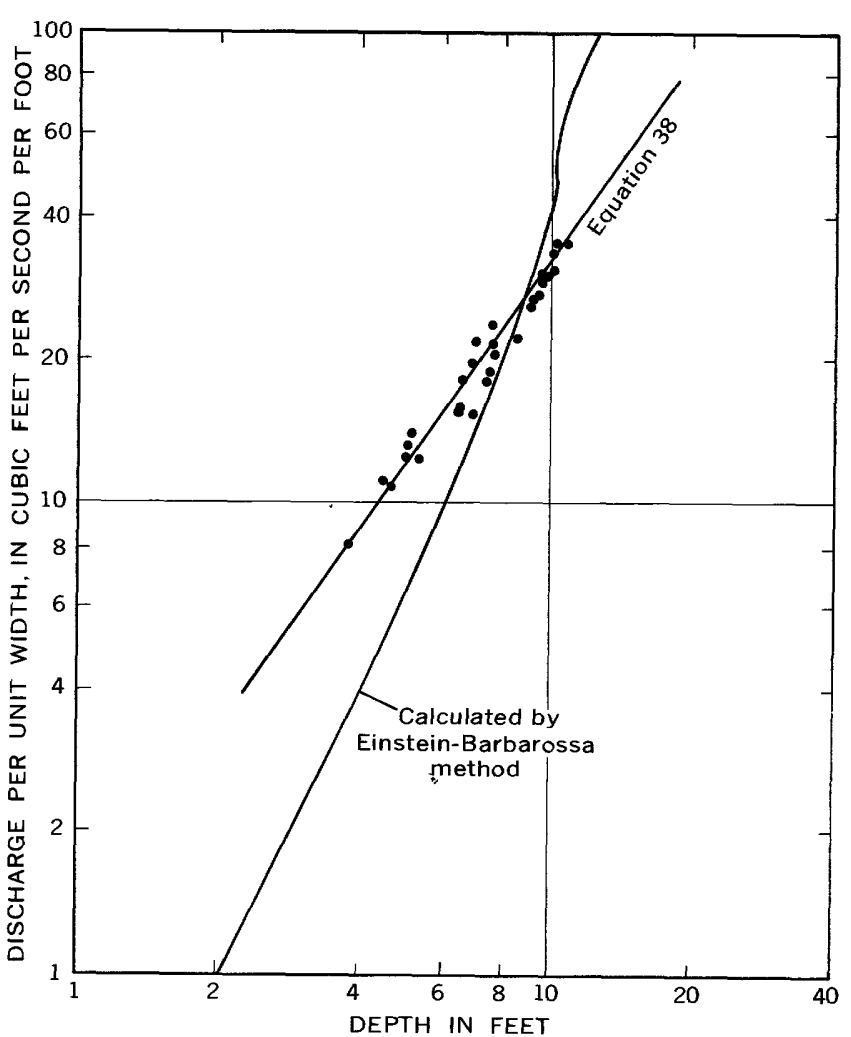

FIGURe 32.-Relation between unit discharge and depth for Colorado River at Taylors Ferry, Ariz., showing observed values (solid circles) and values computed from observations at Yuma, Ariz., using equation 38 and by the EinsteinBarbarossa method. From Vanoni, Brooks, and Kennedy (1961). Slope is 0.000217 foot per foot.

Equation 43 would rarely apply in a natural stream because velocities are usually above the low-velocity range.

BEHAVIOR OF FLUMES OPERATED AT CONSTANT DEPTH

The cause of much of the confusion in the study of alluvial channels can be seen in the behavior of flumes operated at constant depth. If depth is held constant, that is, not permitted to vary, and discharge is an independent variable, held constant for any one run, velocity is uniquely determined, and there is no variance in either velocity or depth. The only variance is in slope. Thus, there may be either minimum variance in the shear stress $\gamma D S$ or minimum variance in the friction factor $\gamma D S / \rho V^{2}$, but not both. If the variance of the shear stress is to be minimized, $S \propto 1 / D$. If the variance of the friction factor is to be minimized, $\mathrm{V} \propto(D S)^{1 / 2}$. Therefore, if $D$ is constant, $S$ must either be a constant and not related to velocity or $V \propto S^{1 / 2}$. If discharge is held constant through a series of runs at different depths in which depth is constant over the period of the run, again velocity and depth are

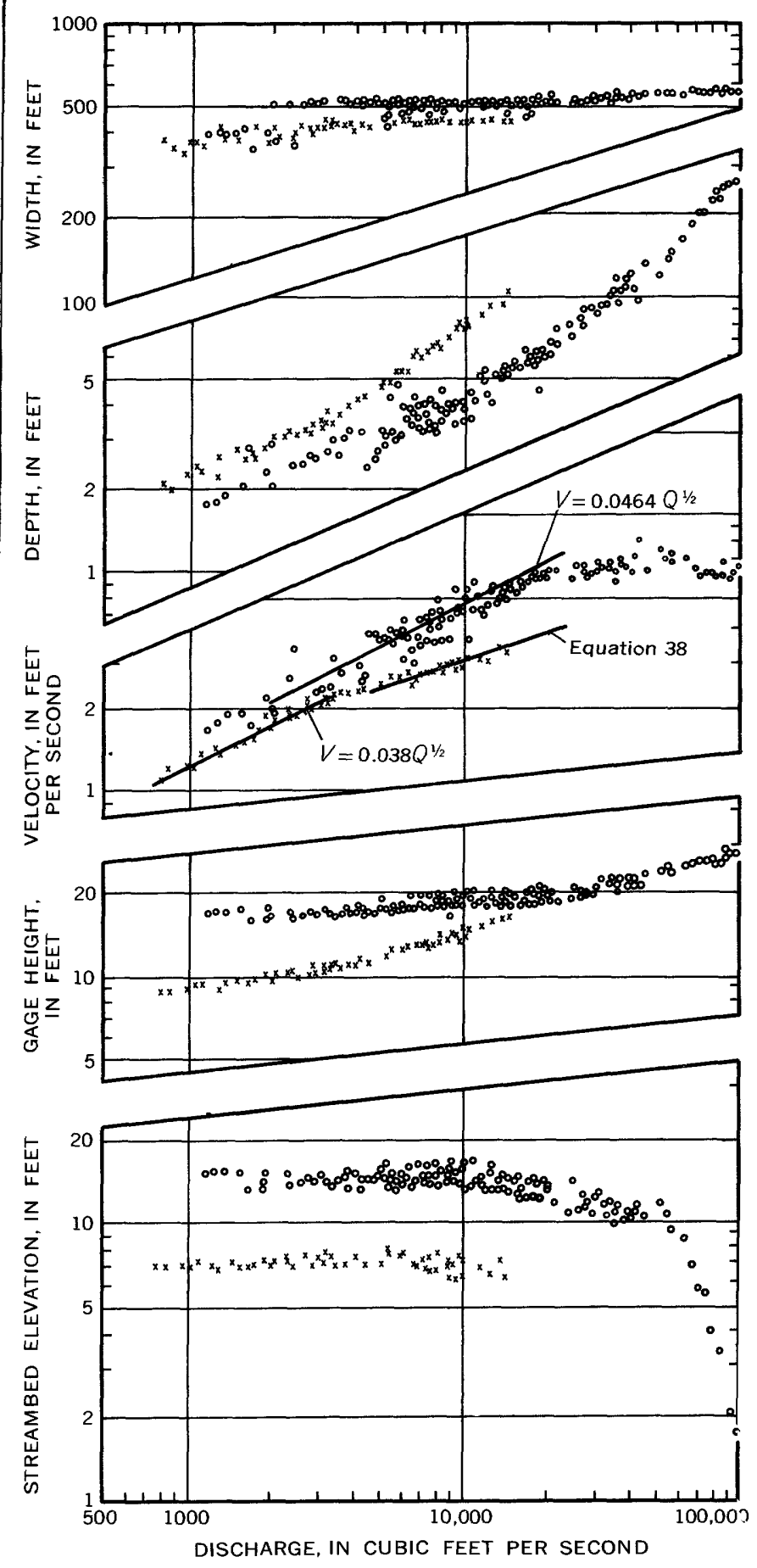

Figdre 33.-Relation of width, depth, velocity, water-surface elevation, and stream-bed elevation to discharge, Colorad? River at Yuma, Ariz. Samples taken during periods befor? and after construction of Hoover Dam are shown. Circles indicate samples taken during 1927-34; X's indicate samples taken during 1945-47. From Leopold and Maddock (1953a)

uniquely related, and slope is the only variable. Agair. the variance of the shear stress or of the friction factor may be minimized, but not both. If the shear stress 


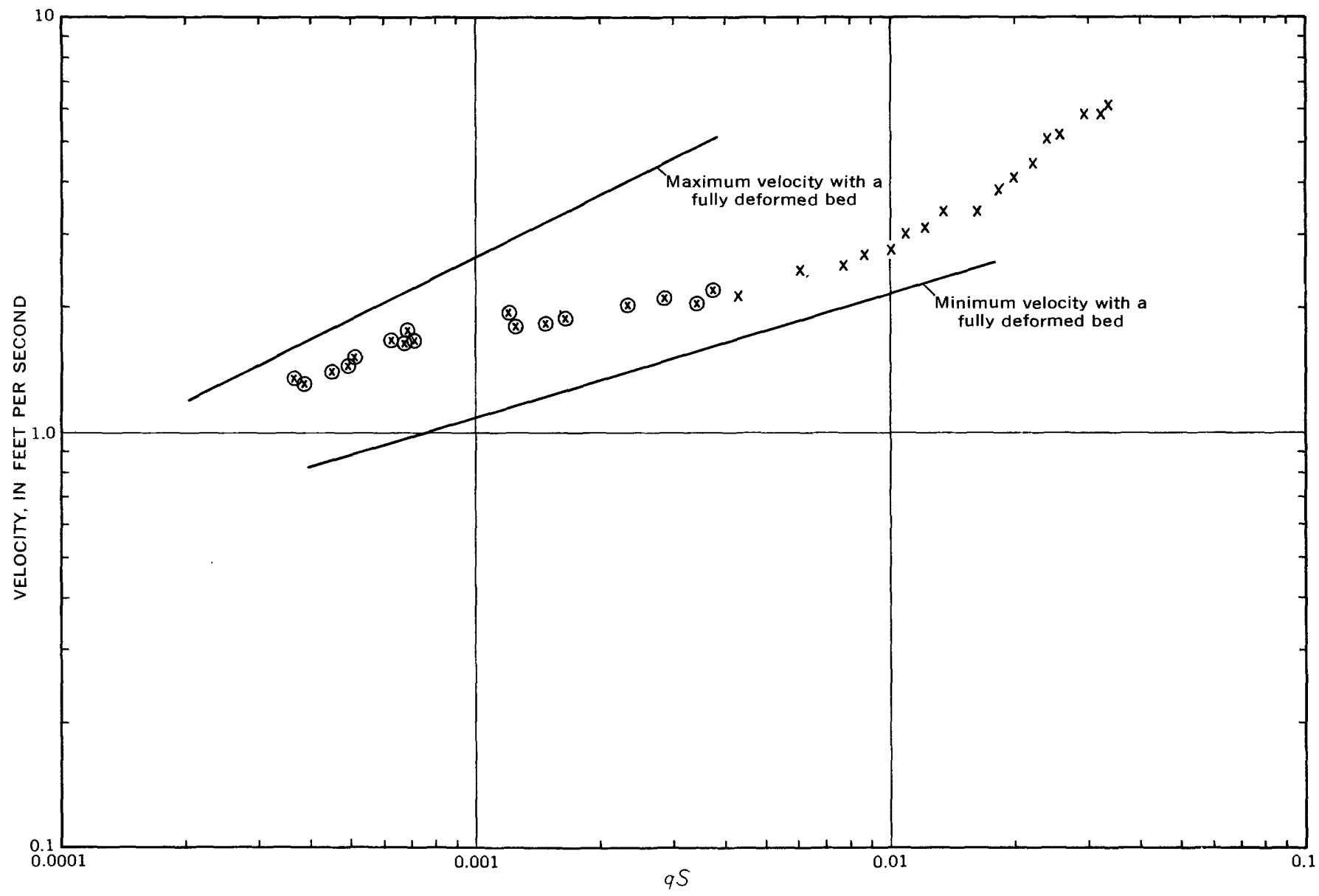

FiguRe 34.-Relations between velocity and unit discharge and slope. Simons and Richardson's 0.93-mm sand in 8-foot recirculating flume. Circles represent low-velocity range $V \propto L e^{1 / 9} ; \mathrm{X}$ 's represent mid-velocity range $V \propto L^{1 / 4} q^{1 / 16}$.

is minimized, $S \propto 1 / D \propto V$. If the variance of the friction factor is minimized, $V \propto S^{1 / 3}$.

When the above possible relations are combined with others previously noted, at least five different relations between velocity and slope can be expected if depth is a constant. The first three are where the value of depth is arbitrarily selected from an array of data: (1) depth is the result of a changing discharge, in which depth, velocity, and slope are free to vary $-V \propto(q S)^{1 / 2}$; (2) depth is the result of changing discharge and slope, in which only depth and velocity are free to vary$V \propto(q S)^{0.4}$; and (3) depth is the result of changing discharge and slope with the constraint of joint minimization of the variance of the sediment concentration and the friction factor- $-V \propto q^{0.32} S^{0.12}$ or $V \propto q^{0.133} \mathrm{~S}^{0.033}$, depending upon the applicable velocity-load relation. For a selected depth, these reduce to $V \propto S, V \propto S^{2 / 3}$, $V \propto S^{0.177}$ or $V \propto S^{0.038}$. For runs where, by flume operation, depth is held constant, then $V \propto S^{0}$ - that is, no relation-or $V \propto S^{1 / 2}$.

Examples of selection of a constant depth from data from the Gilbert (1914) experiments are shown in figure 35. In these experiments discharge and load were the independent variables and velocity, depth, and slope were free to vary. Note that the predicted relation, $V \propto S$, is supported by data from Gilbert's runs with sand $A, 0.305 \mathrm{~mm}$, and sand $B, 0.375 \mathrm{~mm}$. This result should be compared with the results from resirculating flume data to be presented later.

As noted earlier, the Williams (1967) data result from operation of a flume at constant depth; load and depth were independent variables. Because of the near-unique relations among velocity, discharge, and load, the result is the same as if depth and discharge were independent variables. As shown in figure $24, V \propto(q S)^{1 / 3}$ or $V \propto S^{1 / 2}$.

Recirculating flumes are particularly applicable to the study of channels operated at constant depth. If the amount of water in the recirculating system, which includes any storage tank, is kept constant, the mean depth of the water in the flume must remain the same. Thus, through simplicity of operation, many observations of recirculating flumes have been made, perhaps unintentionally, from runs made at constent depth. 

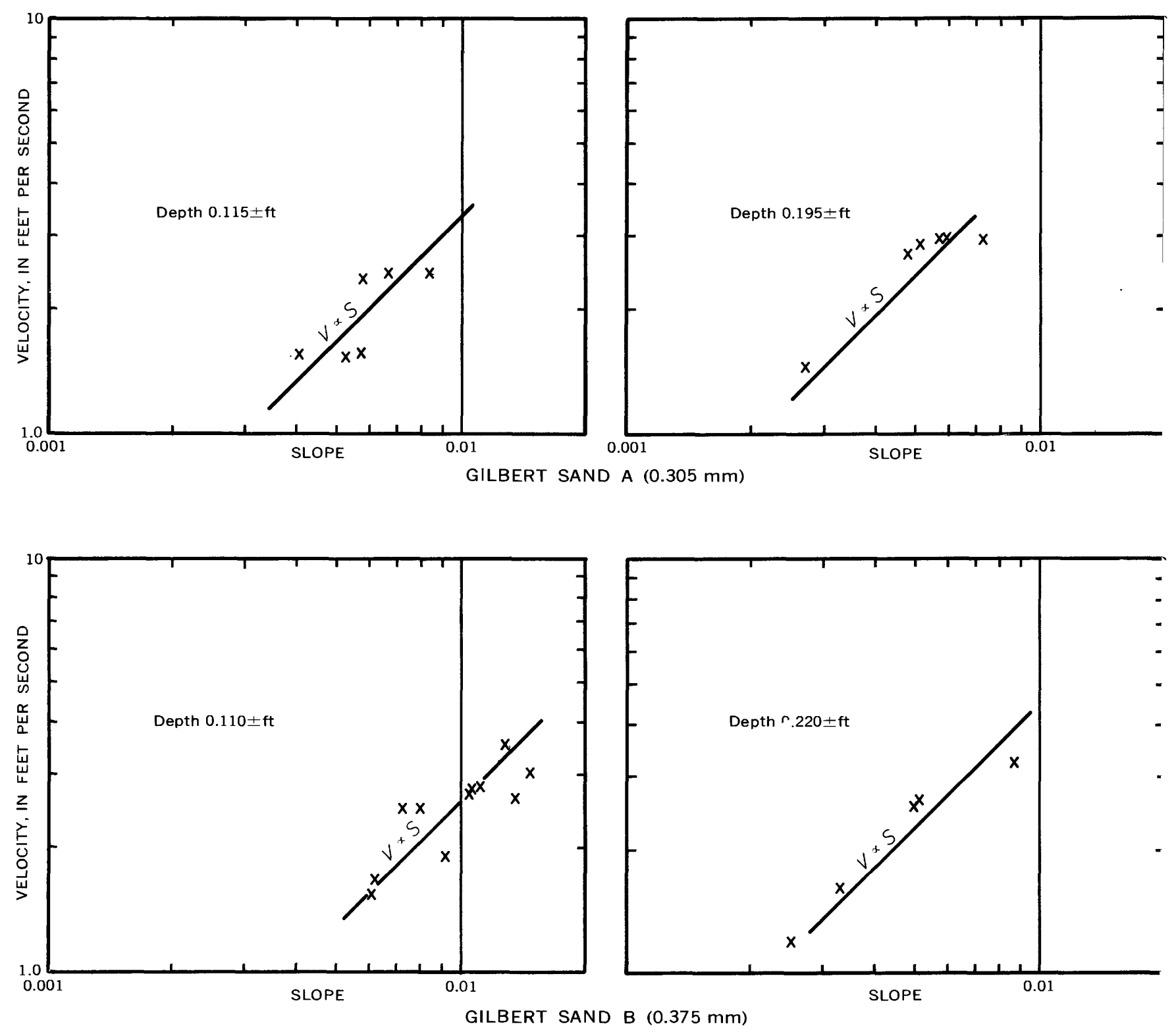

Figdre 35.-Relations between velocity and slope when depth is approximately constant, Gilbert (1914) sands A and B for depth? as shown; X's observed values.

These are, of course, in addition to those operated specifically to conserve the amount of water in the system. Data from a number of small flumes operated in this way are shown in figure 36. Data from larger flumes are shown in figure 37. As will be noted later, not all the data from Simons and Richardson (1961) are for runs with depth held constant.

Examples of sets of runs performed at a constant depth were given by Vanoni and Hwang (1967) for depths of about 0.24 foot and about 0.59 foot (fig. $38 A$ ) and by Vanoni and Brooks (1957) for depths of about 0.24 foot and 0.54 foot (fig. $38 B$ ). As shown in figure $38 A$ and $B$, sand sizes used by Vanoni and Hwang were $0.23 \mathrm{~mm}$ and $0.206 \mathrm{~mm}$, and Vanoni and Brooks used a sand with a geometric mean grain diameter of $0.137 \mathrm{~mm}$. Figure $38 \mathrm{~A}$ also shows data from Simons and Richardson (1961) for runs with depths of about 1 foot and about 0.57 foot with sard sizes of $0.19-\mathrm{mm}, 0.27-\mathrm{mm}$, and $0.28-\mathrm{mm}$ mean grain diameter. Although Guy, Simons, and Richardscn (1966) did not report any special effort to keep depth constant throughout a run, the data shown in figure $38 \mathrm{~A}$ (which includes all data from runs using a $1-\mathrm{ft}$ depth and a part of those using a $0.57-\mathrm{ft}$ depth) indicate that this was probably the situation.

In figure $38 A$ and $B$ the predicted relation $V \propto S^{1 / 2}$ 


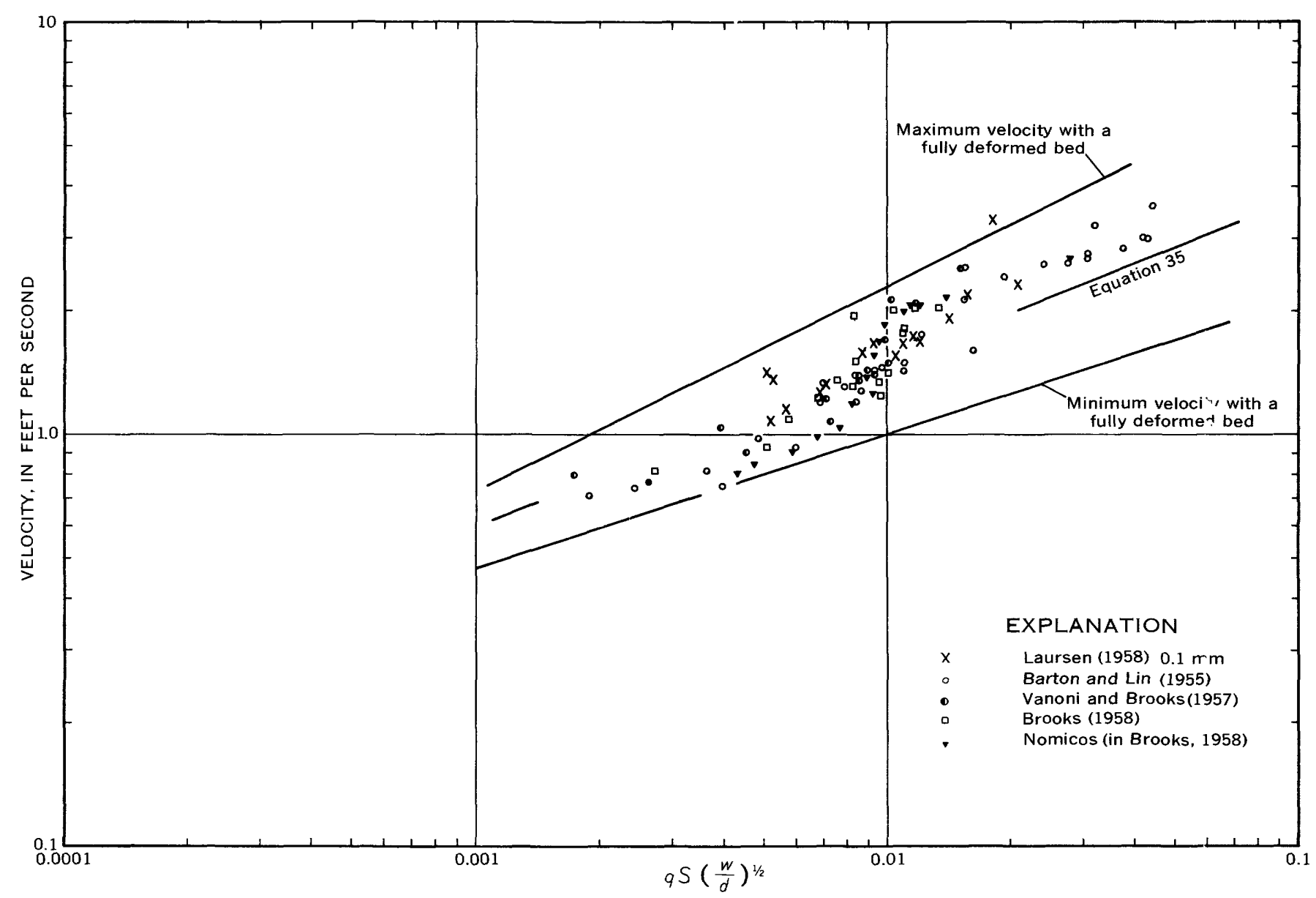

FIGURE 36.-Relations between velocity and unit discharge, slope, and mean grain size of sediment. Small recirculating flumes.

is clearly defined in the lower slopes. The effect of the constraint of constant discharge is shown in figure $38 C$. In accordance with the prediction the friction factor is constant, $\mathrm{V} \propto S^{1 / 3}$. This relation is particularly applicable to the $0.28 \mathrm{~mm}$ grain size of Simons and Richardson (1961).

When the values for $V$ and $S$ for different discharges (fig. $38 C$ ) are combined, the result is very close to $V \propto\left(q S^{1}\right)^{1 / 3}$, or the friction factor is approximately constant for a range of discharges. If the values of $V$ and $S$ for different depths (fig. 38A) are combined, the result is $V \propto D S^{1 / 2}$.

It should be emphasized that although a good correlation exists for the two equations the result is meaningless. If discharge is held constant and depth is permitted to vary or if depth is held constant and discharge is permitted to vary, there is no fixed relation between velocity and depth and slope unless some specific condition is implied. In one situation, depth is a constant and $V \propto Q$; in the other discharge is constant and $V \propto 1 / D$. Thus, no direct relation actually exists between velocity and slope at all.
Although the constant friction factor relation is well defined in figure $38 A, B$, and $C$, the constant shear stress relation is not as clear. The Vanoni and Hwang (1967) data for a depth of 0.24 -foot (fig. $38 \mathrm{~A}$ ), the Vanoni and Brooks (1957) data for a depth of 0.24-foot (fig. 38B), and the Stein (1965) data for different depths (fig. 39A, $B, C)$ all show the shift from a constant friction factor to a constant shear stress sharply and clearly. The shift is only partially defined in the Simons and Pichardson (1961) data for the $0.27-\mathrm{mm}$ and $0.28-\mathrm{mm}$ grain sizes in the 8 -foot flume and for the $0.33-\mathrm{mm}$ sands in the 2 -foot flume. The shift is not obvious in the Simons and Richardson data for the $0.45-\mathrm{mm}$ sand (fig. $3 ? A, B, C$ ).

Part of the problem of obtaining definitive relations is that in a recirculating flume the shift to constant shear stress can take place only after the bed forms have reached some critical size, shape, or other characteristic. This is an unstable situation, because, in the data shown in figure $38 A, B$, and $C$, the friction factor has remained essentially constant at a constant depth of flow despite the fact that the height of the bed forms has increased with increasing slope. In the data for 


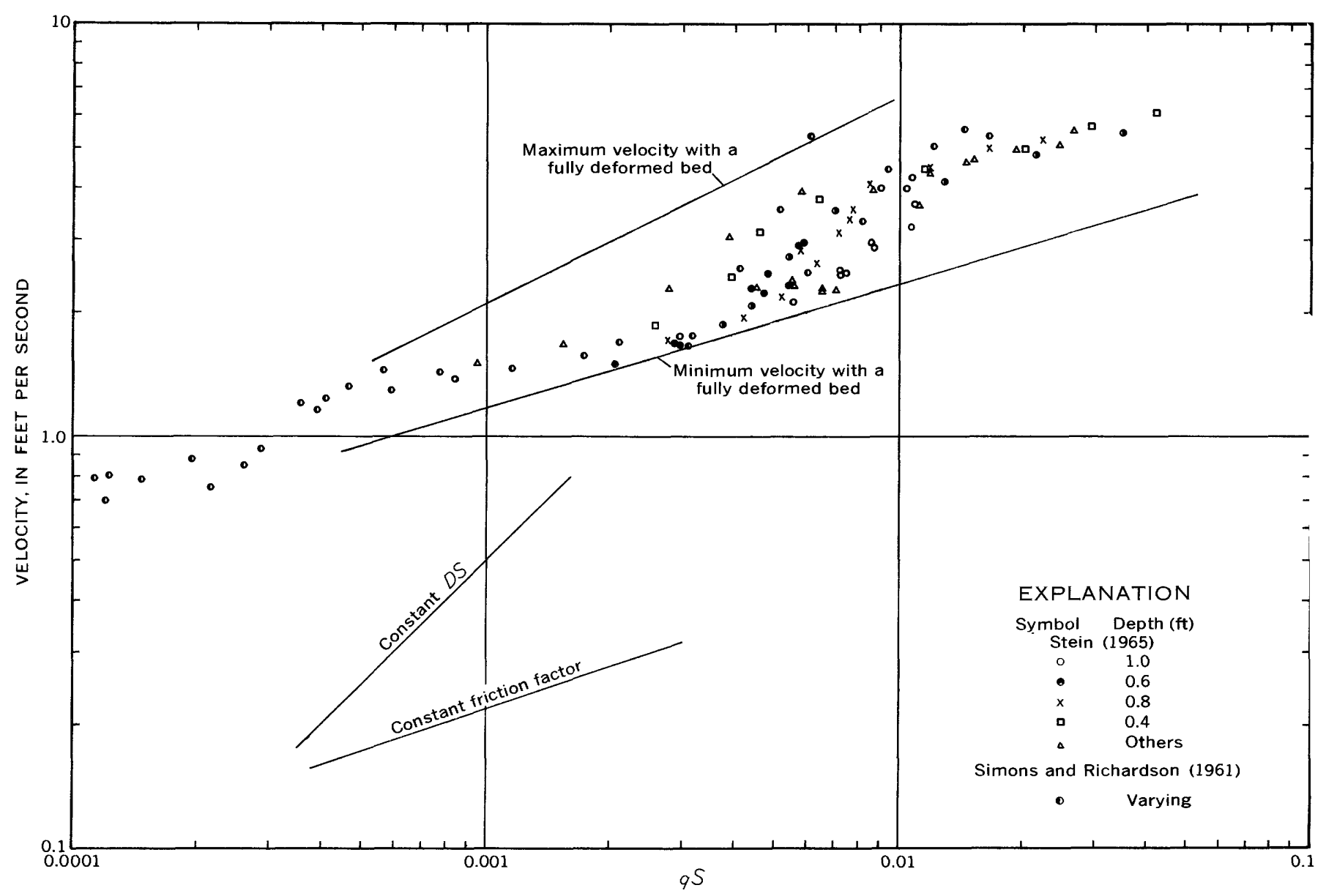

FigURE 37. - Relations between velocity and the product of unit discharge and slope for 0.4 and $0.45 \mathrm{~mm}$ sand. Data from Steir (1965) and from Simons and Richardson (1961). Slopes for constant $D S$ and friction factor are also shown.

1 -foot depths (fig. $38 A$ ), there is a maximum range in height of bed forms of more than 20 times $(0.03 \mathrm{ft}-0.65$ $\mathrm{ft}$ for the $0.19-\mathrm{mm}$ sand) between slopes of 0.00023 and 0.00165 . Increased height of bed form with increased slope, although a change of lesser magnitude (of 20 times), is observed in data shown in figures $38 A, B$, and $C$.

Possibly the flume may make some internal adjustment. The point of instability occurs when sand bars and sand waves appear in the flume. The average depth remains the same, but sediment moves at different rates at different depths at different points in the flume. This could result in flow in which the surface slope could markedly vary and with unknown results and could change the situation to one of depth, velocity, and slope all varying. In this situation $V \propto S$. These changes at the point of instability may account for the behavior of the $0.27-\mathrm{mm}, 0.28-\mathrm{mm}$, and $0.33-\mathrm{mm}$ sands (fig. $38 D$ ) as well as that for the Vanoni and Hwang $0.206-\mathrm{mm}$ sand at a depth of 0.59 foot. The behavior may also be caused by variation in the method of operating the flume, although this would seem doubtful under the special conditions of the Vanoni and
Hwang experiments. The method of operation does, however, seem to be the cause of the variation in the results of the Simons and Richardson experiments with $0.45-\mathrm{mm}$ sand in the 8 -foot flume.

The difference in the behavior of the flume operated by Simons and Richardson and that operated by Stein is shown in figure $39 A, B$, and $C$. The Stein data ar? consistent-that is, low and high flows are constrained by a constant friction factor, and intermediate flow: are constrained by constant shear stress. The Simon and Richardson data are not consistent; at a depth of about 0.4 foot (fig. $39 \mathrm{~A}$ ), the flume seems to have been operated for a few runs in which depth was held constant but for other runs in which slope and discharg? were independent variables and $V \propto S^{2 / 3}$. The same situa tion is observed for 0.8 -foot depth (fig. $39 \mathrm{~B}$ ), but the data for depths of about 0.6 foot (fig. $39 C$ ) appear to have such variation in method of flume operation that one run has no specific relation to another. The operation of the flume as described by Guy, Simons, and Richardson (1966) would permit almost anything to happen. 

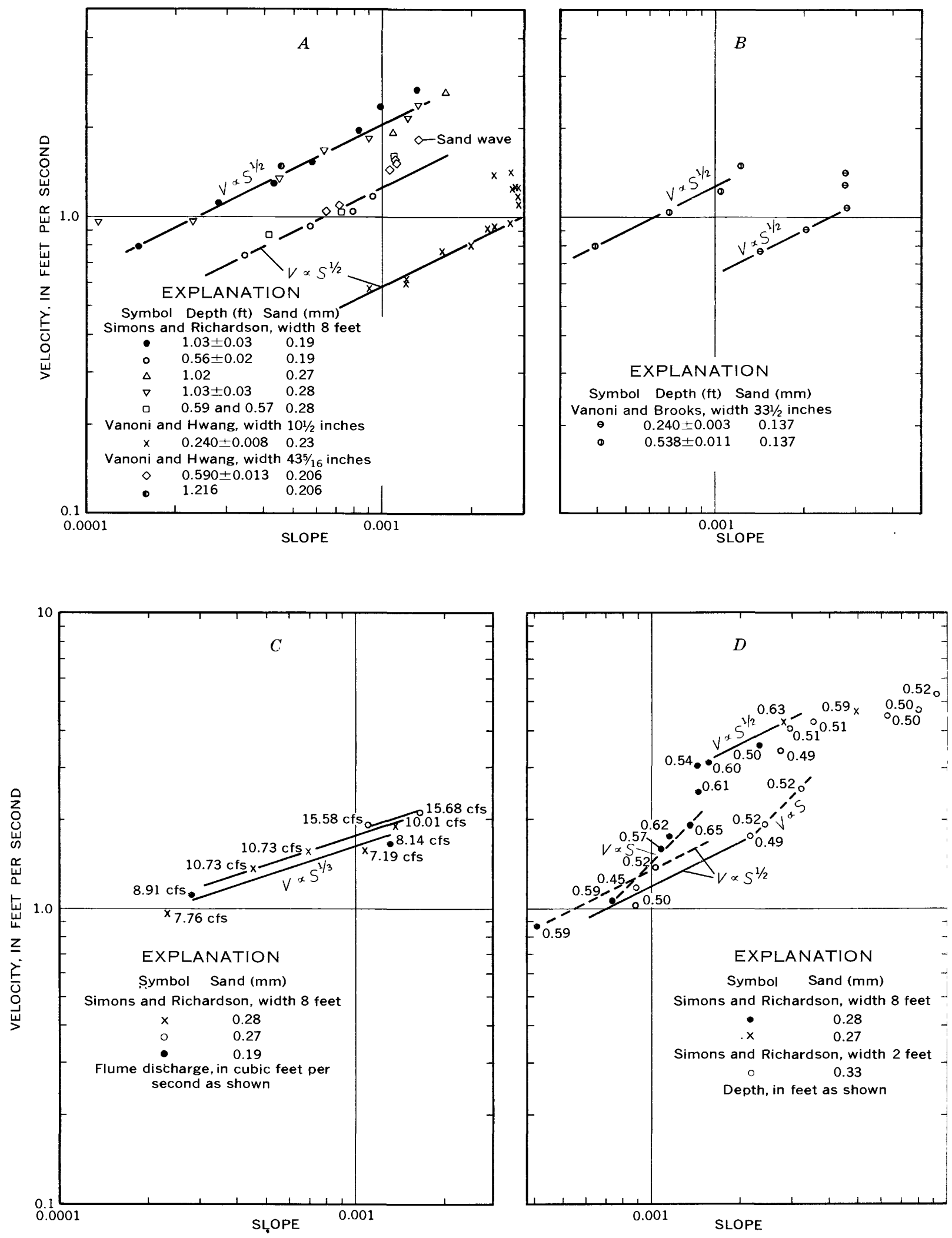

FIGURE 38.--Relations between velocity and slope for various depths of flow and different sizes of sand. Data from Simons and Richardson (1961), Vanoni and Hwang (1967), and Vanoni and Brooks (1957). Dashed lines used so as not to obscure plotted points. 

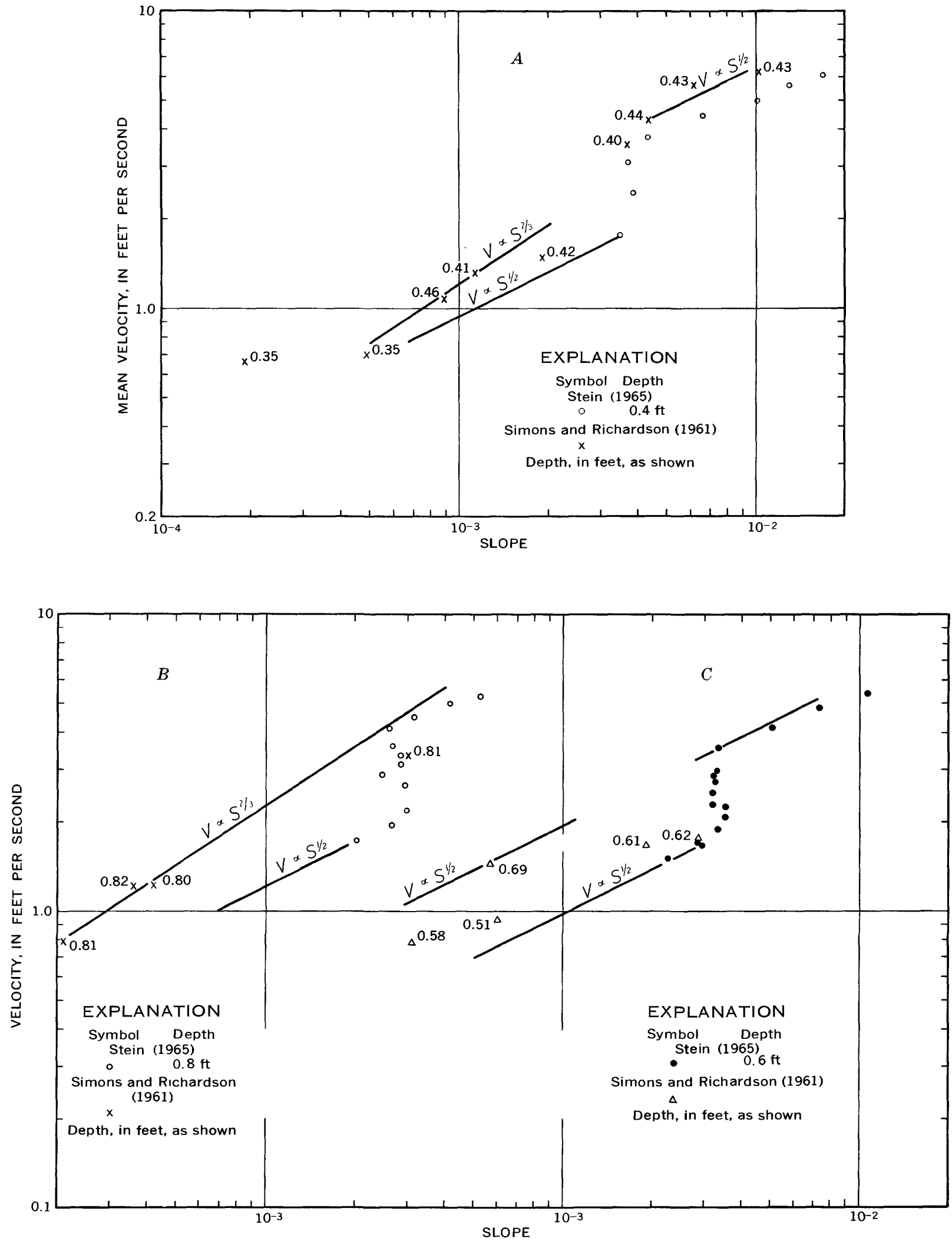

Figure 39.-Relation between velocity and slope for certain depths. Data from Stein (1965) for 0.40-mm sediment and from Simons and Richardson (1961) for 0.45-mm sediment. 
In the Stein (1965) data, with constant slope, there is a variation of about two times in the velocity, and the actual velocity increases somewhat with increasing depth. Therefore, if discharge is held constant and depth varied, the range in which the depth-slope product will be constant is also about 2 . This is shown in figure 40, which shows the relation between depth and slope for a discharge of $7 \mathrm{cfs}$.

Because of the linitation on the range of roughness by changing bed forms, the variation in shear stress with wide ranges in discharge cannot be ignored. Under these conditions, the value of $\gamma D S$ cannot be constant. If values of constant slope are selected from figures $39 \mathrm{~A}$, $B$, and $C$, clearly $\gamma D S$ is not constant. It increases with increasing discharge, but not as nuch as it would if the shear stress and the friction factor were mininized jointly.

Stein also made a set of runs in which he appears to have attenupted to nuaintain a constant velocity. All equations developed herein imply the form $S=K q^{-1}$ under such circumstances, but the relation $\left(S \propto q^{-1}\right)$ from flume data is indeterminate because of the variation in the coefficient. The runs with constant velocity were consistent with those with constant depth, and

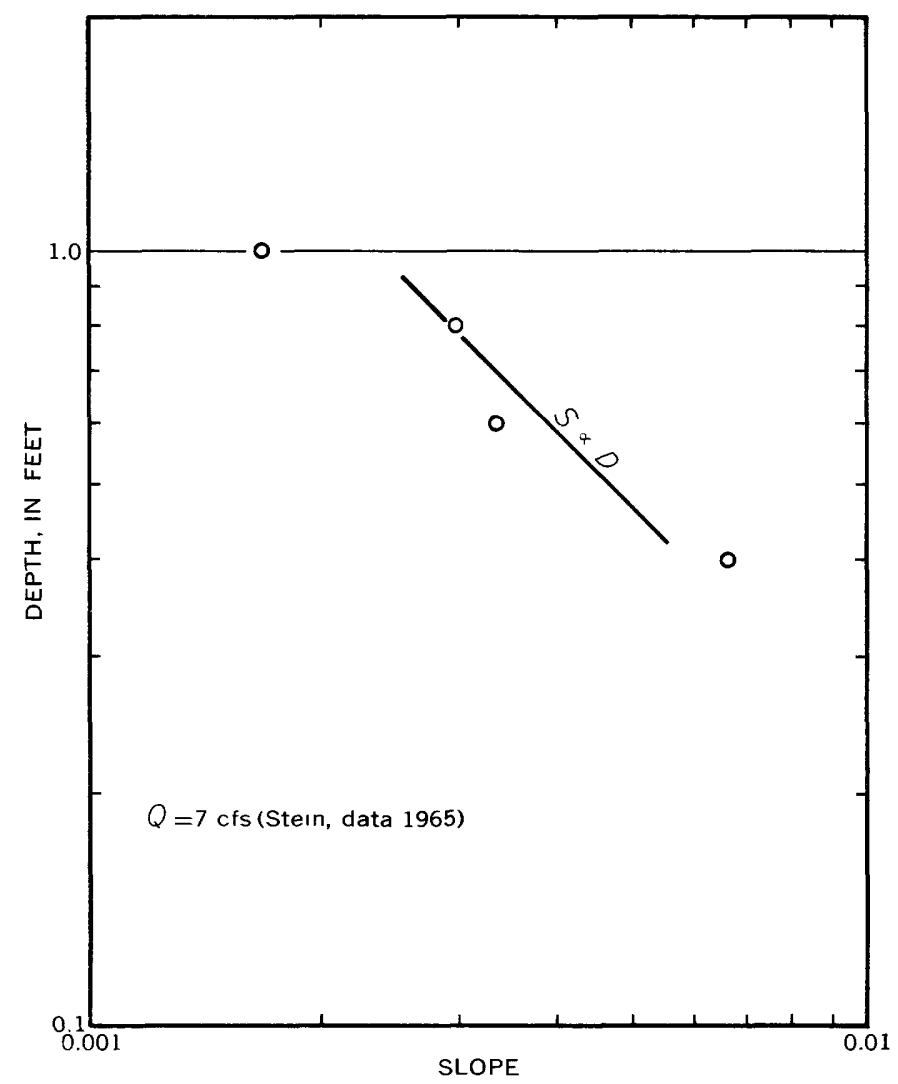

Figure 40.-Relation between depth and slope at constant discharge. the relation can be determined from figure $39 A, B$, and $C$.

Further information on the behavior of channels at constant depth is shown in figure 41 . Sirzons and Richardson (in Guy, Sinıons, and Richardson, 1966) studied a $0.33-\mathrm{num}$ uniform sediment and a nixture having a nuedian dianeter of $0.30 \mathrm{num}$ under a flow of about 0.5 -foot depth in a 2 -foot flune. As shown in figure 41 , there is a considerable difference in the behavior. The uniforn nuaterial acts in the same way as a coarser sand in the 8-foot flume (fig. $38 D$ ). However, the sedinent nixture shows the expected relation that would result if discharge and slope were independent variables and velocity, depth, and load were dependent variables. At least part of the variation in behavior is due to the differences in the way the flunie was operated. Note that for values of $q S$ of 0.0042 and 0.0043 , the uniform sand gave velocities of 2.57 and $3.43 \mathrm{fps}$. This would be expected if the flune were actually operated with depth as an independent variable. Because the record of the flune operations during the different runs is not clear, the actual difference between stream behavior with uniform nıaterial and nixtures will be unclear.

Guy, Rathbun, and Richardson (1966) made studies on a $d_{50}=0.30-\mathrm{mm}$ sand in a flune $20 \mathrm{~cm}$ wide. The results are shown in figure 41 along with date. from the 2 -foot flunie. The studies were nuade to deternine if there was any difference in the behavior of recirculating flunes and behavior of flunies in which the sediment load was introduced by a sand feed system. Their conclusion was that either systen gave the same results because their data so indicated.

Unfortunately the Guy, Rathbun, and Richardson recirculating flume was operated differently fron other recirculating flumes. In other flumes the sediment load was deternined by sampling the water-sediment mixture, measuring the concentration of the sediment, and computing the sedinent discharge as the product of the sedinient concentration and water discharge. Guy, Rathbun, and Richardson trapped all of the sediment leaving the end of the flune during a measuring period. During this tine sand was fed into the flume at an estimated rate. During a critical period of operation the so-called recirculating flume was operating under a feed system for about one-half the tine.

In fact, the recirculating flume probably never behaved like anything other than one with a sand feed systen- - as the data indicate - sinuply becaus? the feed systen was doninant. Nevertheless there is one other possibility that bears investigation.

Given the relation

$$
\Phi\left(D, C, S, B_{f}\right)=0
$$




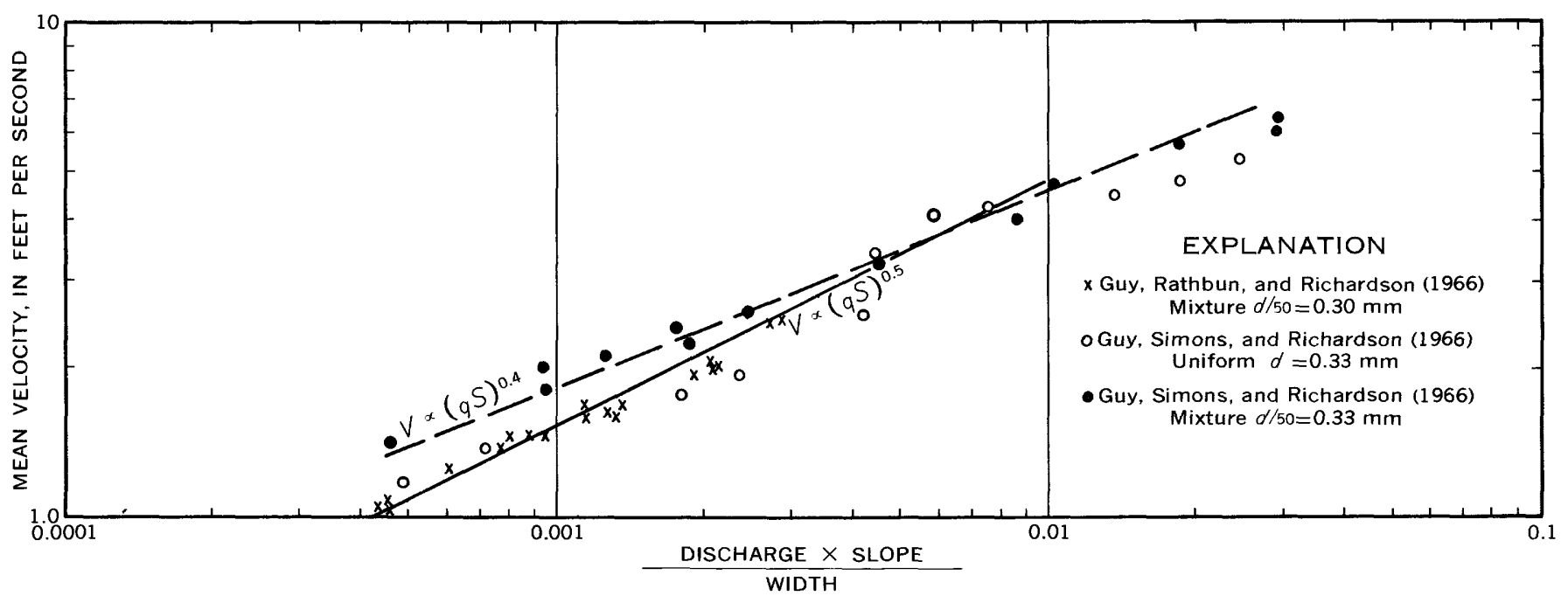

Figure 41.- Relation between mean velocity and $q S$ for uniform and mixed sediments of about 0.3 mm mean diameter in flume experiments. Depth is constant. Dashed line used so as not to obscure plotted points.

where $B_{f}$ is a bed form. It has been noted that given $D$ and $C$ as invariant independent variables, either the variance of the shear stress or the friction factor tends to be minimized, because under these conditions there is no variance of $D$ or $V$. But, if either by chance or by the method of flume operation, some perturbation should be introduced into $C$ so it is not invariant, then the variances of the shear stress and the friction factor in combination would be minimized. The situation would be as follows. Depth and concentration are independent variables. In addition $L \propto V^{\alpha} q^{J}$. Then $C \propto V^{\alpha+J-1} D^{J-1}$, and when $C$ is a constant $V \propto D^{\frac{-J-1}{\alpha+J-1}}$, and when $\mathrm{D}$ is a constant, $V \propto C^{\frac{1}{\alpha+J-1}}$. Let $S \propto D^{e} C^{h}$. Then when $D$ is constant, $S \propto C^{h}$, and when $C$ is constant, $S \propto D^{e}$. In accordance with the past procedures when $D$ is constant variance of the shear $\gamma D S$ is expressed as $h^{2}$ and the friction factor, $\gamma D S / \rho V^{2}$, as $\left(h-\frac{2}{\alpha+J-1}\right)^{2}$. Then the sums of the variances are minimized

$$
h^{2}+\left(h-\frac{2}{\alpha+J-1}\right)^{2} \longrightarrow \text { minimum. }
$$

The first derivative of the function is set equal to zero

or

$$
\begin{gathered}
2 h+2 h-\frac{4}{\alpha+J-1}=0, \\
h=\frac{1}{\alpha+J-1}
\end{gathered}
$$

$$
S \propto C^{\frac{1}{\alpha+J-1}}
$$

When $C$ is constant the variances of the shear stress and the friction factor can be expressed, respectively as $(1+e)^{2}$ and $\left(1+e+2^{\frac{J-1}{\alpha+J-1}}\right)$. Then the sums of the variances are minimized

$$
(e+1)^{2}+(e+1+2 \alpha)^{2} \longrightarrow \text { minimum. }
$$

The first derivative of the function is set equal to zero

$$
\begin{gathered}
2 e+2+2 e+2\left(1+2^{\frac{J-1}{\alpha+J-1}}\right)=0, \\
e=-1-\frac{J-1}{\alpha+J-1}
\end{gathered}
$$

and

$$
S \propto D^{-\left(1+\frac{J-1}{\alpha+J-1}\right)} \text {. }
$$

But $C \propto V^{\alpha+J-1} D^{J-1}$

hence,

$$
S=V^{\frac{\alpha+J-1}{\alpha+J-1}} D^{\frac{J-1}{\alpha+J-1}} D^{-1-\frac{J-1}{\alpha+J-1}}
$$

hence,

and

$$
S=V D^{-1}
$$

$$
V \propto D S \text {. }
$$

This is the relation found in the Guy, Rathbun, and Richardson experiments. The perturbation in load caused by a change from a recirculation system to a feed system or vice versa may have introduced a variance into $C$. This relation is offered to explain the $V \propto D S$ relation found when sand waves appear in recirculating flumes operated at constant depth such as in the Vanoni and Hwang experiments. Under these 
conditions the sediment discharge varies considerably with time.

The so-called transition between a "lower regime" and "upper regime" seems to be directly associated with a recirculating flume that, during each run, is operated at a constant depth. Because there is a natural tendency to operate any recirculating flume in this manner, all recirculating flumes tend to have this transition.

Because the sediment discharge for a unit width of channel may be approximated by the product of the average height of the bed form and its velocity and because the load of a stream is associated with its mean velocity, the height of the dunes and the dune velocity also must be associated with the mean velocity. The spacing of the bed forms, which is essentially unrelated to the load, has a marked effect on the friction factor. Therefore, if the friction factor remains constant in a recirculating flume operated at constant depth, there appears to be one specific but undescribable relation by which dune height, dune velocity, and dune spacing are linked with velocity and slope. One of the elements of this relation seems to be an increase in dune height with increasing discharge. Because this means an increase in the dune height-depth ratio, which normally would result in an increase in the friction factor, dune spacing and dune velocity must be modified to make up for the increased dune height.

When the bed forms have reached the maximum height possible for a given depth of flow, further increases in discharge, with a consequent increase in velocity and load, require that the increased load be taken care of by a rapid increase in the velocity of the bed form relative to the mean velocity of the stream. In this phase of the behavior of a recirculating flume operated at constant depth, the constraint of constant friction factor ceases and the flume operates under the constraint of constant shear stress. The bed forms move faster and the spacing between them increases. Finally there is a reduction in the height of the bed forms so they appear to "wash out." The bed then becomes smooth. With further increase in discharge this phase is succeeded by another wave form-antidunes-and the value of the shear stress no longer approaches a constant.

In conclusion, at least two items determine the friction factor for a given depth of flow: the slope and the sediment concentration. Were the data available, the friction factor of a stream probably could be related to the slope, dune height, dune spacing, and dune velocity. The complexity of such a procedure to determine the friction factor of a stream leaves nothing to recommend it. The idea that given a characteristic sediment for a single depth and single slope there is but one velocity and one load must be flatly rejected. Neither are there two velocities and two loads. The interrelations among velocity, depth, load, and slope are mutually determined under a specific $\mathrm{se}^{+}$of constraints. There are no unique relations, even among velocity, unit discharge, and load. The arerage or most probable condition is the best that can bo defined.

SUMMARY OF SLOPE AS AN ELEMENT IN STREAM BEHAVIOR

The statement that

$$
V=\Phi\left(D, S, d, \sigma, \rho, g, w, \rho_{s}, \mu\right)
$$

is frequently made, but it is incorrect if it implies a continuous unique relationship. Equally incorrect is the statement that given an identical cross section and identical sediment characteristics, a steady two-phase flow phenomenon is unequivocally defined if the values of $\nu, \rho, D, \rho_{s}, d, S$, and $g$ are all stated. Neither is it possible to substitute bed form for one of the variables in equation 45.

A more precise statement of the variables involved is

$$
\begin{array}{r}
\Phi\left[Q, Q_{s}, S, D, V, W, C, d, w, \sigma, g, \nu, \rho, \rho_{s}, B_{f},\right. \\
\left.S_{c}, S_{p}, S_{f}\right]=0,
\end{array}
$$

where $Q_{s}$ is the total sediment load of the stream, $\sigma$ is a measure of the size composition of the sediment, $\rho_{s}$ is the density of the sediment, $B_{f}$ is a bet form or bed configuration, $S_{c}$ is a shape factor of the chennel cross section, $S_{p}$ is a shape factor for the sediment particles, and $S_{f}$ is a sorting factor which describes that portion of the sediment concentration actually effective in determining the characteristics of the channel.

Given a specific fluid, a specific sediment mixture, and a specific temperature, then $d, w, \sigma, \nu, \rho, \rho_{s}, S_{p}$, and $S_{f}$ are all constant as is the acceleration of gravity. If two-dimensional flow or flow in a fixed width flume is to be studied, $W$ is constant. This leaves

$$
\Phi\left[Q, Q_{s}, S, D, V, C, B_{f}, S_{c}\right]=0 .
$$

There are fundamental relations among these variables.

$$
Q / W=V D, Q_{s} / W=L, Q_{s} / Q=C, q=V D, L=q C
$$

which are generally recognized. In addition th 9 relation

$$
L \propto S_{c} V^{\alpha} q^{j}
$$

is equally deterministic. If two-dimensional flow prevails or if velocity distributions are essentially symmetrical about the centerline of the channel, $\Sigma_{c}$ may be ignored. Consequently equation $45 \mathrm{~b}$ reduces to three basic relations 


$$
\begin{aligned}
& \Phi\left[q, L, S, B_{f}\right]=0 \\
& \Phi\left[D, C, S, B_{f}\right]=0 \\
& \Phi\left[q, D, S, B_{f}\right]=0 .
\end{aligned}
$$

For all practical purposes, equations $45 \mathrm{~d}$ and $45 \mathrm{e}$ are alike. In each of these equations $q$ and $L$ are defined and consequently are linked. One cannot be changed without changing the other. In equation 45c, $q$ and $L$ are independent of each other. Consequently, equation $45 \mathrm{c}$ represents a less constrained situation than do the $45 \mathrm{~d}$ and $\mathrm{e}$.

If the first two variables in each of the equations are independent, then $V, D, C, q$, and $L$ or $Q$ and $Q_{S}$ are all determined; experiment will yield consistent relations between $V, D, C$, and $S$ because natural constraints prevail. The relations of equations $45 \mathrm{~d}$ and $45 \mathrm{e}$ are the same but differ from those of equation 45c. Selection of different independent variables and different constraints yield different relations as has been previously discussed.

Nothing in these relations indicates the nature of the bed forms. All that is secured is a number representing a kind of flow behavior. It is known, of course, that this number can vary only within relatively narrow limits. Nevertheless this variation is the key to the behavior of streams with movable beds.

If, as it frequently is in natural streams, sediment discharge is an independent variable, the bed form and the sediment load must be congruent. This automatically results if discharge is the other independent variable. If sediment load is a dependent variable in a flume, bed form may be substituted only if there is, in addition, a precise statement on how the flume is to be operated.

If unit discharge and load are independent variables, the response to change will be dependent spon whether slope is free to vary or whether it is fixed. If it is free to vary, $V$ and $D$ will be dependent on load, and $S$ will be a dependent variable. The constraint is the minimization of the shear stress and the friction factor in combination. If slope is not free to vary, $V$ and $D$ will be dependent on load to the extent that the bed forms can be changed to provide the necessary friction factor. If this is not possible channel instability results.

If unit discharge and slope are independent variables and load is a dependent variable, the response to change will be dependent on the size and construction of the flume and the method of operation. If the variation in concentration is resisted by the flume, change in slope has a small influence, and change in unit discharge will have a large influence. If the slope is held constant and the depth is permitted to vary and there is no resistance to change in concentration, then the con- straints will be the minimization, jointly, of the variances of the shear stress and the friction factor.

If discharge and depth are independent variabless and $q S$ is in excess of a specific amount related to grain size, within the range of change in roughness due to bed forms, slope will be constant.

Much of what has been considered to be functional relations among the hydraulic variables of flow in alluvial channels is simply the operation of different constraints. Too often the constraints have been flume size, discharge, and method of operation. The result is that any supposedly functional relation involving slope is suspect, and this includes both velocity and sediment load, unless the applicable constraints are known. Much about the variation of flow in alluvial channels is unstudied and unknown. In fact, it is probably a good guess that a great deal of variation is wholly unobserved. Consequently, if the character of an alluvial channel is dependent on the minimization of various unknown parameters, the controls over particular or local conditions have not even been touched by th is report.

A consistent relation between discharge and load develops in many natural streams. Under these conditions, it is possible to find consistent relations among discharge, slope, and depth (figs. 22, 23, and 41). But if the relation between discharge and load is not consistent, neither are the relations among discharge, slor ${ }^{\circ}$, and depth. The results of inconsistency are generally found in the discontinuous rating curves of Dawdy (1961) or of Culbertson and Dawdy (1964) and in the shifting controls at gaging stations on alluvial streams. The variation in the velocity-depth relations with changing sediment loads was demonstrated by Leopold and Maddock (1953a, b).

The great difference between a river and a flume is that in a river all natural actions at a single point on its course tend to minimize the variance of slope. In a flume, the variation in slope is minimized only und r certain conditions. Consequently, the effects of varying discharges and loads with slope constant are readily observed in natural streams or even canals, but rot in flumes.

It would appear that, at least with our present knowledge of changing roughness caused by changing bed forms, the only parameters defining velocity with any degree of accuracy are load and unit discharge. Slope becomes redundant. At the present time, we consider slope allied to width and to channel behavior. If load and discharge are independent variables (and they usually are) either equation 18 or equation 42 may be used to determine slope if the coefficient is subject to change. For average conditions use the coefficients shown in equations 18 and 42 . If a tenden'y 
toward aggradation is desired, increase the coefficient; decrease the coefficient for degradation. Changes in the coefficient, however, must conform to the observed ranges for the particular sediment mixture. It is doubtful if the average coefficients are satisfactory for flows with high Froude numbers and where much energy is dissipated by wave action. Neither are they satisfactory for three-dimensional flow, which also increases the rate of expenditure of energy. Under both these conditions, coefficients should be decreased. However, little information is available on such conditions.

\section{THREE-DIMENSIONAL FLOW}

The presentations made thus far have been in terms of unit discharges of water and sediment-that is, in rates per foot of width. The variables, therefore, have been velocity, depth, slope, and load. Channels, particularly those that are self-formed, have a relation between discharge and width or between slope and width, as well as between discharge and the other variables that have been noted.

The introduction of the width term brings up a number of problems that have not been discussed heretofore, particularly the stable channel problem, which is generally associated with the maintenance of channel banks. Channel width is also associated with meandering. Meandering, as such, will not be discussed, as the subject is restricted to straight channels. Nevertheless, the three-dimensional bed forms that lead to meandering also are related to the stable channel problem and must be considered.

Width may be an independent variable, but obviously if a selected width is one that would be developed by a self-formed channel having the same discharge, slope, and load, a high degree of channel stability may result. Thus, it is important to determine the role of width as a dependent variable. However, given a discharge, width, slope, and load, the characteristics of a channel are fixed-no freedom is left-consequently, the effect of the relaxation of one variable on all the other variables must be determined.

In discussing three-dimensional flow, cross-channel or helicoidal flow will not be considered as such. The presence of such flows will be accepted as being related to bed forms and the way in which a stream spends its energy.

In this part of the report, width will be considered first as an independent variable and then as a dependent variable. The first consideration is rather simple, but the second is complex in that the effects of sediment concentration and sediment size are important. A basis for the development of the Lacey (1946) equations will be given for streams transporting sediment. Another "regime" equation will be developed for streams with beds of infrequently moved coarse material. Finally, the stable channel problem will be discussed with particular attention given to field observatiors.

\section{WIDTH AS AN INDEPENDENT VARIABLE}

In any stream a close relation exists betweon width and slope. This relation, quite ubiquitous, can be established by the procedure of minimizing the variance of the shear stress and the friction factor under the constraint of uniform sediment concentration.

The relation among velocity, discharge, and load in the mid-velocity range has been expressed in two equations: one for a sediment of uniform size and another for sediment mixtures. For a constant sediment concentration, the relations between velocity and depth become $V \propto D^{5 / 11}$ for the uniform sediment size and $V \propto D^{1 / 2}$ for the sediment mixture.

If width is an independent variable, velocit:r, depth, and slope can be written in terms of width so that $V \propto W^{m}, D \propto W^{\prime}, S \propto W^{z}$; then, if the stream discharge is constant, $V W D=Q=$ constant, and $m+f+1=0$. For sediment of uniform size $m=5 / 11 f$. Then, $f=-11 / 16$, $m=-5 / 16$, the variance of the shear stress equals $\left(z-\frac{11}{16}\right)^{2}$, and the variance of the friction factor equals $\left(z-\frac{11}{16}+\frac{10}{16}\right)^{2}$

Minimizing the combined variances

$$
z^{2}-\frac{11}{8} z+\left(\frac{11}{16}\right)^{2}+z^{2}-\frac{1}{8} z+\left(\frac{1}{16}\right)^{2} \rightarrow \text { minimum. }
$$

Setting the derivative equal to zero

$$
\begin{gathered}
4 z-\frac{12}{8}=0, \\
z=3 / 8,
\end{gathered}
$$

and

$$
S \propto W^{3 / 8} \text {. }
$$

If the operation is repeated for a sediment mixture,

whence,

$$
m=1 / 2 f, f=-2 / 3 \text {, and } m=-1 / 3 \text {, }
$$

$$
S \propto W^{1 / 3} .
$$

The same results can be achieved by equating equation 19 with equations 5 and 14 . For unigranular material the result is

$$
S=\left(\frac{A}{B}\right)^{2}\left(\frac{C}{10^{6}}\right)^{1 / 2}\left(\frac{\Delta \gamma d}{\rho w^{2}}\right)^{3 / 8}\left(\frac{\Delta \rho}{\rho}\right)^{1 / 2}(w g)^{1 / 8} d^{1 / 2}\left(\frac{W}{Q}\right)^{3 / 8},
$$

and for sediment mixtures

$$
S=\left(\frac{A_{1}}{B}\right)^{2}\left(\frac{C}{10^{6}}\right)^{2 / 3}\left(\frac{\Delta \gamma d}{\rho w^{2}}\right)^{1 / 4}\left(\frac{\Delta \gamma}{\gamma}\right)^{1 / 2} g^{1 / 6} d^{1 / 2}\left(\frac{W}{Q}\right)^{1 / 3},
$$


or

$$
S \propto\left(\frac{A_{1}}{B}\right)^{2}\left(\frac{C}{10^{6}}\right)^{2 / 3} \frac{d^{3 / 4}}{w^{1 / 2}}\left(\frac{W}{Q}\right)^{1 / 3},
$$

in which $A$ and $A_{1}$ are the coefficients of equations 5 and 14, respectively, and $B$ is the coefficient of equation 19. $C$ is the concentration of sediment in parts per million. There is little variation in the values of $A$ and $A_{1}$ as long as the flow is two dimensional. A change is to be expected, however, under three-dimensional flow-that is, when the thread of the main current swings back and forth across the stream. The coefficient $B$ represents an index of bed deformation and, therefore, its variation has a maximum of about three times at high discharges and wide channels but has a very small variation at small discharges and narrow channels.

Equations 49 and 50 should be compared with equation 45. A function of $V$ and $D$ can be substituted for $C$, and $Q$ may be divided by $W$, yielding $V D$. Then

$$
S=\Phi\left(\frac{A_{1}}{B}, V, D, \Delta \rho, \rho, g, d, w\right) .
$$

The difference between equation 51 and equation 45 is the inclusion of $A_{1} / B$ and the elimination of the viscosity and size variation, $\sigma$. The resolution of the effect of sediment mixtures requires two equations. The influence of the viscosity and the shape of the sediment particle appears in the fall velocity, $w$. As neither $A$, $A_{1}$, or $B$ vary greatly in very small flumes with small discharges, the premises of equation 45 may be satisfactory under such conditions. But in natural streams and in larger flumes, these coefficients are indispensable and must be included, as shown in equation 51 .

If both sides of equation 50 are multiplied by $Q$, the result is

$$
Q S=\left(\frac{A_{1}}{B}\right)^{2} Q s^{2 / 3}\left(\frac{\Delta \gamma d}{\rho w^{2}}\right)^{1 / 4}\left(\frac{\Delta \gamma}{\gamma}\right)^{1 / 2} g^{1 / 6} d^{1 / 2} W^{1 / 3},
$$

where $Q s$ is the total sediment discharge of the stream. This should be compared with Rubey's (1952, p. 132) equation

$$
Q^{2 / 3} S=K_{1} \frac{Q s^{2 / 3} d^{1 / 3}}{\left(X_{A}\right)^{1 / 3}}
$$

in which $K_{1}$ is a constant and $X_{A}$ is an optimum form ratio $D / W$. Rubey was trying to express what would now be considered a "regime" relation, but the correspondence between equations 52 and 53 is evident. The relation proposed by Lane (1955), QS $\propto Q_{s} d$, must be considered as nothing more than a general statement of behavior that has been recognized for some time. That is, streams moving coarse material or high sediment loads flow on the steepest slopes.
The appearance of the term $\Delta \gamma d / \rho w^{2}$ in equations 49 and 50 complicates the effect of size of materiel; for coarse material this term is a constant. The terns $\Delta \gamma d / \rho w^{2}\left(d^{4 / 3}\right)$ or $\left(\Delta \gamma d / \rho w^{2}\right)\left(d^{2}\right)$ have a small variation in the sand size, but each becomes larger for material both larger and smaller than this size. There is a lower limit to the size to which these relations are $\operatorname{app}^{\mathbf{l}} \mathrm{i}$ cable, because very small particles become coherert.

Two examples of field behavior will be given. Tvro sections of the rectified channel of the Rio Grande near Vinton, Tex., are a short distance apart. Both sections are tangents of more than 1,000 feet long, but one is 100 feet wide and the other 200 feet wide, and each carries the same discharge of water and sediment. Both are very stable and have no maintenance problems. The relation between width and slope is shown in figure 42 and confirms equations 47 and 48 .

A second example is taken from Rubey (1952, p. 126). Rubey stated that the Illinois River in flowing around islands in its channel increases its total width at bank full stage by about 16 percent. The material on

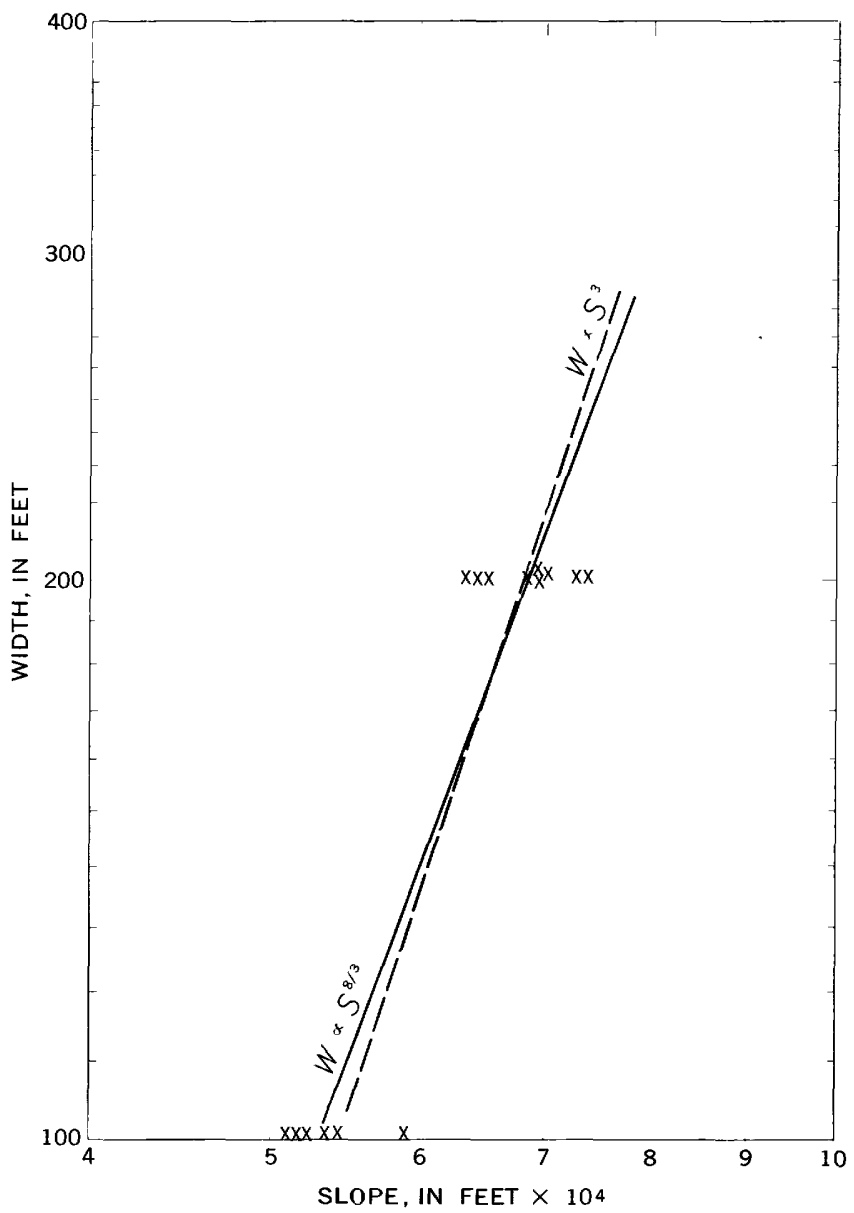

Figure 42.- - Relation between width and slope, the $R$;? Grande near Vinton, Tex. Solid line, equation 47; dashed line equation 48. (T. Maddock, Jr., unpub. data.) 
the bed is a fine uniform sand. As discharge and sediment concentration are the same, equation 47 is applied, $V \propto W^{-5 / 16}, D \propto W^{-11 / 16}$, and $S \propto W^{3 / 8}$. Then the changes expected would be a decrease of 4.7 percent in $V$, a decrease of 11 percent in $D$, and an increase of 6.1 percent in slope. Rubey stated that the depth decreased about 10 percent, that the mean velocity decreased about 4 percent, and that the slope was difficult to determine but increased between 5 and 10 percent.

The relations used in the Rio Grande and Illinois River examples when combined yield $g D S / V^{2} \propto W^{5 / 16}$, when concentration and discharge are constant. Blench (1966) stated that $V^{2} / g D S=3.63(V W / \nu)^{1 / 4}$. Insofar as width is concerned, this is precisely opposite the relation found in the two examples. We conclude that the Blench equation is of very limited application and should be used only in a specialized situation.

Slope, width, and the coefficients $A$ and $B$ from either equation 49 or 50 can remain unchanged if a specific relation exists between $C$ and $Q$. For equation 49 this is $C \propto Q^{3 / 4}$ and for equation $50, C \propto Q^{1 / 2}$. In terms of sediment discharge this is $Q_{s} \propto Q^{7 / 4}$ for equation 49 and $Q_{s} \propto Q^{3 / 2}$ for equation 50. Such relations are commonly observed in straight-walled channels moving heavy sediment loads.

Two other relations may be developed using the lowvelocity range equations for large and small sized sediments in combination with equation 19 . The first is for when the bed material is coarse, $\Delta \gamma d / \rho w^{2}$ is constant, and the sediment moves at just about bank full stage. The equation is

or

$$
S=\left(\frac{A_{2}}{B}\right)^{2}\left(\frac{\Delta \gamma}{\gamma}\right)^{7 / 6}\left(\frac{W}{Q}\right)^{7 / 9} g^{7 / 18} d^{7 / 6}\left(\frac{\Delta \gamma d}{\rho w^{2}}\right)^{1 / 4}
$$

$$
S \propto\left(\frac{A_{2}}{\bar{B}}\right)^{2}\left(\frac{W}{Q}\right)^{7 / 9} d^{7 / 6} ;
$$

$A_{2}$ is the coefficient of equation 7 when concentration is zero. When the size of material is small and the sediment concentration is greater than about7.5 $\left(\rho w^{2} / \Delta \gamma d\right)^{3 / 2}$, the combination of the two equations is essentially

$$
S=\left(\frac{A_{3}}{B}\right)^{2}\left(\frac{\Delta \gamma}{\gamma}\right)^{3 / 2} \frac{g^{13 / 18} d^{3 / 2}}{w^{2 / 3}}\left(\frac{\Delta \gamma d}{\rho w^{2}}\right)^{1 / 4}\left(\frac{W}{Q}\right)^{7 / 9}\left(\frac{C}{10^{6}}\right)^{2 / 9},
$$

or

$$
S \propto\left(\frac{A_{3}}{B}\right)^{2}\left(\frac{d^{1 / 2}}{w^{1 / 3}}\right)^{7 / 2}\left(\frac{W}{Q}\right)^{7 / 9} C^{2 / 9} .
$$

$A_{3}$ is the coefficient of equation 7 under the specified sediment concentration.

If equations 50, 54, and 55 are compared, it will be seen that for a given unit discharge and a given value of $A / B$, slope is greatly affected by size at the beginning of motion, but this effect decreases with increasing sediment concentration. In the mid-velocity range slope is more responsive to sediment concentration than to sediment size.

The size parameter, once sediment begins to move, is $w^{1 / 4} / d^{3 / 8}$. As shown in figure 25 , this parameter has a maximum value at about $0.23 \mathrm{~mm}$ and increases with both increasing and decreasing sediment size. For the same sediment concentration and the same slope, a channel moving $0.25 \mathrm{~mm}$ sediment would have a width, according to equation 55 , about 45 percent greq.ter than a channel moving $0.05 \mathrm{~mm}$ sediment.

Inglis (1949) reported, in accord with such a relation, that in the Sind of Pakistan canels move sediment much smaller in size and in concontration and, as a consequence, the canals are as much as $\mathbf{5 0}$ percent narrower and are also flatter than those in the Punjab. As would be expected from equation 50, canals in the Imperial Valley of California moving heavy sediment loads are narrower than the canals in Pakistan and, as also expected, flow at higher relocities.

\section{WIDTH AS A DEPENDENT VARIABLE}

If, in a natural stream or canal, the water and sediment discharge were constant, there would be no alluvial channel problem. From equation 50, given a discharge and an unchanging size composition of sediment,

$$
S \propto\left(\frac{A}{B}\right)^{2}\left(\frac{C}{10^{6}}\right)^{2 / 3} W^{1 / 3} .
$$

The constraints are (1) a limited range in the coefficient $B,(2)$ an even more limited rance in the coefficient $A_{1}$, (3) a maximum velocity limited by the size of the sediment, (4) a minimum velocity representing the lower limit of the mid-velocity range, and (5) an undefined constraint that when a stream becomes so wide and steep it will either break up into a series of channels or will meander. The last two conditions result when sediment is no longer moved over the bed with some degree of uniformity. ?herefore, the relation between $S$ and $W$ is limited, and, more importantly, $A_{1}$ and $B$ are not completely incependent of some combinations of $W$ and $S$. Width is not a completely independent variable but has to baar some relation to discharge.

The possible combinations of equation 54 yield an equal number of differing characteristic flow patterns. Those patterns that are stable tend to persist; those that are unstable tend to disappear. Therefore, the geometry of a stream system represents a sort of "survival of the fittest," which appears to be a constraint on equation 56.

The effect of changing width is to change the way a stream consumes its energy. For example, from equa- 
tion 50, if discharge and sediment concentration are constant

and

$$
Q S \propto W^{1 / 3},
$$

$$
q S \propto W^{-2 / 3} .
$$

Thus, there is a considerable difference in the relative rates of expenditure of energy per unit of length and per unit of bed area with a simple change in width. This redistribution in the method of energy dissipation is brought about by changes in bed forms.

The hypothesis is made that those persistent patterns that are observed in natural streams, which may be called a "regime," are the result of similar behavior with respect to rate of energy dissipation. Therefore, a "regime" is defined as a set of relations among width, depth, velocity, and slope that exists when the variance of different rates of internal energy expenditure jointly are minimized under a constant or specified sediment concentration.

If width, depth, velocity, and slope are expressed in terms of the total discharge instead of the unit discharge, $W \propto Q^{b}, V \propto Q^{m}, D \propto Q^{f}$, and $S \propto Q^{z}$. If sediment concentration is constant, from equation $14, m=1 / 2 f$. As before, jointly minimizing the variance of the shear stress and the friction factor,

$$
\begin{gathered}
(f+z)^{2}+(f+z-f)^{2} \rightarrow \text { minimum, } \\
f^{2}+2 f z+z^{2}+z^{2} \rightarrow \text { minimum. }
\end{gathered}
$$

Differentiating with respect to $z$ and setting equal to zero,

$$
\begin{gathered}
2 f+2 z+2 z=0, \\
z=-1 / 2 f .
\end{gathered}
$$

Langbein (1965) listed five aspects of rates of energy expenditure or stream power. Three of these can be expressed in terms of width, discharge, and slope. They are (1) power per unit length per unit discharge or $S$, (2) power per unit of area of channel bed or $q S$, and (3) power per unit length of channel or QS. The variances of the three different stream powers are, respectively, $z^{2},(m+f+z)^{2}$, and $(1+z)^{2}$. These variances are now written in terms of $f$ and are jointly minimized. Thus,

$$
(-1 / 2 f)^{2}+f^{2}+(1-1 / 2 f)^{2} \rightarrow \text { minimum. }
$$

Expanding and setting the derivative equal to zero

$$
3 f=1 \text { or } f=1 / 3 \text {. }
$$

From the other relations $m=1 / 6, \quad b=1 / 2$, and $z=-1 / 6$. Thus, there is a set of regime equations, in which

$$
\begin{aligned}
& V \propto Q^{1 / 6}, \\
& W \propto Q^{1 / 2}, \\
& D \propto Q^{1 / 3}, \\
& S \propto Q^{-1 / 6} .
\end{aligned}
$$

These are the well-known Lacey relations.

As it was stated that a "regime" equation would exist for a specified as well as a constant sedimert concentration, a set of "regime" equations may ke written if concentration is some function of stream discharge, such as $C \propto Q^{x}$. Then, $V \propto(Q C / W)^{1 / 3}$ from equation 14 and $C \propto Q^{x}$; then,

$$
V \propto\left[{\frac{Q^{1+x}}{W}}^{1 / 3} D \propto\left[{\frac{Q}{W^{2}}}^{2-x}\right]^{1 / 3}\right.
$$

Substituting these values into equation 19 , the result is

$$
S \propto W^{1 / 3} Q^{\frac{2 x-1}{3}} .
$$

Now the combined variances of the three kinds of stream power are minimized, writing $S, V$, and $D$ in terms of the variables $Q$ and the unknown $W$. Then,

$$
W \propto Q^{1 / 2} .
$$

Thus, what can be called the generalized Lacey equations can be written when concentration varies with discharge to some power.

These are

$$
\begin{array}{r}
W \propto Q^{1 / 2}, \\
V \propto Q^{\frac{1+2 x}{6}}, \\
D \propto Q^{\frac{1-x}{3}}, \\
S \propto Q^{\frac{-1+4 x}{6}} .
\end{array}
$$

Note that the $W \propto Q^{1 / 2}$ relation is independent of the change in load with discharge. The only requirements are that $V^{2} \propto D C$ and $V \propto D S$.

The Lacey (1946) equations were developed from equation 14 for a mixture of sediment sizes. A con1parable set of equations may be secured for a uniform grained material by using equation 5 . These are

$$
\begin{aligned}
& W \propto Q^{0.45} \\
& V \propto Q^{0.17}, \\
& D \propto Q^{0.38} \\
& S \propto Q^{-0.21},
\end{aligned}
$$

and a set of generalized equations also could be developed. However, the Lacey equations have been in existence for a long time, and a considerable amount of information regarding their use is available. Conse- 
quently, it does not seem advisable to propose another set of equations that give essentially the same results unless the pertinent sediment sizes are outside the limit of applicability of equation 14. Again, it is desirable to review the limitations of the Lacey equations in accordance with the manner of their derivation.

Slope is a dependent variable. For every change in discharge, slope is expected to change. This is important to geomorphologists and others who are concerned about misfit or relic streams flowing in valleys obviously formed by a larger stream in some previous geologic time. If slope is constant and if stream discharge is to be estimated from some value of width, equation 49 must be used. Thus, $Q$ is proportional to $W$ and not $Q$ proportional to $W^{2}$ as stated in the Lacey relations or those noted for natural streams by Leopold and Maddock (1953a).

The velocity-load relation used in the derivation applies to sediment mixtures in the mid-velocity range only. Although a "regime" equation could be derived for the low-velocity range, this is usually not of importance except for zero sediment transport. Nevertheless, the use of equation 47 or others of the same form may yield velocities too high for very large canals or velocities too low for small canals or small concentrations of sediment. Whether or not velocity is too high will be dependent upon the magnitude of the largest size found in appreciable quantities in the sediment mixture.

As long as the sediment is in the sand range and the flow is in the mid-velocity range, the influence of size of sediment is minimal. When sizes in the range of $\Delta \gamma d / \rho w^{2}$ are constant or sizes less than about $0.10 \mathrm{~mm}$ are involved, size cannot be eliminated from consideration, and equation 5 should be chosen in place of the Lacey equations.

If equations 57 or 58 are written in the form $W=a Q^{1 / 2}$, $D=c Q^{1 / 3}, V=k Q^{1 / 6}$, and $S=t Q^{-1 / 6}$, then certain relations may be established. Because $V^{2} / D=A_{1}{ }^{3} C$, then $k^{2} / c$ $=A_{1}{ }^{3} C$, or $k=A_{1}^{3 / 2} c^{1 / 2} C^{1 / 2}$. But $a c k=1$, so $c=1 / a^{2 / 3} C^{1 / 3} A_{1}$. There is also a built-in relation between $t$ and $a$. From equation 50 ,

$$
t Q^{-1 / 6}=\left[\frac{A_{1}}{B}\right]^{2}\left[\frac{C}{10^{6}}\right]^{2 / 3}\left[\frac{\Delta \gamma}{\rho^{2}}\right]^{1 / 2} g^{1 / 6} d^{1 / 2}\left[\frac{a Q^{1 / 2}}{Q}\right]^{1 / 3},
$$

which for coarse sizes becomes

$$
\frac{t}{a^{1 / 3} C^{2 / 3}} \propto\left[\frac{A_{1}}{B}\right]^{2} d^{1 / 2}
$$

These relations will be discussed in more detail in the section on stable channels.

The Lacey equations apply only to streams in which the bed material is in general motion. The hydraulic roughness is controlled by the bed forms. The sediment load is an independent variable.

\section{SEDIMENT SIZE AS DEPENDENT OR INDEPENDENT VARTABLE}

In contrast to the Lacey regime channels, other streams flow over beds of material so coarse that there is general movement only at high discharges, usually about bank full stage. Thus, the size of the bed material controls the stream characteristics and another kind of "regime" exists.

Under such conditions, equation 54 applies. and

$$
\begin{gathered}
S \propto\left(\frac{W}{Q}\right)^{7 / 9} d^{7 / 6} \\
d \propto Q^{n}, \\
S=Q^{7 / 6 n-7 / 9} W^{7 / 9} .
\end{gathered}
$$$$
\text { if } d \propto Q^{n},
$$

Then, if $V \propto Q^{m}, D \propto Q^{s}, W \propto Q^{b}$, and $S \propto Q^{z}$, the following relation exists:

$$
m+f+b=1, z=7 / 6 n-7 / 9+7 / 9 b .
$$

From equation 7 ,

$V \propto(Q / W)^{1 / 9} Q^{n / 3}$, so $m=1 / 9+\frac{n}{3}-1 / 9 b$ and $f=8 / 9-\frac{n}{3}-8 / 9 b$.

Now, as was done previously, the variances of three stream powers $z^{2},(m+f+z)^{2}$, and $(1+z)^{2}$ are written in terms of $b$ and jointly minimized to find the values of $b, m, f$, and $z$. The result is

$$
\begin{aligned}
& W \propto Q^{0.382-1.008 n} \\
& V \propto Q^{0.069+0.445 n} \\
& D \propto Q^{0.549+0.563 n} \\
& S \propto Q^{-0.48+0.383 n}
\end{aligned}
$$

If size decreases downstream so that $d \propto O^{-1 / 10}$, the results are $W \propto Q^{0.483}, V \propto Q^{0.024}, D \propto Q^{0.493}$, and $S \propto Q^{-0.518}$, relations that approximate those frequently observed in the headwaters of some clear flowing streams. However, equation 60 is used if the size of the material in the stream bed is not a function of stream discharge, as shown by Hack (1957). If size is constant,

$$
W \propto Q^{0.382}, V \propto Q^{0.069}, D \propto Q^{0.549} \text {, and } S \propto Q^{-0.48} .
$$

If equation 54 is rearranged,

$$
W \propto\left[\frac{B}{A_{2}}\right]^{18 / 7} Q S^{9 / 7} d^{-3 / 2} .
$$

One of the criteria for the development of the "regime" relations of equation 60 was that the variance of the power, $Q S$, tends to be minimized-that is, $Q S$ approaches a constant and $Q \propto S^{-1}$. Then if $W / Q^{0.382}$ is a constant and $Q S$ approaches a constant, the relation $S^{0.668} \propto d^{1.5}$ is approached, providing, of course, that $B / A$ is a constant. This relation may be expressed as $S \propto d^{2.25}$. 
Wolman (1955), in his study of Brandywine Creek, Pa., provided information that permits a test of the validity of such an analysis. Figure 43 shows the relation between width and discharge, slope and discharge, and slope and size of bed material. The agreement between the "regime" relation and that proposed by Wolman is clear. It must be remembered, however, that these relations are not unique, but they are statistically the most probable.

If the coefficients of the three relations are observed in the field, the whole system of "regime" equations may be developed with the use of equation 54 . In the Brandywine Creek basin these relations are

$$
\begin{aligned}
& W=4.6 Q^{0.383} \\
& S=2.6 Q^{-1} \\
& S=0.09 d^{2.25} \\
& V=10.3 Q^{-0.079} \\
& D=0.021 Q^{0.696}
\end{aligned}
$$

The relations of velocity and depth to discharg? from this set of equations are compared with Wolman's in figure 44. Velocity and discharge have the greatest variance because they represent conditions at a specific cross section, and the other relations are more applicable to reaches of a stream.
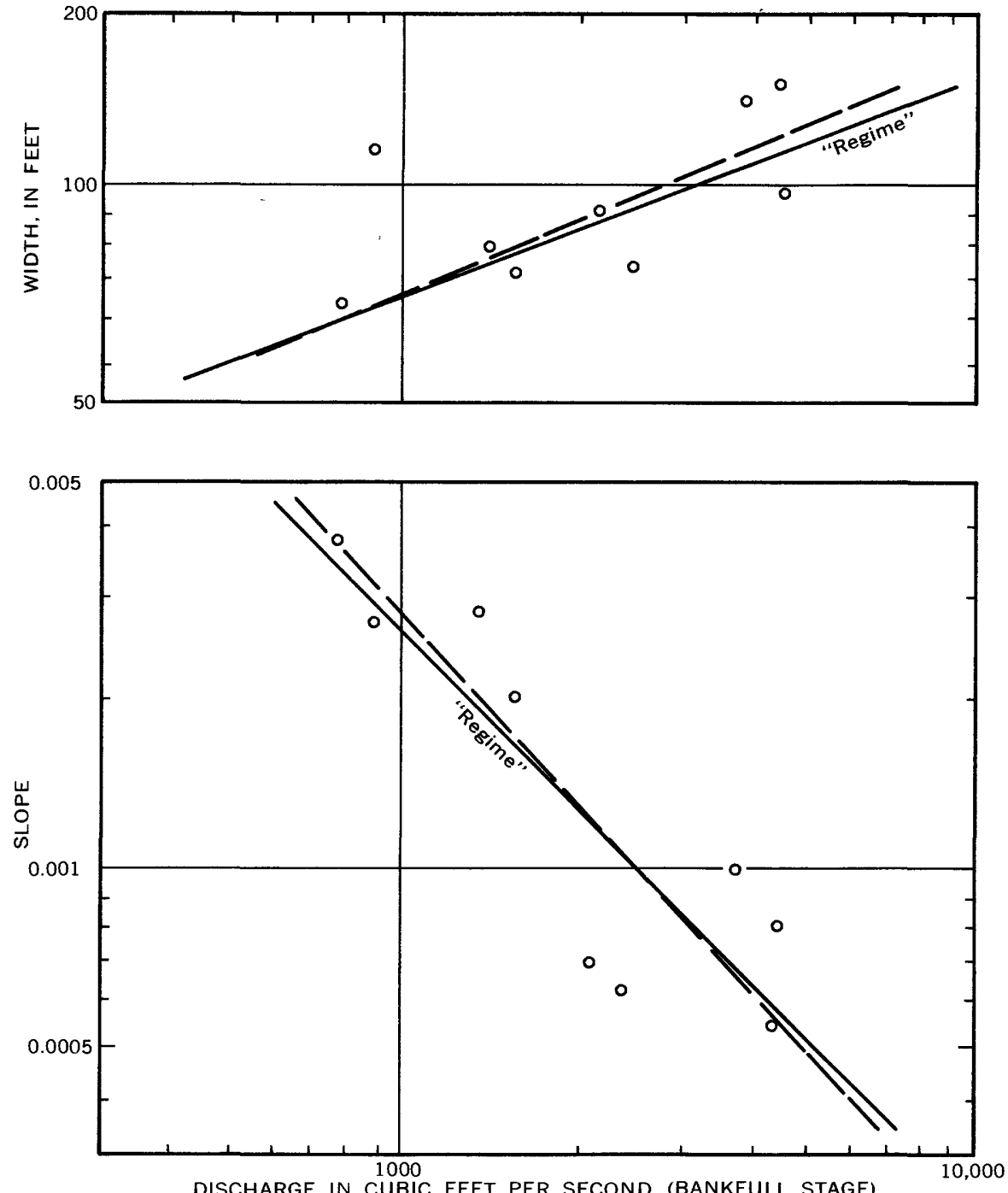

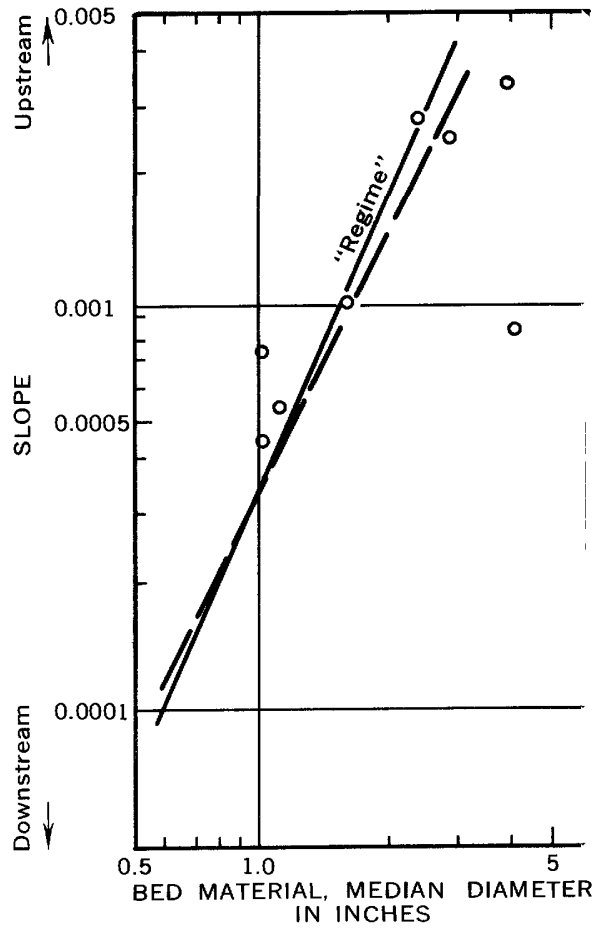

IN INCHES

FIGURE 43.-Variations of width and slope of the water surface with discharge and relation of slope of water surface to size of bed material, Brandywine Creek, Pa. Dashed lines, Wolman's (1955) relation; solid lines, "regime" relation. 

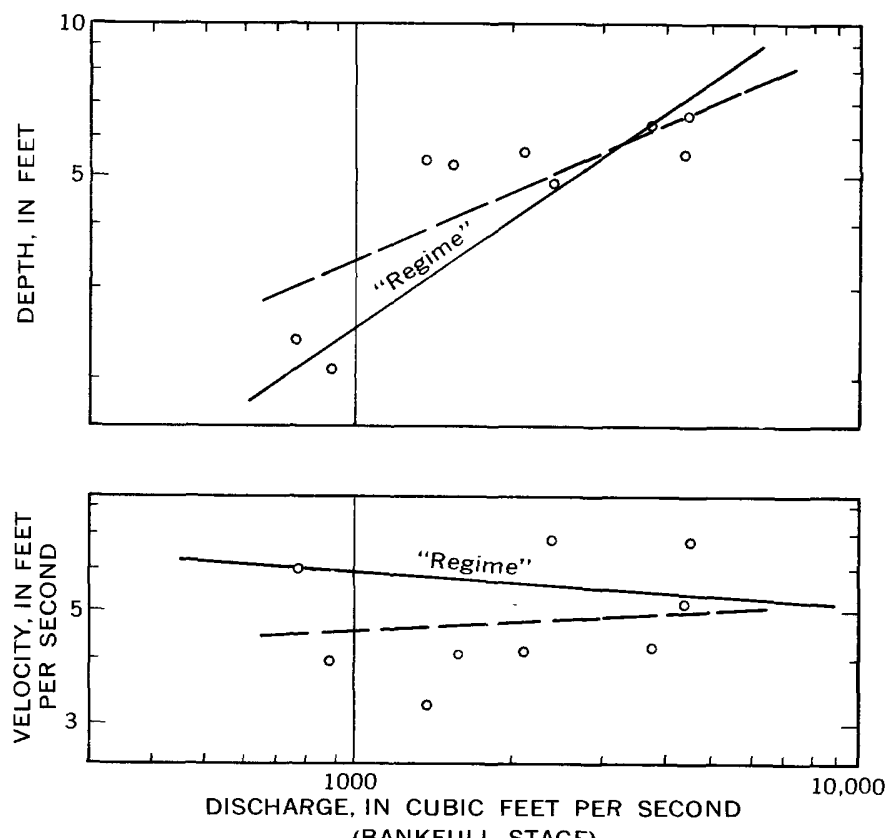
(BANKFULL STAGE)

Figure 44.-Variations of mean depth and mean velocity with discharge in the downstream direction at the bank full stage, Brandywine Creek, Pa. Dashed lines, Wolman's (1955) relation; solid lines, "regime" relation.

In this basin, discharge is a function of climate and drainage area and is, thus, truly independent. Slope to some extent is the result of stream adjustment; however, because slope is constrained by relief it too is, at least in part, an independent variable. Size of material is related to weathering and rock type and, hence, is related to climate and to geology. Nevertheless, it too is constrained by relief. Furthermore, the equations were developed with the premise that a specific relation between $S$ and $d$ existed such that $Q S$ was constant. This is not a usual situation.

The set of equations is, therefore, of limited application. Note that a stream having $1 \mathrm{cfs}$ flow would have a slope of 2.6 , be 4.6 feet wide and 0.021 foot deep, have a velocity of $10 \mathrm{fps}$, and move material with an average gain size of 4.5 feet, obviously an impossibility.

\section{SUMMARY OF WIDTH AS A DEPENDENT VARIABLE}

A discussion of widths of alluvial streams inevitably becomes a discussion of "regime" channels. The word "regime" has different connotations to different workers in the fields of channel behavior and sediment transport. In this paper, "regime" is defined as a set of relations among width, depth, velocity, and slope that exists when the variance of different rates of internal energy expenditure jointly are minimized under a constant or specified sediment concentration. "Regime" channels expend their energy in similar ways.
Because sediment load is an inherent element in channel behavior and because no single function can be used effectively to express the relation of the sediment load to other variables, no one set of "regime" equations is to be expected. Furthermore, even if a set of equations can be developed they are only the most probable relations and do not express a unique relatic 7 .

"Regime" channels must be free to make adjustments. The dependent variables - width, depth, velority, and slope--nust respond to changes in the independent variables - discharge, sediment concentration, and size of sediment in motion. Thus, all "regime" channels must have some movement, even if it is very small, of nearly all the sizes of sediment making up the material on the bed of the stream.

All dependent variables do not respond to changes in the independent variables with the same rapidity; hence, a "regime" channel usually reflects a long-term average condition. Furthermore, some variables, particularly slope but also sediment concentration and size of bed material, may not be wholly dependent or independent. Thus, in a way, "regime" conditions may actually be somewhat ephemeral. At best, they represent a mean condition about which all observed values of the hydraulic parameters tend to deviate. Thua, there is a distinction in this paper between "regime" channels and "stable" channels. This will be discussed in the next section because stability must be considered under conditions where constraints are such that denendency or nondependency of variables changes, either in place or in time.

\section{STABLE CHANNELS}

A stable channel, strictly speaking, would be one in which the bed and banks do not change. Such a channel requires constant discharges of water and sediment. Consequently, it would have to be an artificiel channel because such uniform conditions do not exist in nature. Most channels found in nature, and this includes canals that are called stable, are those whose banks are essentially fixed or change very slowly but whose beds may rise and fall with variable discharges and loads, about some unchanging equilibrium position. Such a channel is called a "regime" channel by Blench (1952). The set of relations that exists among a group of such channels, if any, is called a "regime" in this paper. Thus, stable channels may, in the broadest sense, be "regime" channels, but all "regime" channels may not be stable because their banks may not be fixed.

There are two basic types of stable channels. The first is one that transports no sediment; the bed material does not move during most discharges. The second is one in which both water and sediment are in motion, but the bed forms are such that no persistent thread of 
flow is directed against the banks. If sediment load and water discharge vary, channel scour and fill must be expected. How this can be accommodated with bank stability is the essence of the stable channel problem.

\section{GRAVEL CHANNELS}

An examination of the problems of stable channels may begin with a study of the conditions of no sediment loads. Most channels moving no sediment are armoredthat is, the material on the bed is an accumulation of coarse material left by stream sorting. If this is the situation, the slope is usually fixed. However, if the strean has a very small sediment load, the material on the bed may actually be in transit in some flows. Consequently, the slope may have been self-formed. Thus, two equations for slope are available, equations 19 and 35 . These two equations can be combined with equation 7 to yield, respectively, for zero concentration

$$
\begin{gathered}
\gamma D S=0.066(\gamma D)^{1 / 8}(\Delta \gamma d)^{7 / 8}\left(\frac{\Delta \gamma d}{\rho w^{2}}\right)^{1 / 4} \\
\gamma D S=0.025(\gamma D)^{3 / 16}(\Delta \gamma d)^{13 / 16}\left(\frac{\Delta \gamma d}{\rho w^{2}}\right)^{1 / 4}
\end{gathered}
$$

These equations may also be expressed as

$$
\frac{\gamma D S}{\Delta \gamma d}=0.066\left(\frac{\gamma D}{\Delta \gamma d}\right)^{1 / 8}\left(\frac{\Delta \gamma d}{\rho w^{2}}\right)^{1 / 4}
$$

and

$$
\frac{\gamma D S}{\Delta \gamma d}=0.025\left(\frac{\gamma D}{\Delta \gamma d}\right)^{3 / 16}\left(\frac{\Delta \gamma d}{\rho w^{2}}\right)^{1 / 4} .
$$

The much greater coefficient for equation 63 than for equation 64 would indicate that streams forming their own slopes are hydraulically rougher than those

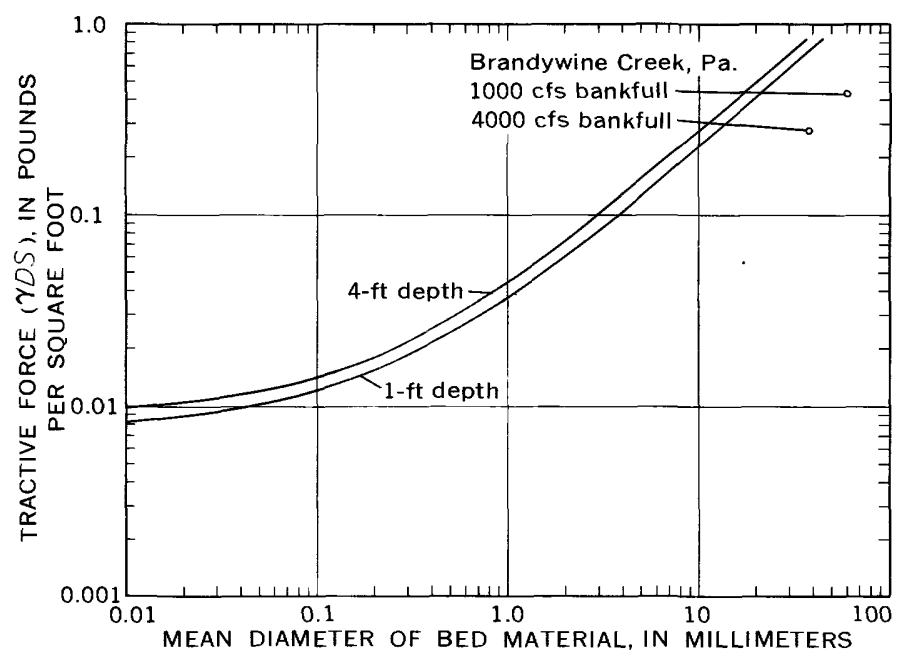

Figure 45.-Relation between tractive force and sediment size with slope a dependent variable. Lines are plots of equation 63 at depths indicated. Data for Brandywine Creek, Pa., from Wolman (1955). where slope is an independent variable. Graphs of equation 63 for depths of 1 and 4 feet are shown in figure 45. Also plotted are values from Wolman's (1955) data for Brandywine Creek, $\mathrm{Pa}$. This stream, presumably self-formed, has a much lower value of $\gamma D S$ at bankfull stage than indicated in the figure. However, the same graphs of equation 63 are shown in figure 46 taken from Lane (1955, p. 1253). The graphs of equation 63 fall within the broad limits of the recommendations of different authorities.

Graphs for 1 and 4 feet depths for equation 64 ar? shown in figure 47. Also plotted in the figure are data from the Bureau of Reclamation studies by Lane and Carlson (1953) on canals in the San Luis Valley, Colo. Other data are from Simons (1957). Data for canal: moving low sediment loads of finer material should b? compared with the graph showing relations between shear stress and mean grain size of sediment for a sediment concentration of $50 \mathrm{ppm}$ (parts per million).

Data presented herein show a wide variation in values of $\gamma D S$ for a given size of material. There are a number of reasons for this variation. Both a characteristic size of sediment and its fall velocity must b. determined; the average or median grain size may $b$, found in different ways. Wolman (1955) tried to measure the distribution of grain sizes actually exposed on the bed. The Lane and Carlson (1954) sizes are those for bed material, but how samples were taken is nct, stated. Lane (1955) sampled the composition of the materials through which the canals were constructed and designated the characteristic size as one of which 25 percent by weight of the materials was larger. The influence of the shape factor and the imbrication of the coarse material on the bed of the stream makes the settling velocity most difficult to determine. Finally, bed material may not move at bankfull stages, although some evidence indicates that it does.

The differences caused by measurement techniques are not enough to account for differences in the coeff cients of equations 63 and 64 . Variation in the value of the coefficients of equations 19, 35, and 7 must be the reason. Because it appears that the coefficient of equation 7 does not vary greatly, most of the variation must be found in the coefficients of equations 19 and 35 .

As was previously stated, the difference in the coefficients of equations 63 and 64 represents a change in the friction factor rather than a measure of shear at the beginning of motion because the movement of the sediment is related to the velocity. Note that equations 63a and 64a tend to approach each other as the depth becomes very great. This leads to the conclusion that streams with very few, if any, definable bed forms w:ll have low coefficients for equations 63 and 64 . Streams having observable bed forms will have higher fricticn 


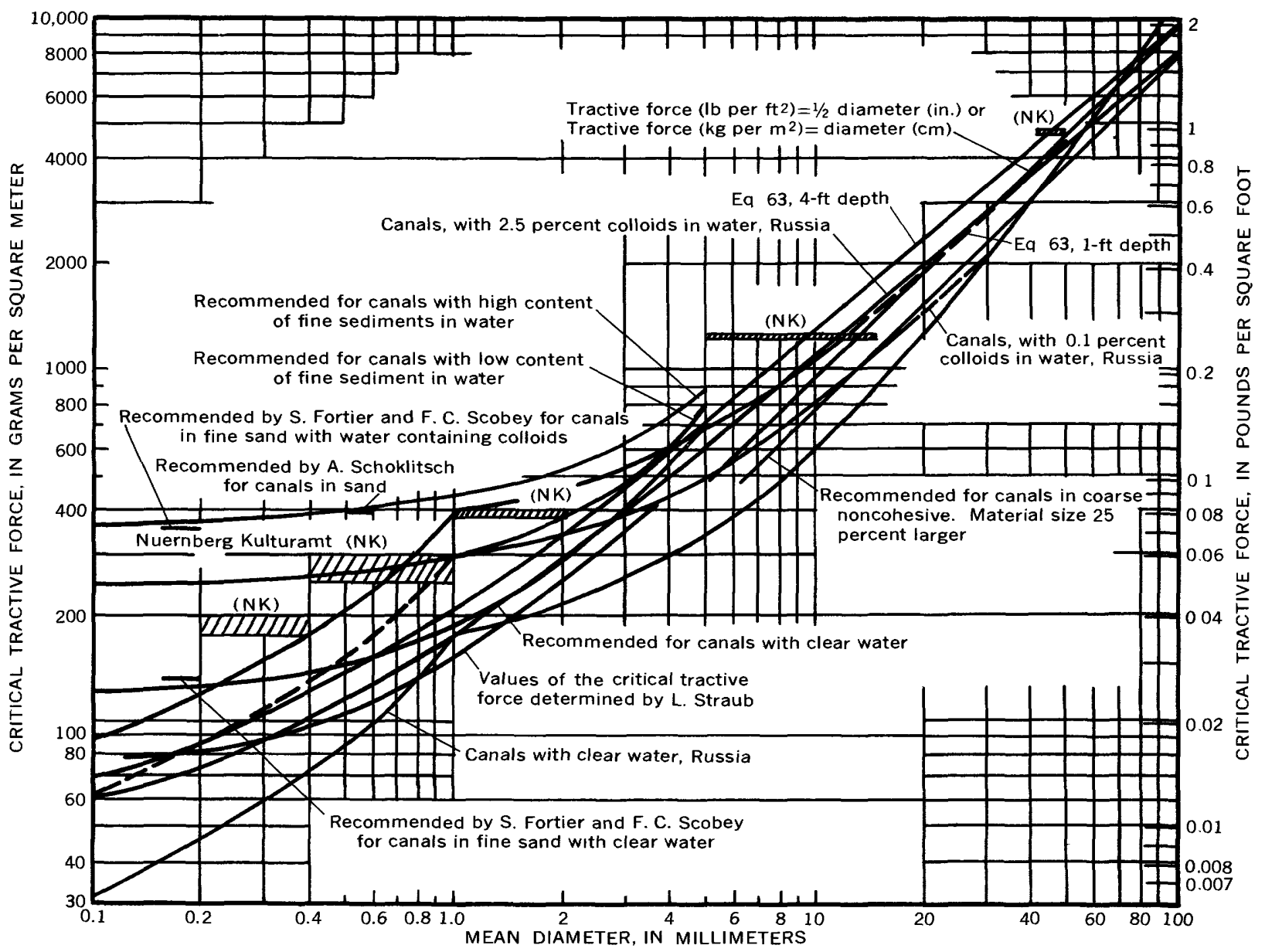

FIgURE 46.--Recommended limiting tractive forces (or shear stresses) for canals. Modified from Lane (1955, p. 1252).

factors and, of course, larger coefficients. Because bed forms require resistant banks, channels whose bank materials are low in clay, yet are made up of sizes considerably smaller than those making up the bed, will have low values of the coefficients of the two equations.

In view of the paucity of data upon which any conclusions could be based, I suggest that the Wolman data for Brandywine Creek be used for minimum values for the coefficient of equation 64a. Brandywine Creek appears to represent a stream with weak banks, even though the banks seem to be protected by trees. A value of about 0.021 is suggested. Lane's (1955) data from the San Luis Valley might be used to provide for the situation of coarse material in both bed and banks. Equation 63 and its coefficient would be used only on relatively deep and narrow streams, most of which would be expected to meander. If immobility of banks is desirable, equation 64 would seem to represent a good average condition.

This is the two-dimensional approach. Given a size of material, velocity is computed. Then for every value of depth there is a corresponding value of slope. If the selection of a slope is constrained by topographic or other conditions, depth is computed, fixing the unit diseharge. The required total discharge then establishes the width. The relations between width and slope, for a given stream discharge and size of bed mater: dependent on the selection of the coefficient.

Equation 54 can be rewritten in terms of width, stream discharge, slope, and composition of bed material as

$$
W=\left(\frac{B}{A_{2}}\right)^{18 / 7} Q S^{9 / 7} \frac{\rho^{1 / 2} \gamma}{(\Delta \gamma d)^{3 / 2}}\left(\frac{\rho w^{2}}{\Delta \gamma d}\right)^{9 / 28}
$$

If a "regime" condition exists, then $W \propto Q^{0.382}$ and

$$
\frac{W}{Q^{0.382}}=\left(\frac{B}{A_{2}}\right)^{18 / 7} Q^{0.618} S^{9 / 7} \frac{\rho^{1 / 2} \gamma}{(\Delta \gamma d)^{3 / 2}}\left(\frac{\rho w^{2}}{\Delta \gamma d}\right)^{9 / 28}
$$

Testing the Lane and Carlson (1954) date from the San Luis Valley, we find that there is a "regime" relation, $W=3.8 Q^{0.382}$, and that it is not a function of 


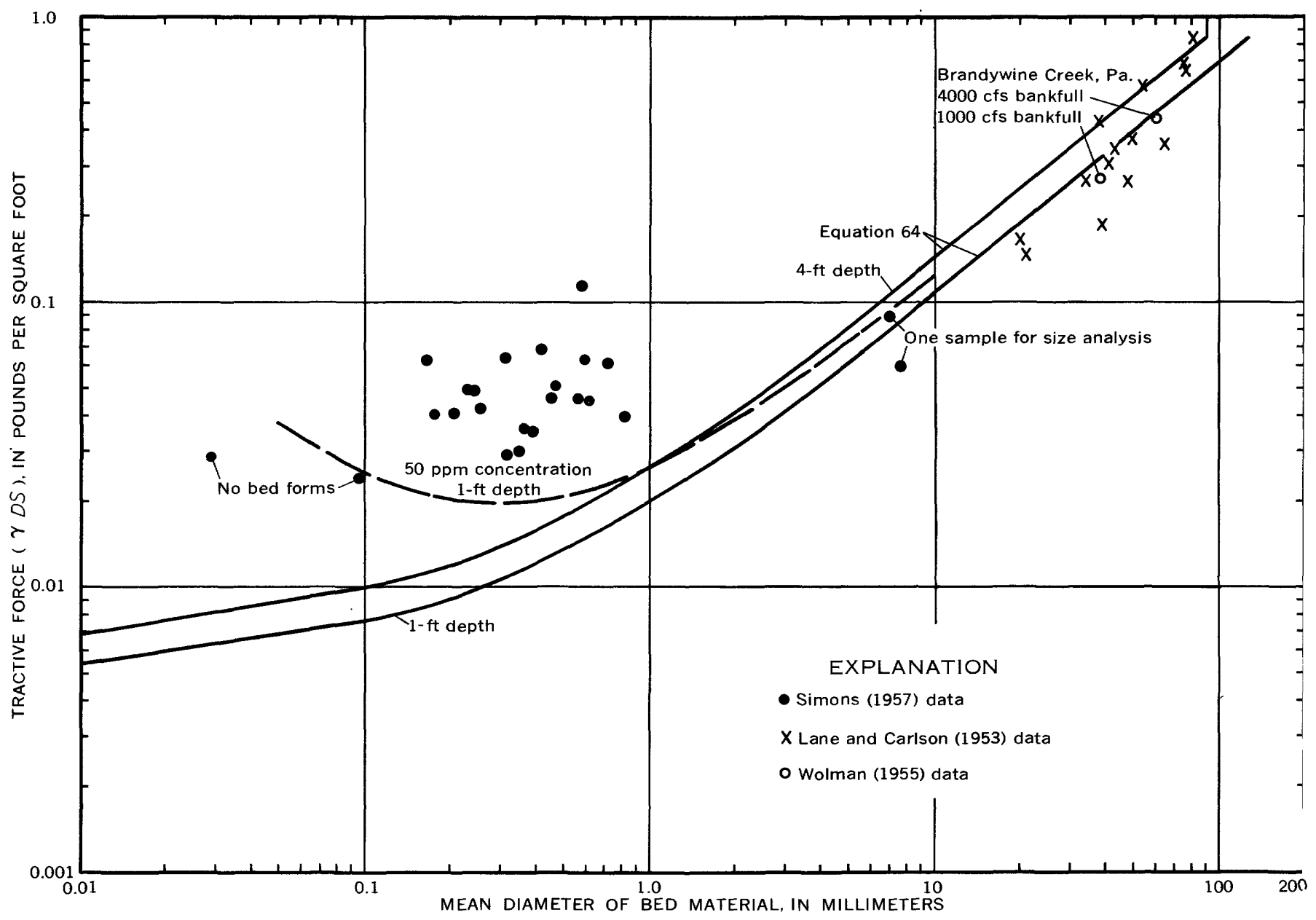

Figure 47.- Relation between tractive force and sediment size with slope an independent variable. Many samples taken to determine size for all values except those indicated. Dashed line, plot of equations 7 and 35 using a concentration of 50 ppm.

size of $m$ aterial (fig. 48). The right-hand side of equation 65 must also equal a constant, 3.8 , and $Q^{0.48} S \propto d^{7 / 6}$ $\left(A_{2} / B\right)^{2}$. As shown in figure 49 , there must be a variation in the coefficients $A_{2}$ and $B$ because there appear to be two relations, $d=1.8 Q^{0.41} S^{6 / 7}$ and $d=3.1 Q^{0.41} S^{6 / 7}$. These two equations are matched by two others, $V=$ $7.45(Q / W)^{1 / 9} d^{1 / 3}$ and $V=6.58(Q / W)^{1 / 9} d^{1 / 3}$. Thus, there are two sets of "regime" equations in the San Luis Valley canals data:

$$
\begin{aligned}
& W=3.8 Q^{0.382} \\
& V=7.45\left(\frac{Q}{W^{7}}\right)^{1 / 9} d^{1 / 3} \text { or } V=6.43 Q^{0.069} d^{1 / 3}, \\
& S=0.505 Q^{-0.48} d^{7 / 6}
\end{aligned}
$$

and

$$
\begin{aligned}
& W=3.8 Q^{0.382} \\
& V=6.58\left(\frac{Q}{W}\right)^{1 / 9} d^{1 / 3} \text { or } V=5.67 Q^{0.069} d^{1 / 3} \\
& S=0.27 Q^{-0.48} d^{7 / 6}
\end{aligned}
$$

These differences probably were caused by different design criteria. Note however, that the canals at the upper ends of the system, and therefore the largest, are relatively steep. This is a desirable situation and should be a general practice.

Except for the width-discharge relation, equations 62 and 66 are each special cases of "regime" systems. The coefficients of the equations are not constant, but this result is to be expected. Because the mean velocity of the stream is related to a size of sediment grain, the shape of the channel may have an influence in addition to the various factors heretofore discussed. Finally the relation between velocity and grain size and unit discharge was determined in relatively small flumes with fairly small grain sizes. Consequently, the extrapolation of the velocity equation to large cobble beds demands a minimum of depth of flow to give good results.

To some extent the agreement between the Lane and Carlson data and the Wolman data is fortuitous because different methods were used for determining the size of bed material. However, if stable channels can be 
observed in the field any consistent method of determining sizes may be used-it even may be size of bed material or, as Lane and Carlson (1954) suggested, the selection of some coarse fraction of the native material through which a canal is built. The velocity equation may be developed from local data to fit any specific condition. Nevertheless, for the present and in the absence of other data it is suggested that for the velocity-discharge-sediment size relation and for the slope-discharge-sediment size relation equation 66 is satisfactory for canals designed for flows of more than $500 \mathrm{cfs}$ and equation 67 for canals designed for discharges of less than $500 \mathrm{cfs}$.

The value of the coefficient of the discharge-width relation appears to be uncertain. For artificial channels a value of 3.8 seems to be satisfactory because it applied to the San Luis Valley canals. A value of from 4.6 to 5 seems best for natural channels subject to over-bank flow. There appears to be considerable margin for error- width does not have to be determined closely, and channels appear to readily adjust to local conditions.

The criteria for gravel channels are somewhat

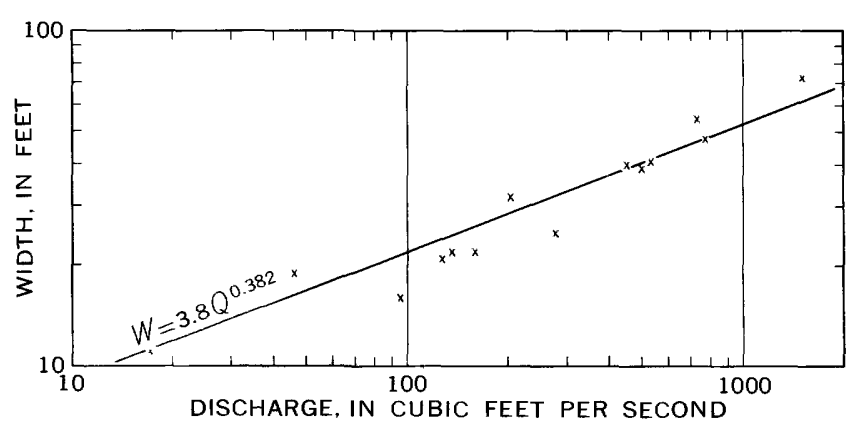

Figure 48.- Relation between width and discharge, San Luis Valley, Colo., canals: X's. data from Lane and Carlson (1954).

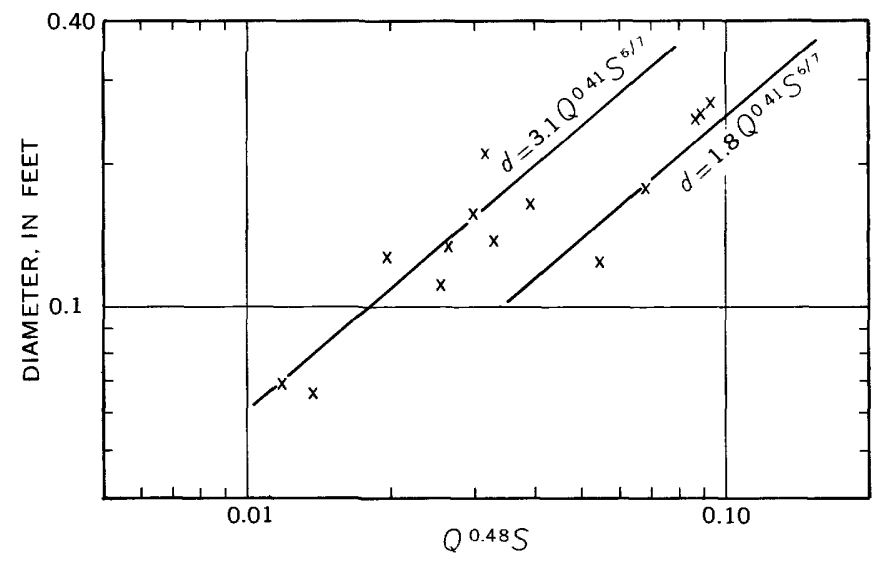

Figure 49.-Relations between sediment size and discharge and slope, San Luis Valley, Colo., canals; X's, data from Lane and Carlson (1954). specialized. Such channels are relatively straight and uniform, with practically no bed forms. These specialized criteria should not be used for channels obviously of a pool and riffle configuration or where there is obviously a considerable amount of sediment in transport at the bank full stage. The assumption made in the beginning of the analysis was that although movement at bank full stage is required it is small in amount. For discharges below bank full stage, these channels operate as rigid-boundary channels under ccnventional hydraulics.

Although channels whose characteristic are controlled by grain size are frequently encountered in humid regions and are of course associated with low sediment loads, they are not often found in arid regions. In the arid regions high sediment loads seem to determine the aspect of the stream system.

\section{SAND CHANNELS}

The stabilization of channels moving sediment presents problems differing from those of channels whose beds are made of a coarse material that is immobile during most discharges. Channels in which the discharges of both water and sediment vary must aggrade or degrade at some time. In a $\operatorname{stal}^{1} \mathrm{e}$ channel this must not be accompanied by any patterns of meandering flow, which would lead to bank erosion.

If discharge is kept constant in an artificial channel, such as a canal, there will be a tendency for the bed to rise during periods of high sediment inflow and to fall in periods of low sediment movement. If the change between high and low sediment load takes place quickly, the bed may not degrade rapidly, and the discharge with a low sediment load will have a higher gage height than did the same water discherge during the period of heavy sediment movement. Channel stability, therefore, requires that removal equal deposition. Were it not for the fact that removal proceeds at a slower rate than deposition it would $k 9$ assumed that a balance would be maintained ratker simply. In practice the balance must be weighted toward degradation unless periodic canal cleaning is to be adopted as a continuing practice.

Examples of this type of flow are showr in photographs of the Colorado River downstream from Davis Dam near the Nevada-California boundary and of the Rio Grande near Vinton, Tex. (figs. 50 and 51). Both channels are lightly riprapped with rock. Without it bank erosion would take place, and the str sam would eventually meander.

The bars that create meandering of flow are formed at high discharges with low sediment loads. The bars are systematic, alternating from one side of the channel to the other, and have a wave length of $2 \pi W$. When 


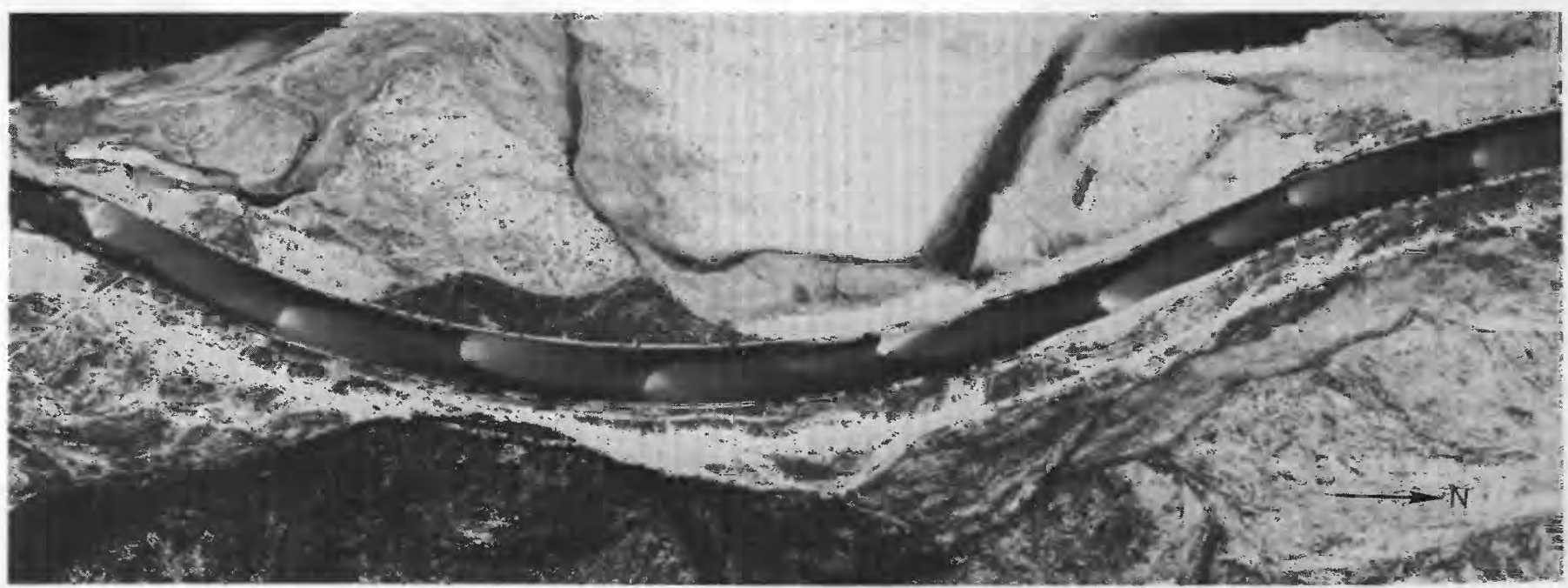

Figure 50.-Aerial photograph of the Colorado River near the Nevada-California boundary showing systematic bed forms (light areas) under water.

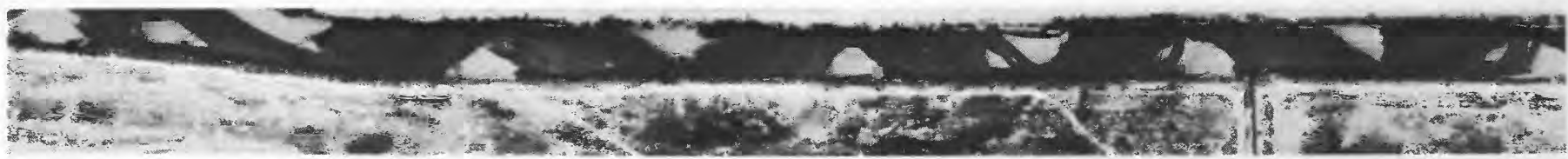

Figure 51.-Strip aerial photograph of the Rio Grande near Vinton, Tex., at low flow showing river reworking systematic bed forms (light areas) that are relics from higher discharges. Flow from right to left.

the discharge declines quickly, the bars are left as relics of the previous discharge and appear above the water surface. Low flows simply erode the bars and redistribute the sediment locally. There is little general sediment movement in a downstream direction at low flow.

\section{"REGIME" CHANNELS}

The designer of a canal hopes to occupy that part of the spectrum of canal regimes that permits the removal of material deposited under high sediment loads yet does not result in a canal width and slope associated with bank erosion during periods of flow with low sediment concentrations.

For areas of similar climatic, topographic, and geologic conditions equations relating to networks of channels may be developed. These are "regime" equations, such as the Lacey (1946) equations, with the inherent assumption that width, depth, velocity, and slope of channels all will change with changing discharge or changing sediment concentration. Consequently, this is a basic system that provides a mean condition. Obviously, should local conditions depart from this mean there must be some local variation from the basic pattern.

If the "regime" system approach is to be used, the relations among the various coefficients must be fully understood.
If the two equations $V=A(L / \rho)^{1 / 3}$ and $V=B(q S)^{1 / 2}$ $(\gamma g / \Delta \gamma d)^{1 / 4}\left(\rho w^{2} / \Delta \gamma d\right)^{1 / 8}$ are combined to eliminate $V$, the result, as has been noted before, is

$$
W=\left(\frac{B}{A}\right)^{6} \frac{Q S^{3} \gamma^{3 / 2}}{C^{2} g^{1 / 2}(\Delta \gamma d)^{3 / 2}}\left(\frac{\rho w^{2}}{\Delta \gamma d}\right)^{3 / 4} \text {. }
$$

If, from the "regime" relations, $W=a Q^{1 / 2}$ and $S=t Q^{-1 / 6}$, then

$$
a=\left(\frac{B}{A}\right)^{6} \frac{t^{3} \gamma^{3 / 2}\left(\rho w^{2}\right)^{3 / 4}}{C^{2} g^{1 / 2}(\Delta \gamma d)^{9 / 4}}
$$

in which $C$ is a system concentration and $d$ and $w$ are related to sediment sizes in the system.

If all the coefficients in equation 68 were independent and uncorrelated, enormous variation in the coefficient $a$ would be expected. Actually, little variation is observed so that a high degree of correlation must exist. However, the objective of a regime approach, from the standpoint of analysis made herein, is to reduce the variation in the values of the coefficients $A$ and $B$. Because the coefficient $A$ does not vary greatly under normal conditions, the important fact is that $B$ be little changed because it represents a specific kind of energy consumption in two-dimensional flow. The end result of the "regime" analysis would be expected to be

$$
a \propto \frac{t^{3}}{C^{2}} \frac{w^{3 / 2}}{d^{9 / 4}}
$$


The Lacey relations appear to be a variant of equation 69 . The Lacey slope equation, when $D$ is substituted for $R$, is $V=16 D^{2 / 3} S^{1 / 3}$. This may be expressed as $V^{5 / 3}=16 q^{2 / 3} S^{1 / 3}$ or $V \propto q^{2 / 5} S^{1 / 5}$. Lacey also states that $V \propto(f D)^{1 / 2}$ or $V^{3 / 2} \propto(f q)^{1 / 2}$ and $V \propto(f q)^{1 / 3}$. Then $f^{1 / 3} \propto q^{1 / 15} S^{1 / 5}$ and $f^{5} \propto(Q / W) S^{3}$. If $W \propto a Q^{1 / 2}, f^{5} \propto Q^{1 / 2} S^{3} / a$. But $t \propto Q^{1 / 6} S$; hence, $f^{5} \propto t^{3} / a$ or, if $a$ is constant, $t \propto[A / B]^{2} C^{2 / 3} d^{9 / 4} / w^{3 / 2}$. Therefore

$$
f \propto\left[\frac{A}{B}\right]^{6 / 5} C^{2 / 5} \frac{d^{27 / 20}}{w^{9 / 10}}
$$

But $f$ must be proportional to $C$; hence, $C^{3 / 5} \propto(A / B)^{6 / 5}$ $\left(d^{27 / 20} / w^{9 / 10}\right)$ or, in the Lacey equation, $B \propto\left(A / C^{1 / 2}\right)\left(d^{9 / 8} /\right.$ $\left.w^{3 / 4}\right)$. Because the term $d^{9 / 8} / w^{3 / 4}$ is essentially constant for sand sizes in the Punjab, as given by Inglis (1949), and because $A$ must be a constant, $B \propto 1 / C^{1 / 2}$. This value should be compared with the one developed in the section on slope. Both values indicate, however, that Lacey channels may be unduly flat if designed for small sizes of bed material. The existence of a correlation between size of bed material and sediment concentration must be assumed. This may be true for canal systems and the higher velocities associated with greater concentrations may result in coarser material being found on the bed. However, within a single canal system, which tends to have a uniform concentration and a uniform value of $V^{2} / D$, there is a small increase in size of bed material associated with the increased velocity of higher discharges.

Although Lacey (1940) considered the coefficient of the width-discharge relation to be essentially constant, Blench (1952) expressed width in terms of a side factor, $F_{s}$, in which $F_{s}=V^{3} / W$. Now if $W=a Q^{1 / 2}$, it follows that $W \propto a(Q C)^{1 / 2}$ because the sediment must move with the water in a "regime" system. Then $W^{1 / 2} \propto a(Q C)$ $W)^{1 / 2}$. But $Q / W=q$, and from the velocity-load relation for mixtures, $(q C)^{1 / 2} \propto V^{3} / a$. Hence, $W^{1 / 2} \propto a V^{3 / 2}$, or $V^{3} / W \propto$ $1 / a^{2}$, or $F_{s} \propto 1 / a^{2}$. Thus, Blench's side factor, $F_{s}$, is inversely related to the square of the coefficient of the width-discharge relation. The three fold range in variation in the value of $F_{s}$ noted by Blench would provide a variation of about 70 percent in the value of the coefficient $a$. Blench stated that $V^{2} / g D S=3.63(V W / \nu)^{1 / 4}$ or, substituting $V^{3} / F_{s}$ for $W, V^{2} / g D S=3.63\left(V V^{3} / F_{s} v\right)^{1 / 4}$, and $V=3.63 g D S /\left(F_{s} \nu\right)^{1 / 4}$. But from equation 19, $V=B^{2} D S(\gamma g / \Delta \gamma d)^{1 / 2}\left(\rho w^{2} / \Delta \gamma d\right)^{1 / 4}$. Hence, $B$ of equation 68 is related to $F_{s}$ by

$$
B \propto \frac{d^{3 / 8}}{w^{1 / 4}}\left(F_{s}\right)^{-1 / 8}
$$

For a constant sediment size, coefficient $B$ is proportional to $F_{s}^{-1 / 8}$. Thus, the premise stated herein that a "regime" relation presupposes a small variation in the coefficient of equation 19 seems to be supported by Blench.

Blench stated that $V^{2} / D=F_{b}$ and assigned it a variation with size of material. Setting the Blench relations in terms of $q, V \propto\left(q F_{b}\right)^{1 / 3}$ and $V \propto(q S)^{1 / 2} / F_{s}^{1 / 8}$, and if $V$ is eliminated, $q^{1 / 6} S^{1 / 2} \propto F_{b}^{1 / 3} F_{s}^{1 / 8}$ or $Q S^{3} / W \propto F_{b}^{2} F_{s}^{3 / 4}$. Then if $W=a Q^{1 / 2}, Q^{1 / 2} S^{3} / a \propto F_{\nu}^{2} F_{s}^{3 / 4}$. Since $Q^{1 / 2} S^{3} \propto t^{3}$, the result is $t^{3} \propto a F_{b}^{2} F_{s}^{3 / 4}$. If $a$ is constant, $F_{s}$ must be constant and $t^{3} \propto F_{b}^{2}$. This would yield the same relation as equation 69 and $F_{b} \propto C$. If $a$ is not constant, $t^{3} \propto F_{b}^{2} F_{s}^{1 / 4}$, whence

$$
S \propto F_{b}^{2 / 3} F_{s}^{1 / 12} Q^{-1 / 6} .
$$

Blench's equation is

$$
S=F_{b}^{5 / 6} F_{s}^{1 / 12} Q^{-1 / 6}\left[k\left(1+\frac{C}{233}\right)\right]^{-1} .
$$

The similarity of equations $69,69 \mathrm{c}$, and $69 \mathrm{~d}$ is apparent. However, the Blench equations result in a decrease in slope with increasing width and increasing concentration, neither of which are confirmed by laboratory or field observations.

The effect of the size parameter on the two coefficients $a$ and $t$ is interesting. The parameter has a maximum value at a size of about $0.20 \mathrm{~mm}$, but between $0.06 \mathrm{~mm}$ and $0.40 \mathrm{~mm}$ the size variation is only about 20 percent. However, the magnitude of the parameter decreases rapidly with both increasing and decreasing size of sediment. Consequently, maximum channel widths should be expected with grain sizes of $0.2-0.3 \mathrm{~mm}$. Also to be noted from equation 69 is that channels decline in width with increased sediment concentrations and with decline in relief (as represented by the coefficient $t$ ) if size of sediment does not vary greatly.

These generalities concur with observations made in the field. Inglis (1949) noted that in the Sind of Pakistan, where most sediment is in the silt size, canal widths are less than in the Punjab of Pakistan where the sediment is in the sand size. Values of the coefficient $a$ are about 2.6 in the Punjab in contrast to about 2.1 in the Sind.

Simons (1957) shows a variation of about two times in the value of coefficient $a$, from about 3 to about 1.5. The highest values are for channels with sand sized material, low concentrations, and a fairly great relief in the canal system. The lowest values, about 1.5, are from the Imperial Valley with low relief, high sediment concentrations, and sediment in the silt size. Canals with beds of very coarse material also have low values of the coefficient $a$.

Rarely is the effect of the change in one variable concentrated in a single remaining variable. For example, a change in the sediment concentration in the 
system results in an appropriate change in both the width and slope coefficients. A change in size affects the other variables in the same way.

According to the argument presented herein, both the Blench and the Lacey relations require an inlerent correlation between sediment concentration and size of material. Blench does provide a correction for sediment concentration but its result is questionable. Note that Blench does not relate $F_{s}$ with size; his size parameter is carried in a bed factor, $F_{b}$, which is equal to $V^{2} / D$. Data presented herein show that for the normal sand-size ranges $V^{2} / D$ is nearly independent of size in sediment mixtures but is related to sediment concentration. Furthermore, data do not support Blench's assumption that the friction factor varies inversely with width because of a hydraulic principal. If there is anything certain in fluvial hydraulics it is that any statement of uniqueness with respect to the friction factor is impossible to make.

The Blench and Lacey equations are restrictive in so far as variation in width for a given discharge is concerned. The equations presented herein are considerably less restrictive. However, the role of sediment concentration requires further consideration. If equation 68 , for example, is to be used with high sediment concentrations, a smaller than average value of $B$ should be selected. This is because if high sediment concentrations are expected, with consequent deposition, slope must be high enough to maintain channel capacity during periods of low sediment discharge when the channel is scouring.

Equation 68 presumes a velocity-load relation of the mid-velocity range. However, equation 19 can be reduced to a relation between velocity and slope if depth, any combination of velocity and depth, or the values of $a$ and $Q$ in the relation $W=a Q^{1 / 2}$ are known. In each, a specific concentration is implied in any relation between slope and velocity.

Using a value of 8.2 for $w^{1 / 4} / d^{3 / 8}$ in equation 19 , the following relations are found

$$
S=\frac{0.009}{B^{2}} \frac{V}{D}
$$

When $V^{2} / D=k, \quad S=\frac{0.009 k}{B^{2} V}$.

When $W=a Q^{1 / 2}, \quad S=\frac{0.009 V^{2} a}{B^{2} Q^{1 / 2}}$.

Apparently neither the limiting velocity nor the limiting tractive approach to canal design is satisfactory for a range of discharges; however, if $V^{2} / D$ is constant, $V S$ is constant for a constant value of $B$. It should be observed that this is in agreement with two of Blench's "dynamical statements," (Blencl, 1966, p. 89). These are (1) channels of the same water. sediment complex tend to acquire the same Froude number in terms of a suitable depth, and (2) channel with the same water sediment complex and the same measure of erosive attack on the sides tend to adjust to the same dissipation of energy per unit mass per unit time. These statements should be restricted to flows in the mid-velocity range.

A set of regime channels was defined as one in which the relation among width, depth, velocity, and slope are such that the different rates of internal energy expenditure tend to remain constant under a constar.t sediment concentration. Three of Langbein's power statements were used to develop the regime relations. The term $V S$ is also one of his power statements. His fifth, power per unit time of stream travel $Q V S$, is not applicable.

The coefficient $B$ is considered to be an indirect measure of the erosive attack on the sides. Apparently Blench's term $\rho \mu V^{3} / W$ does not yield any effective information. As has been shown previously, if $V^{2} / D \propto C$ and $W=a Q^{1 / 2}, V^{3} / W$ is simply a statement that the sediment moves with the water.

An average or regime value of $B$ is about 4 ; variations of plus or minus 10 percent are frequently encountered. This average value is in comparison with a value of 4.7 from the Gilbert data. Some obviously unstable natural streams have values as low as 2 ; however, a range in the value of $B$ from about 3.3 to 7.7 has been observed in canals. Because all these channels of canals appear reasonably stable, obviously some means must be found to limit the range in variation of the stability parameter.

Any stream flowing in alluvium has a pattern of bed forms and velocity distributions in the water prisr. In most natural streams this pattern is constantly changing because of the variation in discharges of water and sediment from tributary streams. Widths are rarely constant and channels seldom are straight. Although the equation of continuity may be valid for water discharge, it is not valid for sediment discharge except as an average over a long period of time. Thus, in water discharge it may be possible to ignore the storage factor. This cannot be done with sediment discharge on beds with highly developed bed forms. Therefore, alluvial channels do not have constant slopes; in what appears to be a uniform reach of stream, slopes over long distances may vary considerably from the average slope.

Heads of canals are locations of varying combinations of water and sediment discharge. The parent stream has a wide range of combinations of water and sediment discharge; consequently, the sediment con- 
centration at the intake will vary considerably. Even if the discharge of water and sediment in the parent stream were constant, sediment movements into the canal would vary as the moving bed forms altered flow patterns at the canal heading. Consequently, there is a considerable variation in slope of the upper ends of canals as well as changes in the topography of the bed.

Given an alluvial channel of considerable length and reasonably uniform width and some limit on the variation of discharges of water and sediment, however, the channel will approach a steady flow. In a way, the water and sediment will "get in step." This is easy to observe in flow of canals, but it happens, to some extent, in natural streams. As the size of a drainage basin increases, the distance between major tributaries declines and variations in the discharge of water and sediment tend to decrease. The net result is a change not only in the values of coefficient $B$ but also in the coefficient $A$ of the velocity-load relation. But it should be clear that any value of $B$ selected for a "regime" equation must represent an average of slopes changing over a long reach of a canal.

Oddly enough, both near-maximum and near-minimum values of $B$ for a reasonably stable canal have been found on the Marala-Ravi Link Canal in Pakistan. This canal was designed for a capacity of $22,000 \mathrm{cfs}$ with a velocity of 4.28 feet per second, a depth of 14.6 feet, and a slope of 1 foot per 10,000 feet. This yields a $B$ of 5.15 and a $V^{2} / D$ of about 1.25 .

When put into operation the canal filled over much of its length and apparently widened slightly in its uppermost reach. The maximum capacity has been reduced to about $15,000 \mathrm{cfs}$; the fill at the intake is about 5 feet. Twenty thousand feet from the intake the fill is about $4 \frac{1}{2}$ feet, and at 70,000 feet it is over 3 feet. One hundred sixty thousand feet from the heading, the canal is about on its original grade. These values of filling are by no means static. The average bed elevation at any one section in the canal may change as much as 2 feet in a short time.

Data from the West Pakistan Water and Power Development Authority Canal and Headworks Observation Program (Harza Engineering Co., 1963) relating to actual canal behavior for three reaches of the Marala-Ravi Link Canal are given in tables 2 and 3.

Table 2 shows values of $V^{2} / D$ and the coefficient $B$ from equation $51 \mathrm{~b}$. The question is, does the increase in the value of $V^{2} / D$ between river sections $2 C, 000$ and 160,000 indicate an increase in the sediment concentration? Although sediment samples and observations of scour and fill indicate some increase or decrease in concentration, there is no reason to assume that this variation is enough to account for the changes in the value of $V^{2} / D$. Thus, the variation in $V^{2} / D$ must be assigned to a variation in the coefficient $A_{1}$ in the equation $V=A_{1}(L / \rho)^{1 / 3}$. If this is true, $V^{2} / D \propto A_{1}{ }^{3} C$. Substituting this for $k$ in equation $51 \mathrm{~b}, S \propto A_{1}{ }^{3} C / B^{2} V$ and $V S \propto A_{1}^{3} C / B^{2}$. However, there is a correlation between $A_{1}{ }^{3} C$ and $B^{2}$ in the form $B \propto\left(A_{1}^{3} C\right)^{1 / 2}$. Cons squently, concentration is the same in the three sections of the Marala-Ravi Link Canal, and there is a tendency for $V S$ to be constant.

In the section on sediment transport it was stated that the value of the coefficient $A_{1}$ is uncertain and; at

TABLE 2.-Data for the Marala-Ravi Link Canal relating to behavior

[Data from Harza Engineering Co. (1963)]

\begin{tabular}{|c|c|c|c|c|c|c|c|c|c|c|c|}
\hline \multicolumn{12}{|c|}{ Behovior at indicated distance from headworks (ft) } \\
\hline \multicolumn{4}{|c|}{$20,000-26,000$} & \multicolumn{4}{|c|}{$66,000-70,000$} & \multicolumn{4}{|c|}{$154,000-160,000$} \\
\hline Date & $Q$ (crs) & $V^{2} / D$ & $B$ & Date & $Q$ (cfs) & $V^{2} / D$ & $B$ & Date & $Q$ (efs) & $V^{2} / D$ & $B$ \\
\hline $6-18-62$ & 15,500 & 2.31 & 4.0 & & & & & $6-19-62$ & 15,000 & 3.52 & 7. 15 \\
\hline $7-5-62$ & 14,500 & 1.4 & 3.5 & & & & & $7-6-62$ & 14,100 & 3.44 & 7.5 \\
\hline $8-22-62$ & 13,300 & 1.14 & 3.74 & & & & & $8-23-62$ & 13,400 & 3.88 & 7.72 \\
\hline $9-6-62$ & 12,800 & 1.17 & 4.39 & & & & & $9-7-62$ & 12,400 & 3.35 & 7. 1 \\
\hline $3-29-63$ & 7,420 & 1. 23 & 4. 71 & $4-6-63$ & 6,090 & 3.19 & 6.3 & $3-29-63$ & 7,610 & 2.83 & 7.76 \\
\hline $4-5-63$ & 8,250 & 1.24 & 4.19 & $4-29-63$ & 13,350 & 3.99 & 6.85 & $4-7-63$ & 6,020 & 2.37 & 7.45 \\
\hline $5-8-63$ & 13,300 & 1.39 & 3.94 & $5-8-63$ & 13,000 & 3.81 & 7. 14 & $4-28-63$ & 11,430 & 3.26 & 7.32 \\
\hline $5-21-63$ & 11,900 & .90 & 3.77 & $5-21-63$ & 12,300 & 2.57 & 5.97 & $5-9-63$ & 13,500 & 2.97 & 6.90 \\
\hline $6-6-63$ & 15,000 & 966 & 3.35 & $6-7-63$ & 15,400 & 1.83 & 5.87 & $5-22-63$ & 11,800 & 2. 14 & 5.42 \\
\hline 6-23-63 & 14,300 & 1.02 & 3.57 & $6-24-63$ & 16,300 & 1.65 & 5. 16 & $6-8-63$ & 14,600 & 2.29 & 5.51 \\
\hline $7-6-63$ & 15,100 & 1. 20 & 3.85 & $7-7-63$ & 15,100 & 1.59 & 4.83 & $6-25-63$ & 15,000 & $3.0 Q^{R}$ & 7.15 \\
\hline $7-25-63$ & 13,300 & 1. 01 & 4.18 & $7-26-63$ & 13,200 & 1.82 & 5.6 & $7-8-63$ & 14,600 & 3.28 & 7.15 \\
\hline $8-6-63$ & 13,800 & 1. 19 & 4. 12 & $8-10-63$ & 13,300 & 3.38 & 6. 6 & $7-26-63$ & 12,400 & 3.1 & 7.40 \\
\hline $8-26-63$ & 11,900 & .96 & 4.0 & $8-26-63$ & 12,100 & 1.37 & 3.76 & $8-11-63$ & 12,700 & 3. 22 & 7.20 \\
\hline $9-9-63$ & 11,400 & 1.23 & 4.14 & $9-10-63$ & 11,000 & .87 & 4.41 & $8-27-63$ & 12,500 & 2.47 & 6. 66 \\
\hline $5-15-64$ & 12,900 & 1.13 & 3.68 & $5-16-64$ & 11,900 & 98 & 4.58 & $9-10-63$ & 11,000 & 1. 38 & 4. 91 \\
\hline $6-11-64$ & 11,900 & 1.02 & 3.62 & $6-12-64$ & 12,600 & 1.15 & 4.22 & $5-16-64$ & 12,300 & 2.57 & 6.6 \\
\hline $7-7-64$ & 12,800 & 1. 19 & 4.0 & $7-6-64$ & 14,100 & 1.34 & 4.78 & $6-13-64$ & 13,400 & 2. $7 ?$ & 6.8 \\
\hline $9-10-64$ & 12,500 & 1.15 & 3.92 & $9-11-64$ & 12,300 & 1.43 & 6.0 & $9-12-64$ & 10,600 & 2.33 & 8.0 \\
\hline
\end{tabular}


TABLE 3.-Data for the Marala-Ravi Link Canal

[Data from Harza Engineering Co. (1963)]

\begin{tabular}{|c|c|c|c|c|c|c|c|c|}
\hline \multicolumn{9}{|c|}{ Behavior at indicated distance from headworks (ft) } \\
\hline \multicolumn{3}{|c|}{$20,000-26,000$} & \multicolumn{3}{|c|}{$66,000-70,000$} & \multicolumn{3}{|c|}{$154,000-160,000$} \\
\hline Date & Discharge (cfs) & Slope & Date & Discharge (cfs) & Slope & Date & Discharge (cfs) & Slope \\
\hline $6-18-62$ & 15,500 & 3,460 & $---y_{1}$ & $-\pi-5$ & 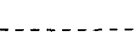 & $6-19-62$ & 15,000 & $8,45 n$ \\
\hline $7-5-62$ & 14,500 & 3,410 & & 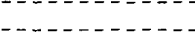 & $\ldots$ & $7-6-62$ & 14,100 & 9,200 \\
\hline $8-22-62$ & 13,300 & 4,620 & & & $\ldots$ & $8-23-62$ & 13,400 & 8,800 \\
\hline $9-6-62$ & 12,800 & 6,200 & $x_{-1}$ & & $---\cdots$ & $9-7-62$ & 12,400 & 8,040 \\
\hline $3-29-63$ & 7,420 & 5,280 & $4-6-63$ & 6,090 & 5,160 & $3-29-63$ & 7,610 & 9,2 n \\
\hline $4-5-63$ & 8,250 & 4,680 & 4-29-63 & 13,300 & 6,800 & $4-7-63$ & 6,020 & 8,820 \\
\hline $5-8-63$ & 13,300 & 4,510 & $5-8-63$ & 13,000 & 7,570 & $4-28-63$ & 11,430 & $8,5] 0$ \\
\hline $5-21-63$ & 11,900 & 5,300 & $5-21-63$ & 12,300 & 6,530 & $5-9-63$ & 13,500 & $8,44 \pi$ \\
\hline $6-6-63$ & 15,000 & 4,330 & $6-7-63$ & 15,400 & 8,700 & $5-22-63$ & 11,800 & $6,2 \varepsilon]$ \\
\hline $6-23-63$ & 14,300 & 4,620 & $6-24-63$ & 16,300 & 7,350 & $6-8-63$ & 14,600 & $6,6 \in n$ \\
\hline $7-6-63$ & 15,100 & 4,940 & $7-7-63$ & 15,100 & 6,620 & 6-25-63 & 15,000 & 9, if \\
\hline $7-25-63$ & 13,300 & 5,260 & $7-26-63$ & 13,200 & 7,680 & $7-8-63$ & 14,600 & 8,700 \\
\hline $8-6-63$ & 13,800 & 4,980 & $8-10-63$ & 13,300 & 7,090 & $7-26-63$ & 12,400 & 9,320 \\
\hline $8-26-63$ & 11,900 & 5,140 & $8-26-63$ & 12,100 & 3,940 & $8-11-63$ & 12,700 & $8,5 ?$ \\
\hline $9-9-63$ & 11,400 & 5,110 & $9-10-63$ & 11,000 & 7,300 & $8-27-63$ & 12,500 & 8,550 \\
\hline $5-15-64$ & $12 \mathrm{9} 0 \mathrm{n}^{-}$ & 440 & $5-16-64$ & 11900 & 7310 & $9-10-63$ & 11,000 & $6,6 f ?$ \\
\hline $\begin{array}{l}5-15-64 \\
6-11-64\end{array}$ & $\begin{array}{l}12,900 \\
11,900\end{array}$ & $\begin{array}{l}4,540 \\
4,510\end{array}$ & $\begin{array}{l}5-16-64 \\
6-12-64\end{array}$ & $\begin{array}{l}11,900 \\
12,600\end{array}$ & $\begin{array}{l}7,310 \\
5,880\end{array}$ & $\begin{array}{l}5-16-64 \\
6-13-64\end{array}$ & $\begin{array}{l}12,300 \\
13,400\end{array}$ & $\begin{array}{l}8,4 i] \\
8,540\end{array}$ \\
\hline $7-7-64$ & 12,800 & 4,570 & $7-6-64$ & 14,100 & 7,020 & & 10,100 & \\
\hline $9-10-64$ & 12,500 & 4,474 & $9-11-64$ & 12,300 & 9,091 & $9-12-64$ & 10,600 & $12,5 i 3$ \\
\hline
\end{tabular}

least, ranges from 5 to 6 . This gives a range in the value of $A_{1}{ }^{3}$ of about 1.7 times. A change of 36 percent in the value of $A_{1}$ will give a change of $A_{1}{ }^{3}$ values of 250 percent, which would seem to be a reasonably expected degree of variation. If $B \propto\left(A_{1}{ }^{3} C\right)^{1 / 2}$, a change of 36 percent in the value of $A_{1}$ would give an 85 percent change in the value of $B$. This is to be compared with an observed change of about 300 percent in the value of the coefficient $B$. Thus, most of the change in the coefficient $B$ seems to be related to changes in the sediment concentration.

Because the coefficient $A$ appears to be associated with velocity distributions within the water prism, and particularly three-dimensional flow, a restriction in its variation would seem essential in the design of stable channels. It should be noted, however, that the relation between the coefficients is still unclear. For example, it has been noted that the Lacey relationship $V \propto R^{2 / 3} S^{1 / 3}$ requires that $B \propto 1 / f$ or $B \propto 1 /\left(A_{1}^{3} C\right)^{1 / 2}$. Thus, from equation $51 \mathrm{~b}$

$$
\begin{gathered}
S \propto \frac{A_{1}{ }^{3} C}{\left(A_{1}{ }^{3} C\right)^{-1}} \text { or, replacing } A_{1}{ }^{3} C \text { with } V^{2} / D, \\
V S \propto \frac{V^{4}}{D^{2}} \text { and } V^{3} \propto D^{2} S \text { or } V \propto D^{2 / 3} S^{1 / 3} .
\end{gathered}
$$

If, in the Lacey relationship $A_{1}$ is constant, an increase in concentration increases the slope. This is in contrast to the situation when concentration is constant and $A_{1}$ is variable where an increase in $A_{1}$ decreases the slope.
In natural channels the coefficient $B$ tends to declir e in a downstream direction; however, the coefficient $A$ in the velocity-load relation also tends to decline. Consequently, in a natural stream system $V S$ is not constant. The result of all the possible variations in the coefficients of the velocity-slope and the velocityload relations is a wide spectrum of $V S$ values, all related to changing bed forms and all having different degrees of stability. The purpose of "regime" analysis is to regulate this spread of values.

The problem of the Marala-Ravi Link Canal seems to be that it was built on too flat a slope. A slope of 1 foot per 8,000 feet would have been much safer. for a canal of 22,000 -cfs capacity that at times had to scour its bed. This is consonant with a $B$ value of about 4.5. The second factor is that the canal carries only $7,000-8,000$ ofs in the early spring months. The canel will not transport a normal sediment concentration a.t this low discharge on such a low slope. Further, the discharge of the Chenab River is low during the early spring months, and a relatively large portion of the discharge is diverted; thus, the possibility of excessive diversion of sediment is increased. Finally, the fact that the canal is usually dry during the winter may have an adverse effect on bed mobility.

Much has been said about the "dominant" or channelforming discharge in discussions of "regime" channel" Insofar as water is concerned, this discharge may $k^{\circ}$ a satisfactory description, but it is important to note that the slope and other characteristies of a channel are dependent not only on the water discharge but also on the sediment concentration. 


\section{NONREGIME CHANNELS}

In a sense, a "regime" channel becomes a nonregime channel the moment it is built. The reason is that it cannot change its slope with changing discharge and loads. Although natural streams do change their slopes with varying discharges, the amount of change is limited. Hence, natural streams, from the short-term view, are also nonregime channels.

If slope is an independent variable, the relation between velocity and discharge and slope is

$$
V=B_{1}\left[\frac{\gamma q S}{\rho^{1 / 2}}\left(\frac{w}{\Delta \gamma d}\right)^{1 / 2}\right]^{0.4}
$$

if this is combined with $V=A_{1}\left(\frac{L}{\rho}\right)^{1 / 3}$,

$$
\frac{A_{1}}{B_{1}}=\frac{S^{2 / 5}}{C^{1 / 3}}\left(\frac{w}{\Delta \gamma d}\right)^{1 / 5}(\gamma q)^{1 / 15} \rho^{2 / 15}
$$

When $S$ is a constant and concentration a variable, the adjustment in the stream is made by a variation in the coefficients $A_{1}$ and $B_{1}$, nearly all of which is in $B_{1}$. A range of a little over two times in the value of $B$ will provide for a tenfold range in the sediment concentration. This range is observed on many streams. The effect of width is so small in equation 70 that it
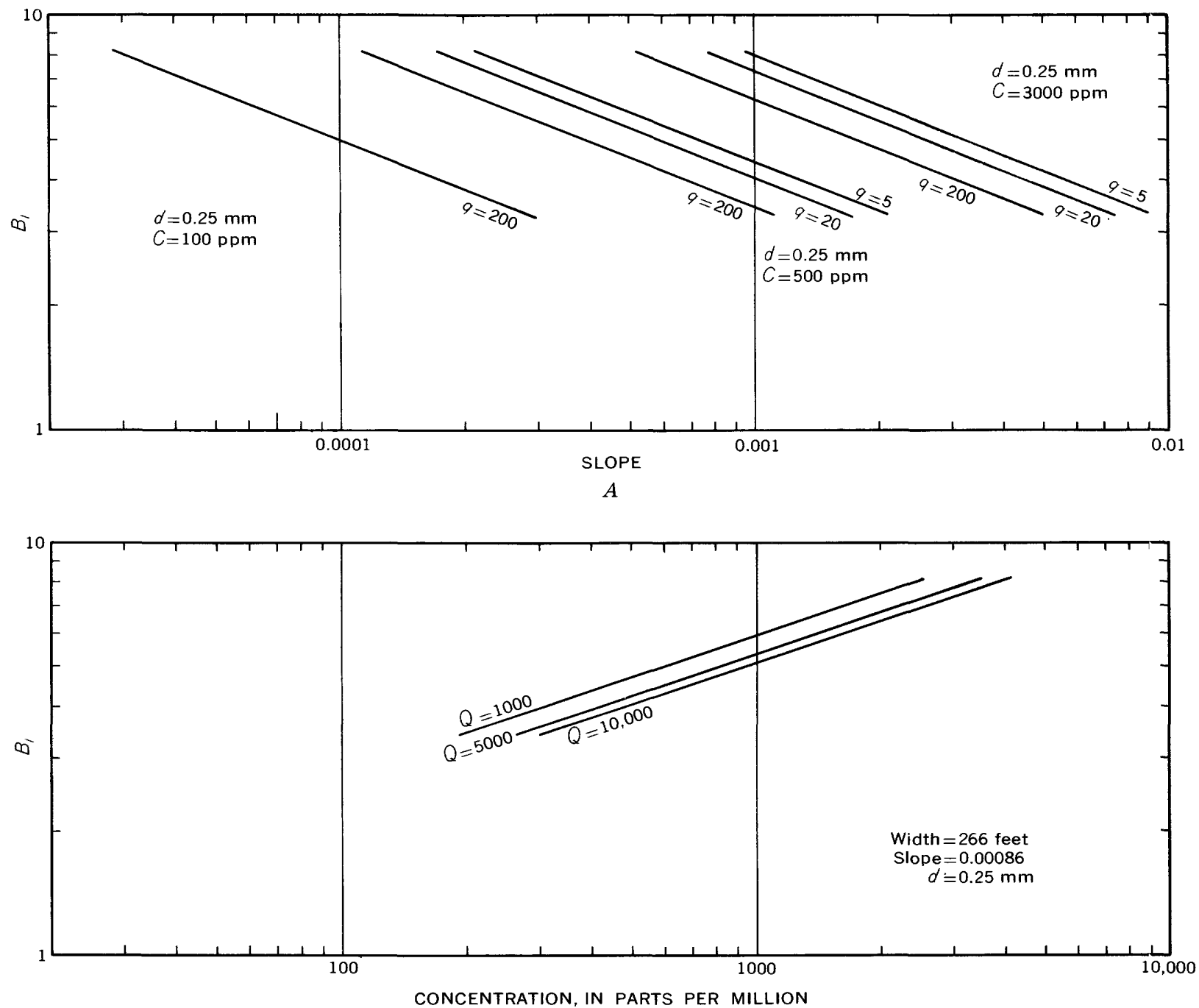

Figure 52.-Relations in equation 70. $A$, Relation between the coefficient $B_{1}$ and slope for a constant concentration and particle diameter and different unit discharges. $B$, Relation between coefficient $B_{1}$ and concentration for a constant width, slope, and particle diameter and varying discharge. 
may be neglected insofar as the relations among concentration, slope, and size of material are concerned because of the overriding importance of the coefficient $B_{1}$. For example, with discharge and concentration constant a change in width of 10 times would result in a change in the coefficient $B_{1}$ of about 17 percent. The relations in equation 70 are shown in figure $52 \mathrm{~A}$ and $B$. Both figures show the relative unimportance of the width (or the unit discharge) as a parameter. Both figures show that if slope is constant, changes in sediment concentration are taken care of by adjustment in the coefficient $B_{1}$. Relations between the coefficient $B_{1}$, sediment load, and slope are shown in figure $52 \mathrm{~A}$.

A considerable error may be made in the estimate of the width of a channel, but the relation between slope and sediment concentration must be fairly precise if the variation in the coefficient $B_{1}$ is to be held within close limits. For practical purposes the Lacey equation, $W=2.6 Q^{1 / 2}$, may be used as an initial estimate of width of a channel. Such a channel width is then tested to determine the effect of the different combinations of discharge and sediment concentration that may be expected. Usually, there is little choice in slope. (If there is a choice of widths and slopes, a "regime" procedure should be used.) Thus, the object of canal design is to pick the kind of section that will give the least trouble or the lowest cost of operation.

The average value of the coefficient $B_{1}$ is about 5.5. The maximum and minimum for stable channels are about 9 and 3.4, although some unusual channels have values greater and less than these. Nearly always, the high values are associated with aggradation and the low values with degradation or bank erosion. Streams moving rapidly varying sediment loads should have lower than average values of the coefficient $B_{1}$. The upper ends of canals in particular have this characteristic. As was noted in the discussion of "regime" channels, the amount of sediment entering the canal not only changes with variation in the overall average rate of sediment movement in the main stream, but it also changes, at any main-stream discharge, with the passage of bars in front of the diversion works. Even with good design of the canal heading, the upper 1 mile of a canal moving appreciable amounts of sediment ought to have a coefficient of about 4.7 , and the next 2-4 miles, a value of about 5. Any stream that has rapidly varying discharges of water and sediment throughout its length should have a value of about 5 or somewhat less for the coefficient. Otherwise, scour between periods of deposition is not likely to take place.

\section{CONCLUSION}

The 10 variables associated with flow of water and sediment in alluvial channels are discharge of water, discharge of sediment, size composition of the movin? sediment, size composition of the material making up the bed, the fall velocity of a characteristic sediment particle, width, depth, velocity, slope, and a characteristic of the pattern of streamflow. Masses and weights are assumed constant. These 10 variables can be reduce to nine by the equation of continuity-discharge equals the product of width, depth, and velocity.

Nine equations are required for the complete solution of the problems of flow in alluvial channels. The equations do not exist and probably never will. Therefore it is not possible, and probably never will be possible, to provide a precise answer to all flow proklems. The question is, what is needed to provide approximate answers to the problems? If there is $n$ ? movement of bed material, conventional hydraulics will apply. Such a statement does not provide a high degree of certainty, but it at least provides consistency. If an appreciable amount of sediment is being transported by the stream and is in motion over the bed, conventional hydraulics are inapplicable because many of the variables are mutually determined and are nct, unique.

The best and most consistent of all relations in channels with movable beds is a complex one between velocity and unit discharge and load for sediment $\mathrm{cf}$ material of uniform size. The relation is not simple and does not lend itself to a simple mathematical expressior. There is less certainty about the relations for a mixture of sediment sizes; but, fortunately, for the range of velocities commonly observed in nature, the effect of size composition of mixtures is small for a considerable range of sizes. Therefore, although it is impossible to get precision in the estimate of the rate of sediment movement, the magnitude of the mean velocity can $b$ ? determined with assurance if the unit discharges of water and sediment are known.

The common characteristic of natural channels in alluvium is the lack of stability in the relations among width, depth, velocity, and slope. Most of this instability is caused by variation in the water and sediment discharge and by changes in the size composition of the sediment mixture. The variability of natural channel cannot be studied in flumes because of constraints placed upon the possible combinations of width, depth, velocity, slope, and load that are inherent in flume operations.

In natural channels and in canals, for a given discharge and with slope essentially a constant, within the range of adjustment of hydraulic roughness througl changes in bed forms, filling will occur with high velocities and scour with low velocities. This statement is fully justified by field observations and is in accord 
with the presentation made in this report. An increase in concentration of sediment requires a higher velocity to move the increased load. At constant discharge and width this means a lower depth. If the slope is unchanged, the friction factor must decrease, and this decrease is associated with sediment deposition on the bed. A decrease in sediment concentration yields the converse of the previous situation. Velocity must decrease; hence, depth must increase. This is accompanied by scour which is associated with a greater friction factor.

If the friction factor is already at the lowest possible value, an increase in sediment concentration can only be accommodated by a continuous deposition of material on the bed and an increase in the slope of the stream. It is practically impossible to increase velocity and depth quickly by decreasing width by natural processes. If the friction factor is already great, a decrease in concentration may result in a decrease in slope, but more likely the result will be an increase in the width of the stream, braiding channels, or meandering. Streams with well-developed bed forms usually do not degrade their beds rapidly; hence, a sudden decrease in sediment load usually results in a rise in the stage-discharge relation. This condition is frequently observed at the upper ends of canals in the Indus River basin.

Although the premise of a velocity-sediment-load relation will be congruent with these behavior patterns, any relation between a parameter containing a depthslope product and sediment load will not be satisfactory under the conditions of a constant slope and of sediment and water discharge as independent variables. Thus, no relation between $\gamma D S, \gamma R S$, or $\gamma q S$ and either velocity or load can be unique; hence, it cannot be wholly acceptable.

The reason for the adoption of such parameters in the past is that their apparent rationality is supported by any flume experiment operated in a consistent manner. For example, there is a consistent relation between load and $q S$ in the Gilbert data. Like the relation between load and velocity based on the same data, it cannot be expressed in any simple mathematical function. But such a relation will not fit one developed from data from Brooks (1958), Vanoni and Brooks (1957), or Vanoni and Hwang (1967), which are consistent among themselves.

With the conclusion that an effective relation can be developed between velocity or depth and unit discharges of water and sediment, width, slope, and a characteristic river behavior remain as unknowns. As is to be expected from the preceding discussion, the relation between velocity and unit discharge and slope is complex. It depends upon the constraint placed upon depth and slope. Expressing this relation in the form
$V=B q^{x} S^{y}$, the range in the coefficient $B$ is dependent on the variation in the roughness due to bed forms. The use of a bed form parameter is not a solution of the equation for two reasons: first, at the present time it is impossible to evaluate bed forms in this way, and second, a bed form has to be associated with an amount of sediment in motion. Therefore, given $B, q$, and $S$, velocity cannot be determined unless the sediment load is known because $x$ and $y$ are unknown. If sediment load is an independent variable, the velocity cannot be forecast from known values $B, q$, and $S$.

Nevertheless, given the proper combination of independent variables, it is possible to provide a solution to the equation $V=B q^{x} S^{y}$. The most probable condition is represented by one value of $B$. If $B$ is less than this amount, the tendency is toward degradation. If $B$ is more, the tendency is toward aggradation. The only reason this is possible is because of natural constraints operating - the most usual being the tenden $y$ of the variances of the shear stress and the friction factor, jointly, to be minimized.

The two velocity relations apply to two-dimensional flow; hence, the result is a suite of values in which width and slope are two variables. The pattern of flow in a channel appears to vary with each combination of sediment discharge, width, and slope. This pattern again is reflected by change in bed forms. Some of these patterns lead to a considerable amount of cross-channel flow. Because they are associated with banl- erosion, they must be avoided or controlled; this is the crux of the problem of channel stabilization.

Given a stated relation between sediment concentration and discharge, it appears that a similarity of energy dissipation processes is developed when width is proportional to the product of a coefficient and the square root of the stream discharge, provided width, depth, velocity, and slope are all free to vary. If slope is fixed, it is not possible to secure this similerity.

If, over a considerable geographic region, concentrations and sizes of sediment in natural streams are of about the same magnitude and channels of varying discharge capacity have a type of bed form which does not lead to bank erosion, a set of regional equations can be developed by a study of existing stable channels. One such set is the Lacey equations.

Channels whose beds are made up of coarse material that moves only at the higher discharges (hence, also are self-formed) are also subject to analysis. But a set of these channels will not have the same characteristics as will a set of channels with sediment transport at the velocities most encountered.

It must be remembered that the presumption of the well known "regime" channel relations is that slope varies with discharge. If slope is fixed, clanges in 
discharge and load are accommodated by changes in width or changes in the friction factor. The latter is the most common.

Clearly, there is a great range of possible adjustments a stream may make yet remain in equilibrium as far as slope is concerned. These are all associated with changes in the size distribution of the sediment discharge or changes in the bed form. The easily observed behavior factors of an alluvial channel-scour, fill, bank erosion, overbank flow or anastomosis-are all related to these two highly complex phenomena. In view of this complexity, it will never be possible for an alluvial channel to remain stable and still pass a wide range of discharges of sediment and water. It appears, however, that given a good appraisal of local behavior, much can be done to mitigate the ill effects of any specific set of conditions.

\section{REFERENCES}

Barton, J. R., and Lin, P. N., 1955, A study of sediment transport in alluvial channels: Colorado State Univ. Dept. Civil Eng. Research Rept. 55JRB2, 43 p.

Blench, T., 1952, Regime theory for self-formed sedimentbearing channels: Am. Soc. Civil Engineers Trans., v. 117, p. 383-400.

1964, Dynamical statements of regime formulas, in Panel discussion on the pros and cons of regime theory: Am. Soc. Civil Engineers, 13th Hydraulic Div. Conf., Sedimentation Mtg., Aug. 18-21, 1964, Vicksburg, Miss.

- 1966, Mobile bed fluviology: Edmonton, Alberta, Univ. Alberta Dept. Tech. Services, 300 p.

Bogardi, J. L., 1965, European concepts of sediment transportation: Am. Soc. Civil Engineers Proc., Jour. Hydraulics Div., v. 91, no. HY1, p. 29-54.

Brooks, N. H., 1958, Mechanics of streams with movable beds of fine sand: Am. Soc. Civil Engineers Trans., v. 123, p. 526-549.

Casey, H. J., 1935, Uber geschiebebewegung: Berlin, Mitt der Preuss. Versuchanst. Wasserbau und Schiffbau, no. 19, $104 \mathrm{p}$.

Chow-Ven, Te, 1959, Open channel hydraulics: New York, McGraw-Hill Book Co., 680 p.

Colby, B. R., 1964, Practical computations of bed-material discharge: Am. Soc. Civil Engineers Proc., Jour. Hydraulies Div., v. 90, no. HY2, p. 217-246.

Corfitzen, W. E., 1940, Fifth annual report on retrogression observations, salinity studies, and suspended load investigations, Colorado River: Denver, Colo., U.S. Bur. Reclamation, memo. to Chief Engineer, 22 p.

Craven, J. P., 1953, The transportation of sand in pipes, full pipe flow, in 5th Hydraulic Conf. Proc.: Iowa State Univ. Studies Eng. Bull. 34, p. 67-76.

Culbertson, J. K., and Dawdy, D. R., 1964, A study of fluvial characteristics and hydraulic variables, middle Rio Grande, New Mexico: U.S. Geol. Survey Water-Supply Paper 1498-F, 74 p.

Dawdy, D. R., 1961, Depth-discharge relation of alluvial streams-discontinuous rating curves: U.S. Geol. Survey Water-Supply Paper 1498-C, 16 p.

Durand, R., 1953, Basic relationships of the transportation of solids in pipes-experimental research: Minneapolis, Minn., Internat. Hydraulics Convention Proc., p. 89-103.
Einstein, H. A., and Barbarossa, N. L., 1952, River channel roughness: Am. Soc. Civil Eng. Trans., v. 117, p. 1121-1132.

Engelund, F., 1966, Hydraulic resistance of alluvial strears: Am. Soc. Civil Engineers Proc., Jour. Hydraulics Div., v. 92, no. HY2, p. 315-326.

Fahnestock, R. K., 1963, Morphology and hydrology of a glac'al stream-White River, Mount Rainier, Washington: U.S. Geol. Survey Prof. Paper 422-A, 70 p.

Gilbert, G. K., 1914, The transportation of debris by running water: U.S. Geol. Survey Prof. Paper 86, 263 p.

Guy, H. P., Rathbun, R. E., and Richardson, E. V., 1966, Recirculation and sand-feed type flume experiments: Am. Scc. Civil Engineers Proc., Jour. Hydraulies Div., v. 93, no. HY5, p. 97-114.

Guy, H. P., Simons, D. B., and Richardson, E. V., 1966, Summary of alluvial channel data from flume experiments, 1956-61: U.S. Geol. Survey Prof. Paper 462-I, 96 p.

Hack, J. T., 1957, Studies of longitudinal stream profiles in Virginia and Maryland: U.S. Geol. Survey Prof. Papar 294-B, p. 45-97 [1958].

Harza Engineering Co., International, 1963, Canal and hearworks data observation programme, 1962 data tabulation: West Pakistan Water and Power Development Authority, Lahore, West Pakistan.

Hill, R. A., 1925, Discussion of the Colorado River problem: Am. Soc. Civil Engineers Trans., v. 88, p. 419-422.

1926, Discussion of permissible canal velocities: Am. Soc. Civil Engineers Trans., v. 89, p. 961-964.

Ho, Chitty, 1935, Determination of bottom velocity necessary to start erosion in a sand: Iowa Univ., unpub. thesis, $116 \mathrm{p}$.

Hubbell, D. W., and others, 1956, Investigations of some sedimentation characteristics of sand-bed streams: U.S. Geol. Survey open-file report.

- 1960, Investigations of some sedimentation characterist"cs of sand-bed streams: U.S. Geol. Survey open-file report.

Inglis, C. C., 1949, The behavior and control of rivers and canals: Central Waterpower, Irrigation and Navigation Research Sta., Poona Research Pub. 13, 487 p., Poona, India.

Kalinske, A. A., and Hsia, C. H., 1945, Study of transportation of fine sediments by flowing water: Iowa Univ. Studies Enঙ. Bull. 29, $30 \mathrm{p}$.

Kennedy, J. F., 1961, Further laboratory studies of the roughness and suspended load of alluvial streams: Pasadena, California Inst. Technology Rept. KH-R-3, 36 p.

Kennedy, J. F., and Brooks, N. H., 1963, Laboratory study of an alluvial stream at constant discharge: Jackson, Miss., Federal Inter-Agency Sedimentation Conf., 21 p.

Kondrat'ev, N. E., 1962, River flow and river channel formation: Washington, D.C., U.S. Dept. Commerce Office Tech. Services, translation, $172 \mathrm{p}$.

Lacey, Gerald, 1940, Regime flow in incoherent alluvium: Central Board Irrig. (India), pub. 20, Simla, 65, p.

- 1946, A general theory of flow in alluvium: Inst. Civil Eng. Jour., v. 27, no. 1, Paper 5518, p. 16-47.

Lane, E. W., 1955, Design of stable channels: Am. Soc. Civil Engineers Trans., v. 120, p. 1234-1260.

Lane, E. W., and Carlson, E. J., 1953, Some factors affecting the stability of canals constructed in coarse granular material: Internat. Assoc. Hydraulic Research Proc., p. $37-48$.

1954, Some observations on the effect of particle shape on the movement of coarse sediments: Am. Geophys. Union Trans., v. 35 , no. 3 , p. $453-462$. 
Langbein, W. B., 1964, Geometry of river channels: Am. Soc. Civil Engineers Proc., Jour. Hydraulies Div., .v. 90, HY2, p. 301-312.

__ 1965, Geometry of river channels: Am. Soc. Civil Engineers Proc., Jour. Hydraulics Div., v. 91, HY3, p. 297-313.

Laursen, E. M., 1958, The total sediment load of streams: Am. Soc. Civil Engineers Proc., Jour. Hydraulies Div., v. 84, HY1, pt. 1, 36 p.

Leopold, L. B., and Maddock, T., Jr., 1953a, The hydraulic geometry of stream channels and some physiographic implications: U.S. Geol. Survey Prof. Paper 252, 57 p.

1953b, Relation of suspended-sediment concentration to channel scour and fill, in 5th Hydraulic Conf. Proc.: Iowa City, Iowa Inst. Hydraulic Research, p. 159-178.

Maddock, T., Jr., 1966, Discussion of Engelund, 1966, Am. Soc. Civil Engineers Jour., v. 92, no. HY6, p. 260-262.

Meyer-Peter, E., Favre, H., and Einstein, H. A., 1934, Neuere versuchsresultate uber den Geschiebetrieb. Schweizer. Bauzeitung, v. 103, no. 12, p. 147-150.

Nordin, C. F., Jr., and Beverage, J. P., 1965, Sediment transport in the Rio Grande, New Mexico: Geol. Survey Prof. Paper 462-F, $35 \mathrm{p}$.

Rubey, W. W., 1938, The force required to move particles on a stream bed: U.S. Geol. Survey Prof. Paper 189-E, p. 121-141.

- 1952, Geology and mineral resources of the Hardin and Brussels quadrangles (in Illinois): U.S. Geol. Survey Prof. Paper 218, $179 \mathrm{p}$

Simons, D. B., 1957, Theory and design of stable channels in alluvial materials: Colorado State Univ. unpub. thesis, $392 \mathrm{p}$.

Simons, D. B., and Richardson, E. V., 1961, Studies of flow in alluvial channels-basic data from flume experiments: U.S. Geol. Survey open-file report.
Simons, D. B., Richardson, E. V., and Albertson, M.. L., 1961, Flume studies using medium sand: U.S. Geol. Survey Water-Supply Paper 1498-A, 76 p.

Stein, R. A., 1965, Laboratory studies of total load ant apparent bed load: Am. Geophys. Union Jour. Geophys. Research, v. 70 , no. 8 , p. 1831-1842.

U. S. Bureau of Reclamation, 1958, Interim report-total sediment transport program, Lower Colorado River basin: U.S. Bur. Reclamation, Sedimentation Sec., Div. Proj. Inv., $175 \mathrm{p}$.

Vanoni, V. A., and Brooks, N. H., 1957, Laboratory studies of the roughness and suspended load of alluvicl streams: Pasadena, California Inst. Technology Sedimentation Lab. Rept. E-68.

Vanoni, V. A., Brooks, N. H., and Kennedy, J. F., 19^1, Lecture notes on sediment transportation and channel stability: Pasadena, California Inst. Technology Rept. KH-R-1, $141 \mathrm{p}$.

Vanoni, V. A., and Hwang, L. S. ,1967, Relation bet,ween bedforms and friction in streams: Am. Soc. Civil Engineers Jour., v. 93, no. HY3, p. 121-144.

Vanoni, V. A., and Nomicos, G. N., 1960, Resistanc 3 properties of sediment-laden streams: Am. Soc. Civil Engin sers Trans., v. 125, p. 1140-1167.

Velikanov, M. A., 1949, Dynamics of watercourses: Leningrad, U.S.S.R., 529 p. (in Russian).

Waterways Experiment Station, 1935, Studies of river bed materials and their movement with special reference to the lower Mississippi River: U.S. Waterways Expt. Sta. Paper 17, Vicksburg, Miss., 161 p.

Williams, G. P., 1967, Flume experiments on the transport of a coarse sand: U.S. Geol. Survey Prof. Paper 552-B, 31 p.

Wolman, M. G., 1955, The natural channel of Brandywine Creek, Pennsylvania: U.S. Geol. Survey Prof. Paper 271, $56 \mathrm{p}$. 